Uma ferramenta acessível de apoio à modelagem de software na Web

Filipe Del Nero Grillo 

SERVIÇO DE PÓS-GRADUAÇÃO DO ICMC-USP

Data de Depósito: 24 de junho de 2014

Assinatura:

\title{
Uma ferramenta acessível de apoio à modelagem de software na Web
}

\author{
Filipe Del Nero Grillo
}

Orientadora: Profa. Dra. Renata Pontin de Mattos Fortes

Dissertação apresentada ao Instituto de Ciências Matemáticas e de Computação - ICMC-USP, como parte dos requisitos para obtenção do título de Mestre em Ciências - Ciências de Computação e Matemática Computacional. VERSÃO REVISADA 
Ficha catalográfica elaborada pela Biblioteca Prof. Achille Bassi e Seção Técnica de Informática, ICMC/USP, com os dados fornecidos pelo(a) autor(a)

G859f Grillo, Filipe Del Nero

Uma ferramenta acessível de apoio à modelagem de software na Web / Filipe Del Nero Grillo;

orientador Renata Pontin de Mattos Fortes. -- São Carlos, 2014 .

$99 \mathrm{p}$.

Dissertação (Mestrado - Programa de Pós-Graduação em Ciências de Computação e Matemática Computacional) -- Instituto de Ciências Matemáticas e de Computação, Universidade de São Paulo, 2014.

1. Acessibilidade na Web. 2. Modelagem de software. 3. Tecnologia assistiva. 4. MDD. 5. UML. I. Fortes, Renata Pontin de Mattos, orient. II. Título. 


\section{Agradecimentos}

Agradeço aos meus pais e minha queria irmã pelo amor incondicional e pela minha formação como pessoa e profissional.

À minha namorada Virginia, por todo o carinho, compreensão e apoio, mas também pelas incansáveis revisões de textos.

À professora, orientadora e amiga Renata Pontin de Mattos Fortes, por todos esses anos de convívio, todas os esforços e todas as vitórias, pessoais e profissionais. Por dividir mais do que conhecimento e orientação acadêmica, mas também um pouco de sabedoria de vida.

Ao professor Daniel Lucrédio cujas discussões objetivas, orientações e insights tiveram um valor inestimável para este projeto.

A todos os alunos do grupo de pesquisa, que contribuíram ativa e continuamente para o caminhar do projeto.

Aos participantes do estudo de caso realizado como parte deste projeto, por dedicarem de bom grado seu tempo para contribuir com este projeto.

A todos os entes queridos e familiares pelo convívio e carinho. Em especial às minhas tias Olga e Silvana, pelo trabalho minucioso de revisão deste texto.

A todos os amigos, por ouvirem pacientemente as reclamações nos momentos de dificuldade, pelas palavras de apoio. Em especial ao Bruno Oliveira pelo apoio mútuo nos momentos de desespero e pela companhia durante essa jornada e Henrique Gnann, pela paciência e pelas discussões filosóficas sobre a vida, o universo e tudo mais.

Por fim, a todo o pessoal do ICMC-USP, funcionários e professores, que fazem parte dessa grande comunidade e ao $\mathrm{CNPq}$ pelo apoio financeiro. 

If you always put limits on everything you do, physical or anything else, it will spread into your work and into your life. There are no limits. There are only plateaus, and you must not stay there, you must go beyond them.

Bruce Lee 

Com o aumento do uso das atividades de modelagem em processos de desenvolvimento de software, a participação de pessoas com deficiência visual em tais processos requer esforços dedicados para que os modelos sejam passíveis de entendimento, caso contrário essa participação fica comprometida. Os modelos são em sua maioria visuais e, portanto, seu processo de construção requer o posicionamento de elementos no espaço do documento por meio de um dispositivo de apontar, como o mouse, e sua leitura requer o uso da visão, uma vez que os diagramas são compostos não apenas por textos, mas também por elementos visuais como retângulos e arcos conectando-os. Neste contexto, o objetivo deste projeto foi desenvolver uma técnica textual para representação e interação com diagramas que possibilite que pessoas com deficiência visual sejam capazes de colaborar em projetos de software, tanto utilizando uma abordagem de desenvolvimento orientado a modelos, quanto em uma abordagem de desenvolvimento tradicional. Para atingir o objetivo proposto foi desenvolvido um protótipo de uma ferramenta Web, a AWMo (lê-se letra a letra: A-W-M-O), a partir da qual a edição de modelos pode ser realizada por meio de duas visões equivalentes: uma visão gráfica, na qual o engenheiro de software poderá inserir novos elementos no diagrama, posicioná-los e definir suas propriedades de modo visual; e uma visão textual, na qual o engenheiro de software pode inserir novos elementos, propriedades e relacioná-los utilizando uma gramática textual. Um estudo de caso foi conduzido para avaliar sua eficácia e os resultados mostraram que a linguagem textual desenvolvida não representa uma barreira para a utilização da abordagem proposta pela AWMo. Os resultados sugerem que a AWMo é uma opção viável para facilitar o acesso de deficientes visuais a modelos de software, ajudando a promover a colaboração e comunicação efetiva e de maneira independente entre usuários com e sem visão para atividades de modelagem de software.

Palavras-chave: Acessibilidade na Web, Modelagem de Software, Tecnologia Assistiva, MDD e UML. 

With the growth of modeling activities in software development processes, the participation of visually impaired users requires dedicated efforts so that the models are capable to be understood, otherwise this participation is compromised. The models are mostly visuals and, therefore, their construction process requires the positioning of elements in the document space with a pointing device, like the mouse, and their reading requires the use of vision, since the diagrams are composed not only by text, but also by visual elements such as rectangles and arcs connecting them. In this context, the goal of this project was to develop a textual technique to represent and interact with diagrams to allow visually disabled people to collaborate in software development projects, either using an model driven development approach or a tradicional development approach. To achieve the proposed goal, a prototype Web tool called AWMo was developed. The prototype allows the edition of models to be done in two distinct views: a graphical view, where the software engineer is able to insert new elements and define their position in a visual and traditional way; and a textual view, where the software engineer is able to insert new elements, their properties and relationships using a textual grammar. A case study was conducted to evaluate the efficacy of the approach and the results show that the textual language developed did not posed itself as a barrier to the use of the AWMo. The results suggest that AWMo is a viable option to allow the access of the visually impaired to software models, promoting collaboration and effective communication between sighted and blind users in software modeling activities, but most importantly, in an independent way.

Keywords: Web Accessibility, Software Modeling, Assistive Technology, MDD and UML. 

1 Introdução 1

1.1 Contextualização . . . . . . . . . . . . . . . . . . . . . . 1

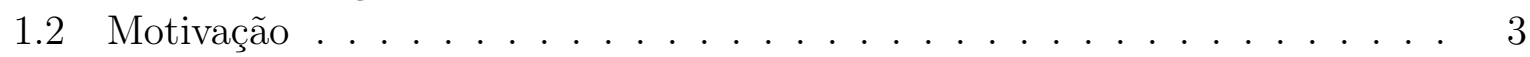

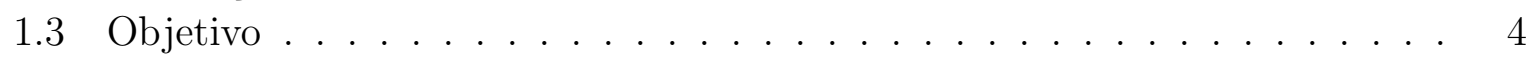

1.4 Organização do texto . . . . . . . . . . . . . . . . . . 4

2 Desenvolvimento orientado a modelos 5

2.1 Considerações iniciais . . . . . . . . . . . . . . . . . . . . . . . . . . . . . .

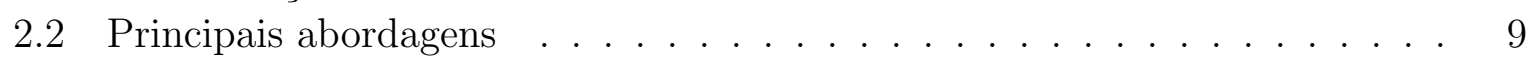

2.2.1 Object Management Group . . . . . . . . . . . . . . . . . . . 10

2.2 .2 Eclipse Foundation . . . . . . . . . . . . . . . . . . . . . . . . . . . . . . . . 11

2.3 Considerações finais . . . . . . . . . . . . . . . . . . . . 14

3 Acessibilidade na $W e b \quad 15$

3.1 Considerações iniciais . . . . . . . . . . . . . . . . . . . . . 15

3.2 Web Accessibility Initiative . . . . . . . . . . . . . . . . . . . . . . . . . . . . . . . . . . . . . .

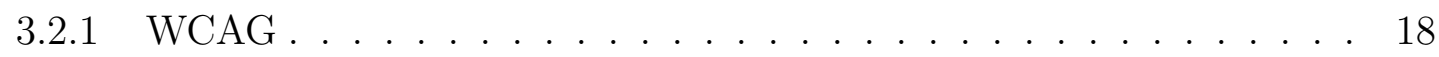

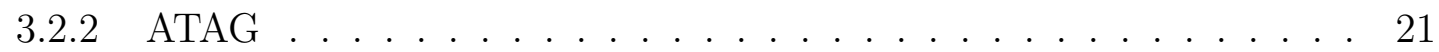

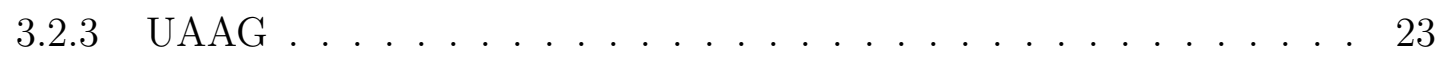

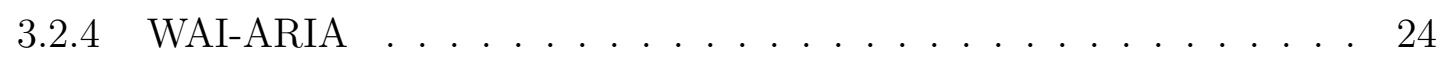

3.3 Regulamentação . . . . . . . . . . . . . . . . . . . . . 26

3.4 Trabalhos sobre modelagem na Web e alternativas para deficientes visuais . 32

3.5 Considerações finais . . . . . . . . . . . . . . . . . . . 34

4 AWMo $\quad 35$

4.1 Considerações Iniciais . . . . . . . . . . . . . . . . . . . . . . 35

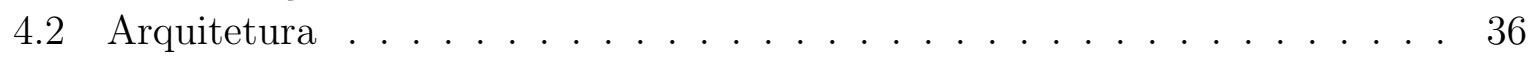

4.3 Linguagem textual . . . . . . . . . . . . . . . . . . . . . . . . . . . . . . . . . . . . . . . . . . .

4.4 Uso da ferramenta . . . . . . . . . . . . . . . . . . . . . . . . 41

4.4 Navegação . . . . . . . . . . . . . . . . . . . . . . . . 44

4.4 Acessibilidade . . . . . . . . . . . . . . . . . . . . . . . . . . . . . . . . . . . . . . . . . . . 45

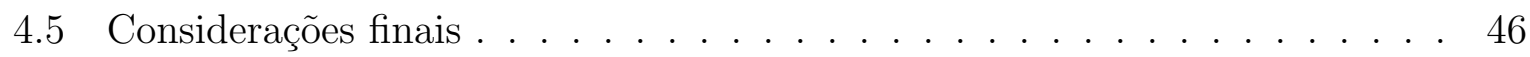


5 Estudo de caso $\quad 49$

5.1 Considerações iniciais . . . . . . . . . . . . . . . . . . . . . . . 49

5.2 Questões de pesquisa . . . . . . . . . . . . . . . . 50

5.3 Estratégia de seleção . . . . . . . . . . . . . . . . . . . 51

5.4 Coleta de dados . . . . . . . . . . . . . . . . . . . . . . 51

5.4 .1 Entrevistas . . . . . . . . . . . . . . . . 51

5.4 .2 Observação . . . . . . . . . . . . . . . . . . . . . . . . . . . . . . . 52

5.4 .3 Medições e métricas . . . . . . . . . . . . . . . . . 53

5.5 Triangulação . . . . . . . . . . . . . . . . . . . . 54

5.6 Ameaças à validade . . . . . . . . . . . . . . . . . . . 55

5.7 Piloto . . . . . . . . . . . . . . . . . . 57

5.8 Plano de Análise . . . . . . . . . . . . . . . . . . . . . 61

5.9 Resultados obtidos . . . . . . . . . . . . . . . . . . 61

5.9 .1 Arthur . . . . . . . . . . . . . . . . . 62

5.9 .2 Ford . . . . . . . . . . . . . . . . . . . 67

5.9 .3 Análise . . . . . . . . . . . . . . . . . . . . . . 73

5.10 Considerações finais . . . . . . . . . . . . . . . . . . 80

6 Conclusões e trabalhos futuros $\quad 83$

6.1 Considerações Iniciais . . . . . . . . . . . . . . . . . . . . . . . . . . . . . . . . . . . . . . . 83

6.2 Contribuições . . . . . . . . . . . . . . . . . . . . . . 84

6.3 Premiação da ferramenta AWMo . . . . . . . . . . . . . . . . . . . 85

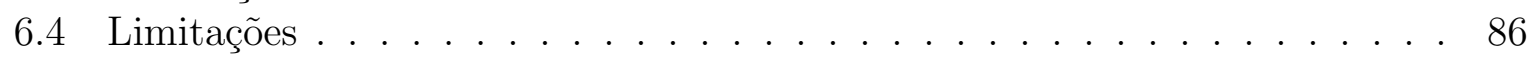

6.5 Trabalhos futuros . . . . . . . . . . . . . . . 86

$\begin{array}{ll}\text { Referências } & 96\end{array}$

$\begin{array}{ll}\text { A Diagrama Sistema Bancário } & 97\end{array}$ 
1.1 Exemplo de um diagrama de classes UML, adaptado de [49]. . . . . . . . . 3

2.1 Representação do processo de desenvolvimento de software com uma abordagem tradicional. . . . . . . . . . . . . . . . 6

2.2 Representação do processo de desenvolvimento de software com uma abordagem orientada a modelos. . . . . . . . . . . . . . . 6

2.3 Principais elementos da abordagem de desenvolvimento orientado a mode-

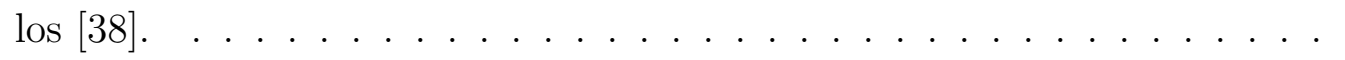

2.4 Transformação de um modelo independente de plataforma para um modelo específico de plataforma $[43] \ldots \ldots$. . . . . . . . . . . . 12

2.5 Transformação de um modelo independente de plataforma para um modelo específico de plataforma por meio de várias transformações subsequentes [43]. 12

3.1 Relação entre as recomendações da W3C e seus componentes de atuação [64]. 17

3.2 Código da Listagem 3.1 exibido pelo navegador Firefox. . . . . . . . . . . . 19

3.3 Captura de tela de um modelo UML sendo desenvolvido no ambiente SLIM em um navegador Web [56]. . . . . . . . . . . . . . . . . . . 33

4.1 Tickets criados para o desenvolvimento do protótipo da AWMo. . . . . . . 36

4.2 Cenários de uso previstos para a ferramenta, considerando-se a colaboração entre usuários desenvolvedores de software, sejam eles com ou sem deficiências visuais. . . . . . . . . . . . . . . . . . . . . . . 36

4.3 Visão de alto nível da arquitetura utilizada na AWMo com o conceito de MVC (Model-View-Controller) e as tecnologias empregadas em cada uma das camadas. . . . . . . . . . . . . . . . . 37

4.4 Modelo de funcionamento da AWMo, mostrando os passos, ferramentas e bibliotecas utilizadas para transformação dos modelos para ambas as visões disponíveis.

4.5 Captura de tela da AWMo com um modelo chamado Carro, aberto para edição na visão textual. . . . . . . . . . . . . . . . . . . . . . . . . . . 42

4.6 Exemplo do diagrama da listagem 4.2 como exibido pela visão gráfica da AWMo. 
4.7 Captura de tela mostrando a aparência da AWMo quando não existe um diagrama sendo editado. . . . . . . . . . . . . . . . 44

4.8 Captura de tela mostrando a aparência da AWMo com um diagrama aberto para edição. . . . . . . . . . . . . . . . . . . . . . . 45

4.9 Captura de tela parcial mostrando a barra de ferramentas de acessibilidade da AWMo. . . . . . . . . . . . . . . . . . . . 46

5.1 Foto da configuração do ambiente do experimento como foi conduzido durante a execução piloto. O computador à direita, utilizado pelo sujeito executa o Morae Recorder e o computador à esquerda, utilizado pelo pesquisador executa o Morae Observer. . . . . . . . . . . . . . 54

5.2 Gráfico mostrando a quantidade de tempo utilizado por Arthur para completar cada um dos objetivos propostos neste estudo de caso. . . . . . . . . 63

5.3 Gráfico extraído da gravação de vídeo da fase de observação contendo o número de falhas inseridas por Arthur ao decorrer da execução de cada objetivo. . . . . . . . . . . . . . . . .

5.4 Gráfico extraído da gravação de vídeo da fase de observação, contendo o número de vezes em que mensagens de erro foram exibidas para Arthur em cada um dos objetivos propostos.

5.5 Captura de tela de um dos momentos em que o interpretador retornou mensagens de erro para Arthur. Foi aplicado um mosaico sobre o rosto de Arthur para preservar sua identidade. . . . . . . . . . . . 66

5.6 Gráfico mostrando a quantidade de tempo utilizado por Ford para completar os objetivos propostos neste estudo de caso. . . . . . . . . . . . .

5.7 Gráfico mostrando o número de falhas inseridas por Ford ao decorrer da execução dos objetivos. . . . . . . . . . . . . . . . . . . . 71

5.8 Gráfico mostrando o número de vezes em que mensagens de erro do interpretador de texto foram exibidas para Ford em cada um dos objetivos. . . 72

5.9 Gráfico mostrando a quantidade de tempo utilizado por cada um dos sujeitos para completar os objetivos propostos neste estudo de caso. . . . . . 74

5.10 Gráfico mostrando o número de falhas inseridas por Arthur e Ford ao decorrer da execução dos objetivos. . . . . . . . . . . . . . . . . 75

5.11 Gráfico mostrando o número de vezes em que mensagens de erro do interpretador de texto foram exibidas para os sujeitos em cada um dos objetivos. 76

5.12 Gráficos ilustrando a categorização das falhas exibidas nas Tabelas 5.3 e 5.4 sendo: (a) - quantidade de falhas de Arthur em cada categoria e separadas por objetivo, (b) - quantidade de falhas de Ford em cada categoria e separadas por objetivo, (c) - proporção entre as categorias das falhas cometidas por Arthur e (d) - proporção entre as categorias das falhas cometidas por Ford . . . . . . . . . . . . . . . . . . . . . 79 


\section{Lista de Tabelas}

1.1 População brasileira por tipo de deficiência. Adaptada dos resultados do

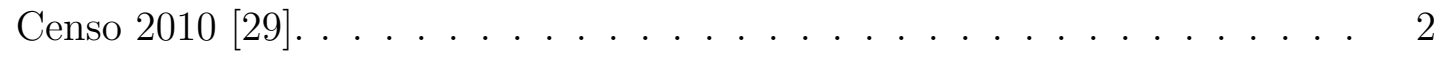

3.1 Categorias do WAI-ARIA e seus respectivos papéis. . . . . . . . . . 26

5.1 Ameaças à validade interna. . . . . . . . . . . . . . . . 56

5.2 Ameaças à validade externa. . . . . . . . . . . . . . . . . 57

5.3 Categorização das falhas inseridas por Arthur ao longo do estudo. . . . . . 77

5.4 Categorização das falhas inseridas por Ford ao longo do estudo. . . . . . . 78 



\section{Lista de Listagens}

3.1 Trecho de código HTML para inserir uma imagem sem texto alternativo. . 19

3.2 Trecho de código HTML para inserir uma imagem com texto alternativo. . 20

3.3 Trecho de código que mostra um botão utilizando os atributos de papel e estado do WAI-ARIA. . . . . . . . . . . . . . . . . 26

4.1 Gramática em notação EBNF que define a linguagem da AWMo. . . . . . 40

4.2 Exemplo de um diagrama criado com a linguagem textual da AWMo. . . . 42

A.1 Modelo de um sistema bancário fictício na linguagem textual da AWMo e que foi utilizado durante a fase de observação do estudo de caso. . . . . . . 97 



\section{Lista de Abreviaturas e Siglas}

$\begin{array}{ll}\text { AJAX } & \text { Asynchronous JavaScript and XML } \\ \text { API } & \text { Application Programming Interface } \\ \text { ARIA } & \text { Accessible Rich Internet Applications } \\ \text { ASP } & \text { Active Server Pages } \\ \text { ATAG } & \text { Authoring Tool Accessibility Guidelines } \\ \text { ATL } & \text { Atlas Transformation Language } \\ \text { AWMo } & \text { Accessible Web Modeler } \\ \text { CIM } & \text { Computational Independent Model } \\ \text { CMOF } & \text { Complete MOF } \\ \text { CMS } & \text { Content Management System } \\ \text { COMA } & \text { COllaborative Modeling Architecture } \\ \text { CSS } & \text { Cascading Style Sheets } \\ \text { DFD } & \text { Diagrama de Fluxo de Dados } \\ \text { DSL } & \text { Domain-Specific Language } \\ \text { EBNF } & \text { Extended Backus-Naur Form } \\ \text { e-MAG } & \text { Modelo de Acessibilidade de Governo Eletrônico } \\ \text { EMF } & \text { Eclipse Modeling Framework } \\ \text { EMOF } & \text { Essential MOF } \\ \text { GEF } & \text { Graphical Editing Framework } \\ \text { GEMS } & \text { Generic Eclipse Modeling System } \\ \text { GME } & \text { Generic Modeling Environment } \\ \text { GMF } & \text { Graphical Modeling Framework } \\ \text { HTML } & \text { HyperText Markup Language } \\ \text { IBGE } & \text { Instituto Brasileiro de Geografia e Estatística } \\ \text { IDE } & \text { Integrated Development Environment } \\ \text { JET } & \text { Java Emitter Templates } \\ \text { JSF } & \text { Java Server Faces } \\ \text { JSON } & \text { JavaScript Object Notation } \\ \text { JSP } & \text { Java Server Pages } \\ \text { M2M } & \text { Model to Model } \\ \text { MDA } & \text { Model-Driven Architecture } \\ \text { MDE } & \text { Model-Driven Engineering } \\ \text { MDD } & \text { Model-Driven Development } \\ & \end{array}$


MDSD Model-Driven Software Development

MOF Meta Object Facility

MVC Model-View-Controller

NVDA NonVisual Desktop Access

OMG Object Management Group

PDF Portable Document Format

PHP PHP: Hypertext Preprocessor

PIM Platform Independent Model

PSM Platform Specific Model

QVT Queries/Views/Transformations

RIA Rich Internet Application

SISP Sistema de Administração dos Recursos de Tecnologia da Informação

SVG Scalable Vector Graphics

TIC Tecnologias de Informação e Comunicação

TMF Textual Modeling Framework

UAAG User Agent Accessibility Guidelines

UML Unified Modeling Language

VB3 Visual Basic 3

VB6 Visual Basic 6

WAI Web Accessibility Initiative

WCAG Web Content Accessibility Guidelines

XHTML Extensible HyperText Markup Language

XMI XML Metadata Interchange

XML Extensible Markup Language

XML World Wide Web Consortium 


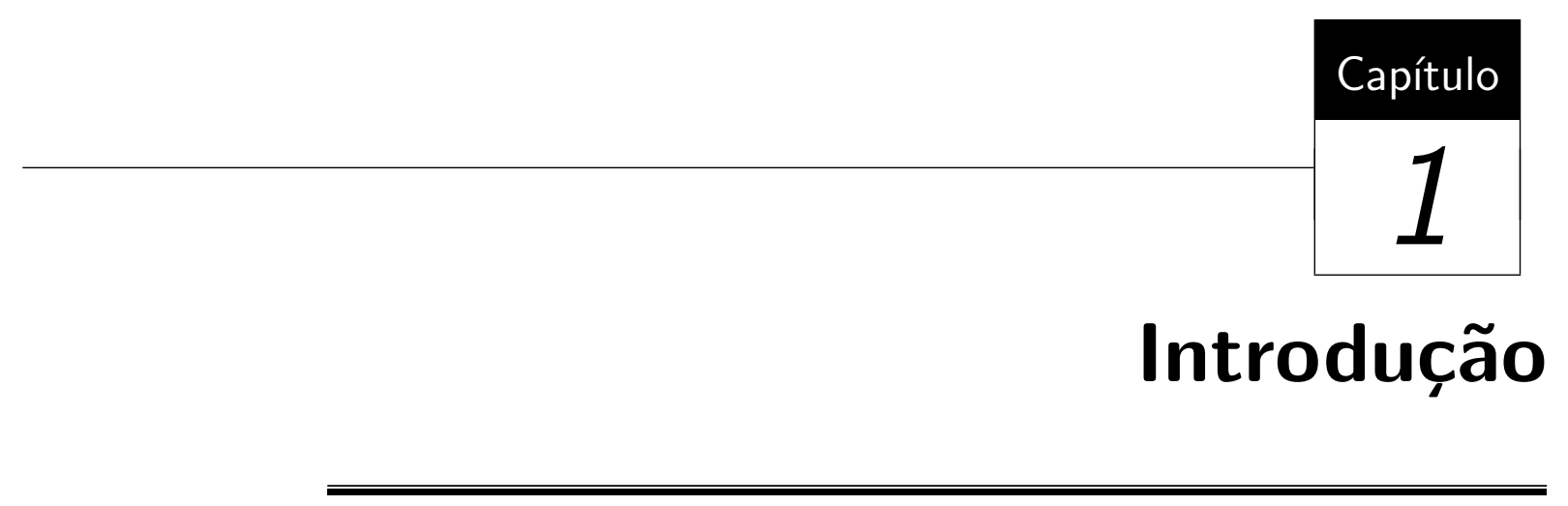

\subsection{Contextualização}

No Brasil, de acordo com resultados do Censo 2010 [29], existem mais de 45,62 milhões de pessoas que possuem pelo menos um tipo de deficiência. Esse número representa uma parcela de $23,92 \%$ de toda a população do país. A Tabela 1.1 mostra a distribuição dessa população entre os diferentes tipos de deficiência considerados pelo IBGE (Instituto Brasileiro de Geografia e Estatística).

Se considerarmos apenas pessoas que apresentem grande dificuldade para enxergar ou não enxergam de modo algum e pessoas com grande dificuldade motora, temos uma população de aproximadamente 10,29 milhões de pessoas que poderiam se beneficiar de conteúdos e aplicações $W e b$ que possam ser acessados por meio de leitores de tela e interação com o teclado.

Para a utilização de uma aplicação $W e b$, por exemplo, pessoas que possuem dificuldades na visão teriam problemas para ter acesso a informações em um monitor de vídeo e pessoas com deficiência motora podem apresentar dificuldades ao operar um mouse para realizar uma tarefa que exija grande coordenação motora, como a edição de um diagrama.

Nesse contexto, existem desenvolvedores de software que possuem deficiências visuais e que fazem uso de aplicações adaptadas ou plugins, em ambientes de desenvolvimento como Eclipse $^{1}$ ou NetBeans ${ }^{2}$, que possibilitam a leitura do texto ou até mesmo hardwares dedicados, que são produtos de Tecnologia assistiva, como dispositivos que mostram o

\footnotetext{
${ }^{1}$ http://www.eclipse.org/

${ }^{2}$ https://netbeans.org/
} 
Tabela 1.1: População brasileira por tipo de deficiência. Adaptada dos resultados do Censo 2010 [29].

\begin{tabular}{|c|c|c|c|}
\hline \multicolumn{3}{|r|}{ Total } & \multirow{2}{*}{$\begin{array}{r}190.755 .799 \\
45.606 .048\end{array}$} \\
\hline \multirow{12}{*}{ Tipo de deficiência } & \multicolumn{2}{|c|}{ Pelo menos uma das deficiências investigadas (1) (2) } & \\
\hline & \multirow{3}{*}{ Visual } & Não consegue de modo algum & 506.377 \\
\hline & & Grande dificuldade & 6.056 .533 \\
\hline & & Alguma dificuldade & 29.211 .482 \\
\hline & \multirow{3}{*}{ Auditiva } & Não consegue de modo algum & 344.206 \\
\hline & & Grande dificuldade & 1.798 .967 \\
\hline & & Alguma dificuldade & 7.574 .145 \\
\hline & \multirow{3}{*}{ Motora } & Não consegue de modo algum & 734.421 \\
\hline & & Grande dificuldade & 3.698 .929 \\
\hline & & Alguma dificuldade & 8.832 .249 \\
\hline & \multicolumn{2}{|c|}{ Mental/Intelectual } & 2.611 .536 \\
\hline & \multicolumn{2}{|c|}{ Nenhuma dessas deficiências (3) } & 145084976 \\
\hline \multicolumn{4}{|c|}{ (1) As pessoas incluídas em mais de um tipo de deficiência foram contadas apenas uma vez. } \\
\hline \multicolumn{4}{|c|}{ (2) Inclusive as pessoas sem declaração dessas deficiências. } \\
\hline \multicolumn{4}{|c|}{ (3) Inclusive a população sem qualquer tipo de deficiência. } \\
\hline
\end{tabular}

texto da tela em braille ou apontadores que utilizam os olhos ou os dedos do usuário ao invés de um mouse. Tecnologias assistivas são recursos ou serviços que buscam ampliar as habilidades de pessoas com deficiência [12].

No entanto, quando se trata de uma fase de especificação em um projeto de software, em uma abordagem de desenvolvimento tradicional, temos grande uso de diagramas como é o caso da UML (Unified Modeling Language). Os diagramas UML são modelos visuais utilizados para realizar atividades como design e representação da arquitetura de projetos de software. A Figura 1.1 mostra um exemplo de um diagrama de classes da UML. Nesse exemplo simples temos as classes Pessoa, Estudante e Professor. Ambos, professor e estudante são Pessoas, por isso o relacionamento de herança/generalização com a classe Pessoa. A classe Professor também contém uma lista de estudantes que representam seus alunos.

Além disso, existem abordagens de desenvolvimento de software orientadas a modelos, ou seja, os modelos não servem apenas para apoiar o desenvolvimento, como na abordagem tradicional citada anteriormente, mas são utilizados como principal artefato no processo do desenvolvimento de software, o que torna o desafio ainda maior para usuários com deficiência. O desenvolvimento de software orientado a modelos será caracterizado com mais detalhes no Capítulo 2.

Em ambas as abordagens citadas, o uso dos modelos impõe restrições quanto à participação de pessoas com deficiência, pois essas pessoas, em muitos casos, não são capazes de realizar atividades de edição e até mesmo leitura destes artefatos. Como resultado, elas 


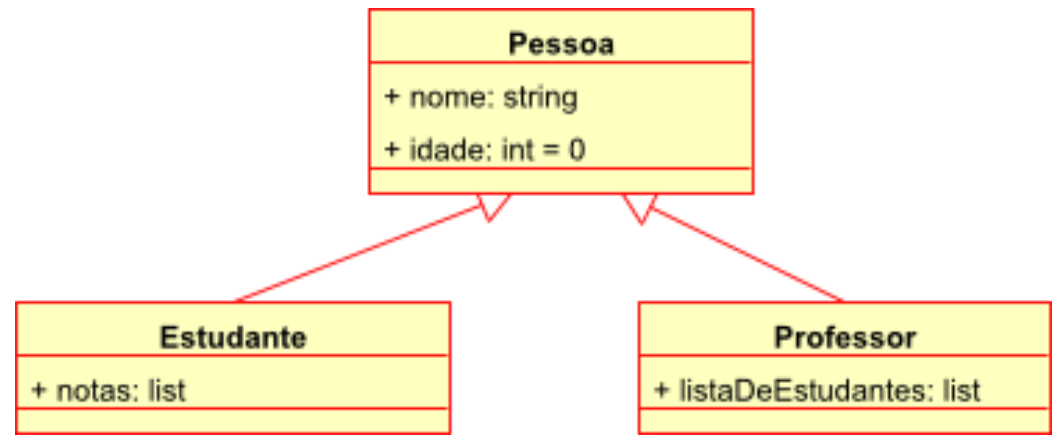

Figura 1.1: Exemplo de um diagrama de classes UML, adaptado de [49].

dependem de outras pessoas para lhes explicarem os conceitos por meio da fala, no caso de uma abordagem tradicional e possivelmente se tornam excluídas no caso do desenvolvimento orientado a modelos, em que se busca a geração de código de maneira automática a partir dos modelos.

\subsection{Motivação}

A computação sempre foi uma área na qual deficientes visuais podem trabalhar e até mesmo lecionar, pois os códigos de programas são em sua maioria textuais e, portanto, acessíveis por meio do uso de tecnologias assistivas como leitores de tela. No entanto, à medida em que modelos visuais aumentaram sua popularidade com o crescimento da disciplina de engenharia de software, a participação dos deficientes visuais ficou comprometida em atividades de modelagem [33].

Encontram-se na literatura relatos de trabalhos científicos que exploram o desenvolvimento de ferramentas Web para edição de modelos, tais como o GEMSjax [16] e o SLIM [59]. Ambos são ambientes nos quais os usuários podem realizar atividades de modelagem de maneira colaborativa e na $W e b$. No entanto, pelo fato da edição dos modelos se dar de maneira unicamente visual, o acesso de pessoas com deficiência visual fica comprometido.

Embora existam trabalhos que busquem desenvolver ferramentas para possibilitar atividades de modelagem de software na $W e b$, por meio de aplicações $W e b$ ricas, a questão do acesso a essas ferramentas nem sempre recebe a devida atenção ou é o foco principal do desenvolvimento. No entanto, possibilitar o acesso universal a uma aplicação Web é de primeira importância para a inclusão social de cidadãos com deficiências na sociedade, de modo que eles possam levar uma vida ativa e independente. 


\subsection{Objetivo}

O objetivo deste projeto foi desenvolver uma técnica textual para representação e interação com diagramas que possibilite que pessoas com deficiência sejam capazes de colaborar em projetos de software, tanto utilizando uma abordagem de desenvolvimento orientado a modelos, na qual os modelos são os principais artefatos no processo de desenvolvimento [38], quanto em uma abordagem tradicional, na qual os modelos são utilizados em fases de especificação e design do sistema [50].

\subsection{Organização do texto}

Neste capítulo foram apresentadas as considerações iniciais deste trabalho, o contexto no qual ele se insere, suas motivações e objetivos.

O restante deste trabalho é organizado da seguinte forma: o Capítulo 2 contextualiza a área de desenvolvimento orientado a modelos, mostrando as principais abordagens existentes atualmente e quais as motivações para sua utilização. O Capítulo 3 apresenta uma visão geral sobre conceitos de acessibilidade na $W e b$, são citadas as principais recomendações existentes e uma breve discussão sobre a regulamentação da acessibilidade. No Capítulo 4 é apresentado o protótipo da ferramenta desenvolvida, sua arquitetura, definição da linguagem textual e trabalhos relacionados. O Capítulo 5 mostra os detalhes do estudo de caso conduzido com o objetivo de avaliar a abordagem proposta. Nele são apresentados o protocolo, resultados obtidos, as análises realizadas e suas conclusões. Por fim, no Capítulo 6 são apresentadas as principais contribuições deste trabalho e artigos publicados, um prêmio que foi concedido à AWMo, algumas das limitações do trabalho e possibilidades de trabalhos futuros. 


\section{Desenvolvimento orientado a modelos}

\subsection{Considerações iniciais}

O MDD (Model-Driven Development) é uma abordagem de engenharia de software que se utiliza de modelos para elevar o nível de abstração com que os desenvolvedores trabalham nos processos de criação e manutenção de software. Os principais objetivos dessa abordagem são tornar a tarefa de desenvolver software mais simples e menos repetitiva, com o uso de automações e maior nível de abstração, e aumentar a padronização dos sistemas pois os elementos abstratos são combinados para formar um modelo de software que posteriormente poderá ser utilizado para gerar código executável por meio de transformações.

Os principais conceitos inerentes à abordagem MDD são os modelos e as transformações. Os modelos são artefatos de software que representam um sistema, parte dele ou mesmo processos ou etapas para se realizar determinada tarefa. Pode-se utilizar modelos com diferentes níveis de abstração, desde um modelo que não tenha nenhuma relação com a plataforma para a qual o software será desenvolvido quanto um modelo específico e otimizado para determinada plataforma. Além disso, é possível que, por meio de transformações, um modelo dê origem a outro modelo menos abstrato, por exemplo.

As transformações são procedimentos realizados para transformar um modelo em algum outro artefato ao longo do ciclo de desenvolvimento de um software. Com as transformações é possível, por exemplo, transformar um modelo em outro modelo diferente, artefatos de documentação ou mesmo em código executável. 


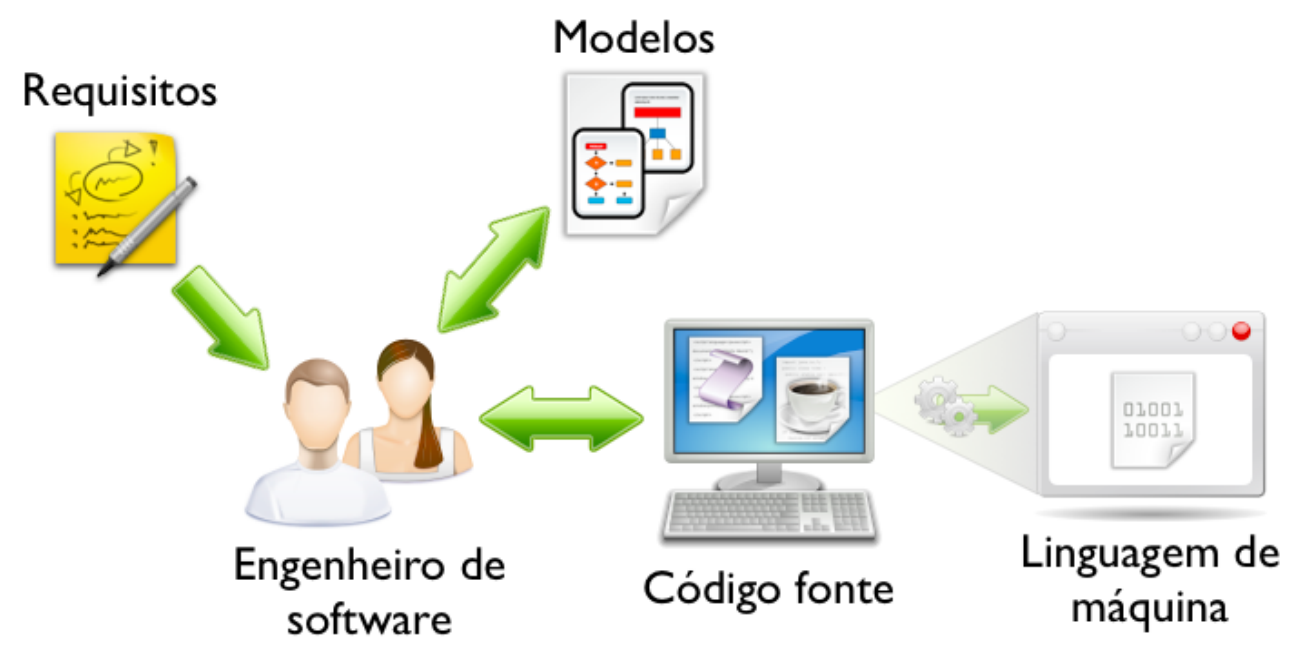

Figura 2.1: Representação do processo de desenvolvimento de software com uma abordagem tradicional.

A Figura 2.1 ilustra um processo de desenvolvimento tradicional; neste caso, os modelos geralmente são construídos pelos engenheiros de software durante as fases iniciais do projeto e, posteriormente, precisam ser atualizados para que reflitam de maneira fiel o código desenvolvido e as possíveis alterações que surgem ao longo do desenvolvimento.

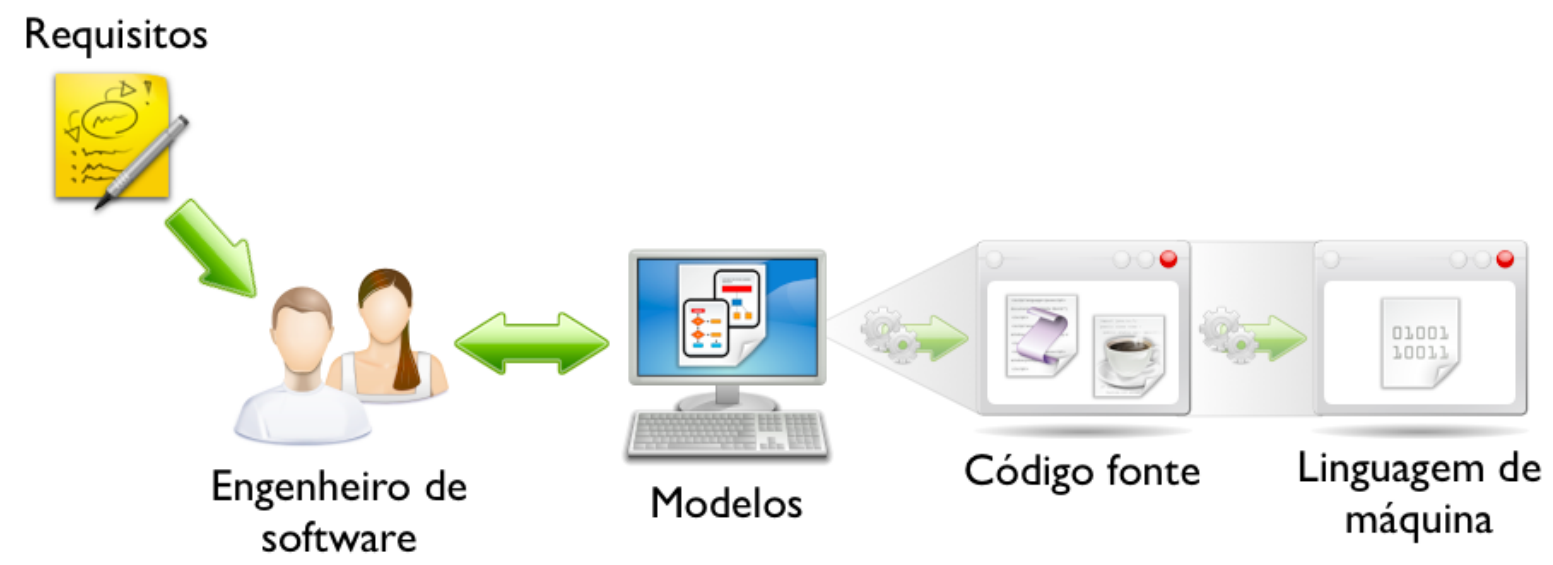

Figura 2.2: Representação do processo de desenvolvimento de software com uma abordagem orientada a modelos.

A Figura 2.2, por sua vez, ilustra um processo de desenvolvimento utilizando uma abordagem orientada a modelos. Pode-se notar que nessa abordagem os modelos fazem parte do processo de desenvolvimento, não apenas como apoio como é o caso da abordagem tradicional. O código é gerado a partir dos modelos e, portanto, quando alguma alteração de projeto precisa ser realizada, ela é realizada diretamente no modelo e um novo código 
é produzido com base em transformações, a partir do modelo atualizado. Dessa forma, os modelos são sempre um reflexo fiel do código.

De acordo com Lucrédio (2009), algumas das principais vantagens de se utilizar a abordagem MDD são:

- Diminuição do fardo da modelagem: em uma abordagem tradicional de desenvolvimento de software, os modelos são construídos em uma fase de estudos preliminares para se compreender e delimitar características e funcionalidades do software desejado. No entanto, esses modelos são utilizados apenas para comunicar os conceitos aos desenvolvedores e todo o código é desenvolvido manualmente. Ao decorrer do desenvolvimento é comum que os modelos desenhados inicialmente se tornem desatualizados. Assim, atualizar os modelos a cada vez que o software sofre uma alteração torna-se um fardo, pois os desenvolvedores já internalizaram o conhecimento a respeito do funcionamento do sistema e não necessitam mais do auxílio dos modelos, o que torna a tarefa de manutenção ainda mais árdua. É comum que estes modelos, que funcionam como uma documentação do sistema, acabem sendo utilizados apenas por novos desenvolvedores que possam vir a fazer parte da equipe.

- Melhoria na comunicação: com o uso de modelos que escondem detalhes técnicos de implementação e ao mesmo tempo se aproximam do domínio do problema, a abordagem de desenvolvimento orientado a modelos fornece um vocabulário comum entre os stakeholders, gerentes, projetistas, desenvolvedores e equipe de testes. Este vocabulário facilita, portanto, a comunicação entre pessoas com diferentes níveis de conhecimento técnico.

- Evitar repetições: com automação das transformações, os desenvolvedores realizam menos tarefas repetitivas para transformar modelos em código executável. Além disso, é possível consolidar conhecimentos de especialistas em desenvolvimento para fazer com que os códigos gerados sigam boas práticas e evitem erros comuns que ocorrem durante a codificação manual de um software.

- Padronização: o aumento da padronização ocorre tanto pelo uso de modelos comuns em diversas fases do projeto, quanto pela reutilização dos próprios modelos em outros projetos e em função da geração de código por meio de transformações. Dessa forma, se um mesmo modelo for transformado automaticamente em código, ele sempre resultará no mesmo código. Por outro lado, o código de um mesmo modelo que é desenvolvido manualmente pode variar se desenvolvido por diferentes engenheiros de software ou mesmo pelo mesmo engenheiro em um momento diferente. 
Entretanto, o desenvolvimento orientado a modelos também traz suas desvantagens. O ferramental utilizado para MDD, como ferramentas de modelagem e transformações, são ferramentas complexas de se construir e manter e, por esse motivo é comum encontrar ferramentas que não atendem a todas as necessidades da equipe [37]. O fato de grande parte do código ser gerado por meio de processos automáticos faz com que o software final seja menos flexível e também pode resultar em um software com menor desempenho se comparado a um software feito manualmente, pois as transformações podem resultar em uma quantidade maior de código. Além disso, os membros da equipe devem ser treinados tanto para o uso dessas ferramentas quanto ao novo processo de desenvolvimento com o qual não estão habituados $[7,38,58]$.

Segundo Lucrédio (2009), os principais elementos que devem ser utilizados por essa abordagem são ferramentas de modelagem, ferramentas para definição de transformações e mecanismos para se executar as transformações. A Figura 2.3 ilustra o relacionamento entre cada um desses elementos, que serão descritos individualmente a seguir.

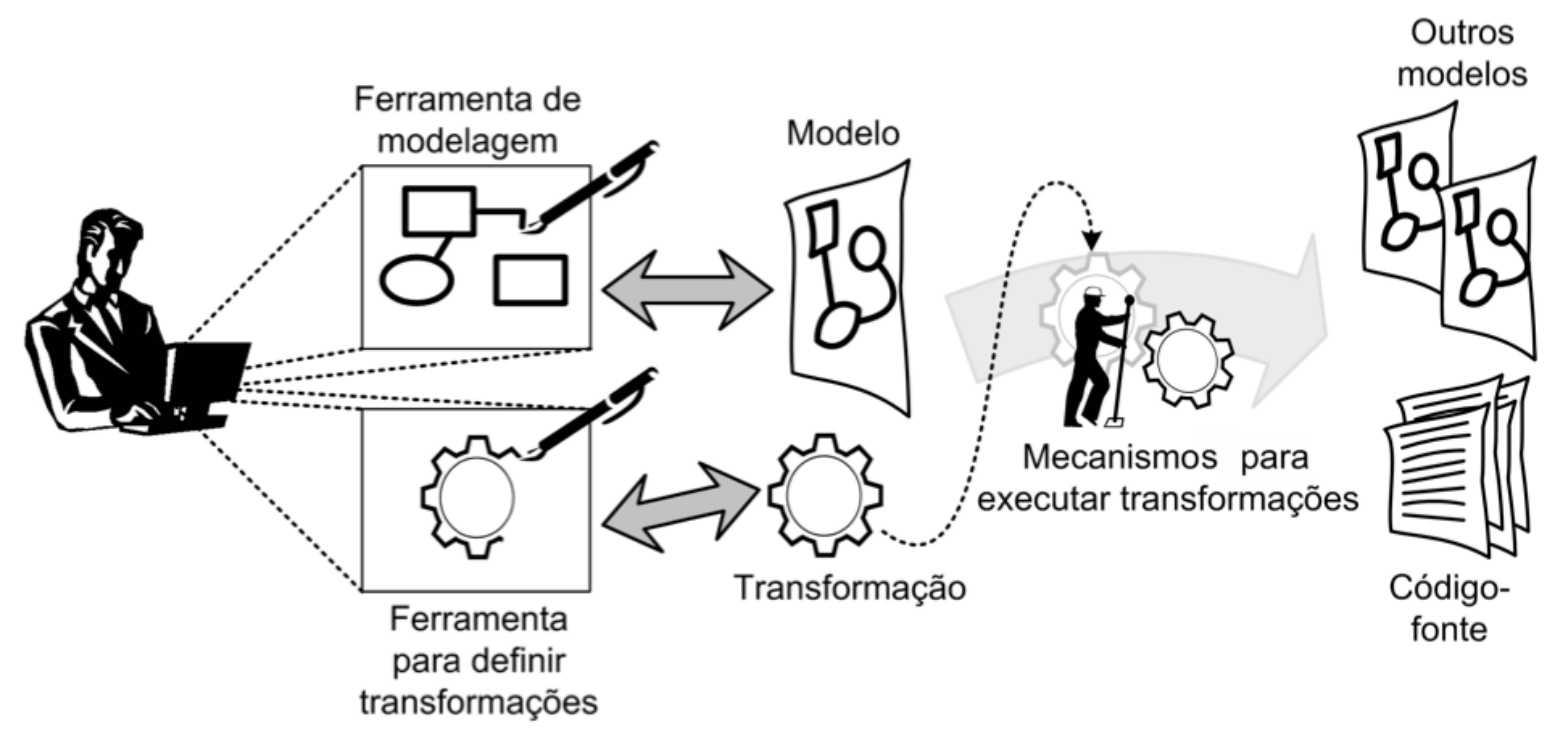

Figura 2.3: Principais elementos da abordagem de desenvolvimento orientado a mode$\operatorname{los}[38]$.

Ferramentas de modelagem: São as ferramentas de software que são utilizadas por engenheiros de software para elaborar os modelos. Essas ferramentas precisam ser fáceis de se utilizar e, principalmente, precisam ser capazes de gerar modelos semanticamente completos e corretos, pois apenas assim será possível que esse modelo seja utilizado como artefato de entrada para uma transformação. Modelos semanticamente incompletos necessitam da intervenção humana no processo de transformação. 
Ferramentas de definição de transformações: As transformações de modelo para modelo ou modelo para código são, em geral, bastante complexas de serem realizadas. É necessária uma ferramenta que auxilie os engenheiros de software na tarefa de especificar as transformações. Nesta ferramenta devem ser definidas regras de mapeamento que transformam os elementos de um modelo em elementos de um outro modelo ou em linhas de código. A complexidade destas transformações se dá também pelo fato dos modelos abstraírem grande parte dos detalhes de implementação. Como resultado disso, um único elemento de um modelo pode dar origem a centenas de linhas de código, por exemplo.

Mecanismos para execução de transformações: Depois de definidas as transformações, é necessário um mecanismo que aceite um modelo como entrada e aplique as regras de transformações definidas na ferramenta citada anteriormente. Nesta fase, é importante que sejam documentadas quais partes do modelo de entrada deram origem a determinadas partes do artefato de saída para que seja possível rastrear essas transformações e os desenvolvedores possam utilizar esse conhecimento para realizar alterações ou correções no modelo, com conhecimento de quais partes do artefato alvo serão afetadas.

O desenvolvimento orientado a modelos foi estudado neste trabalho de pesquisa devido a dois principais motivos: (a) espera-se que o protótipo desenvolvido possibilite a inclusão de deficientes visuais nas práticas de MDD, ao possibilitar o acesso de edição dos modelos e, (b) a abordagem proposta se fundamenta na definição de uma linguagem textual que instancia o metamodelo comum para as duas visões durante a modelagem: gráfica e textual; ferramentas tradicionalmente utilizadas em abordagens MDD, como o Xtext ${ }^{1}$, foram de grande valia no decorrer deste projeto por possibilitarem a criação dessa linguagem textual, que consiste no ponto crucial para o desenvolvimento da prova de conceito, a ferramenta que implementou a estratégia idealizada.

O restante deste capítulo detalha as duas principais abordagens de MDD existentes: a OMG (Object Management Group) ${ }^{2}$ e a Eclipse ${ }^{3}$, respectivamente nas Seções 2.2.1 e 2.2.2 e, por fim, são apresentadas as considerações finais.

\subsection{Principais abordagens}

$\mathrm{Na}$ indústria e na academia existem diversas abordagens para o desenvolvimento orientado a modelos. As duas mais difundidas são a da OMG e a da Eclipse Foundation, que

\footnotetext{
${ }^{1}$ http://www.eclipse.org/Xtext/

${ }^{2}$ http://omg.org

${ }^{3}$ http://www.eclipse.org/modeling/
} 
tem o apoio da IBM. Ambas serão explicadas em mais detalhes nas seções seguintes; no entanto, é importante salientar que estas não são as únicas abordagens existentes. Como exemplos de outras, podemos citar a GME (Generic Modeling Environment) da Universidade de Vanderbilt [14] e a abordagem de fábricas de software (Software Factories) da Microsoft [21].

\subsubsection{Object Management Group}

A abordagem de desenvolvimento orientado a modelos MDA (Model-Driven Architecture) foi criada em 2001 e é mantida pela OMG. Essa abordagem se apoia em padrões como a UML para modelagem e metamodelagem e foi criada com o intuito de permitir interoperabilidade de ferramentas.

Alguns dos padrões utilizados nessa abordagem são:

- MOF: Acrônimo para Meta Object Facility, esse padrão se encontra atualmente em sua versão 2.4.1 e provê meios para definição de metamodelos. Este padrão pode ser considerado um meta-metamodelo, a partir do qual todos os metamodelos nesta abordagem são definidos. Existem dois níveis de conformidade com MOF, o Essential MOF (EMOF) e o Complete MOF (CMOF), ambos definidos com a utilização da UML [45].

- UML: A Unified Modeling Language provê um framework de modelagem pelo qual os modelos são definidos, enquanto o MOF, citado anteriormente, trata dos metadados. A especificação da UML se encontra atualmente em sua versão 2.4.1, publicada em agosto de 2011 [47].

- XMI: Significa XML Metadata Interchange e é o padrão utilizado pela OMG para tornar possível a transmissão e armazenamento de modelos e sua interoperabilidade entre ferramentas distintas [46].

- QVT: Outro padrão definido pela OMG é o QVT (Queries/Views/Transformations). O QVT consiste em um conjunto de linguagens textuais que tem por objetivo realizar consultas, transformações e obter dados de modelos que seguem o padrão MOF. Atualmente essa especificação se encontra na versão 1.1 que foi lançada em janeiro de 2011 [44].

O processo de desenvolvimento seguindo a abordagem MDA é fundamentada em três modelos principais: o CIM (Computational Independent Model), o PIM (Platform Independent Model), o PSM (Platform Specific Model), quer serão descritos a seguir. 
O CIM é um modelo totalmente independente da implementação, ele é construído a partir dos requisitos do sistema e tem como objetivo mapear as regras de negócio no ambiente em que o sistema será utilizado. Como ele é independente de qualquer recurso ou conhecimento computacional, seu papel principal é diminuir a distância entre os especialistas no domínio em questão e seus requisitos, e os projetistas de software que irão construir o sistema.

A partir do modelo CIM, os projetistas devem extrair as informações importantes e criar o modelo PIM; este último é um modelo computacional que será utilizado posteriormente para geração de outros modelos, como o PSM, por exemplo. O PIM já pode ser considerado como uma visão do sistema a ser desenvolvido, no entanto, ele não contém nenhum detalhe que atrele seu funcionamento a alguma plataforma específica. Em função disso, um modelo PIM pode ser transformado em diversos modelos PSM, cada um para uma plataforma específica, como aplicações desktop, aplicações Web ou uma aplicação para dispositivos móveis.

A Figura 2.4 ilustra o processo de transformação de um modelo PIM em um modelo PSM no qual são adicionadas informações referentes à plataforma em que se deseja desenvolver o software. É importante notar que essa transformação pode ocorrer em apenas um passo como mostrado na Figura 2.4 ou pode possuir diversas outras transformações intermediárias, como mostra a Figura 2.5.

Os retângulos com as informações que são utilizadas para as transformações nas Figuras 2.4 e 2.5 são ilustrados em branco propositalmente pela OMG, pois representam alguma informação sobre a plataforma, que pode ser um outro modelo ou não. No caso de modelos, a OMG define os chamados Modelos de Plataforma, que são um mapeamento de especificidades de uma plataforma em um formato que pode ser utilizado nas transformações.

Por fim, o resultado destas transformações são os modelos PSM, que representam a visão do sistema em uma plataforma específica. A partir do PSM pode-se utilizar transformações automáticas ou semiautomáticas para geração de código. Todas as transformações citadas podem ser realizadas de forma manual, com assistência do computador ou de maneira completamente automática, dependendo de como os modelos são definidos e das ferramentas disponíveis.

\subsubsection{Eclipse Foundation}

O Eclipse é um ambiente integrado de desenvolvimento (Integrated Development Environment - IDE) desenvolvido em Java e utilizado para desenvolvimento de software e que recebe apoio da empresa IBM. Além disso, conta com uma vasta comunidade de desenvolvedores ao redor do mundo que também contribuem para o projeto [10]. Entre 


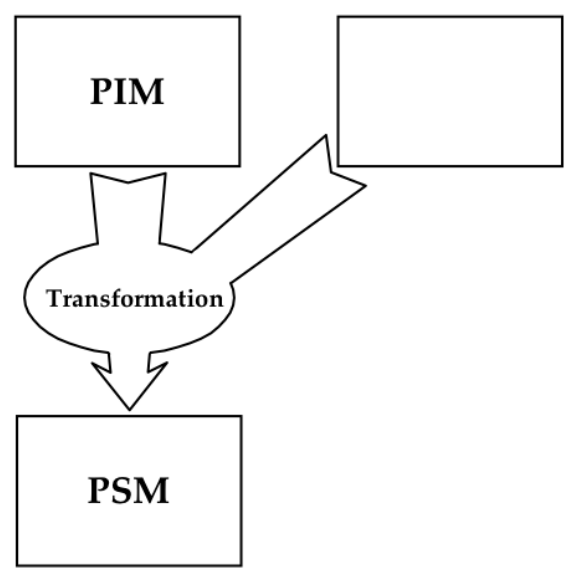

Figura 2.4: Transformação de um modelo independente de plataforma para um modelo específico de plataforma [43].

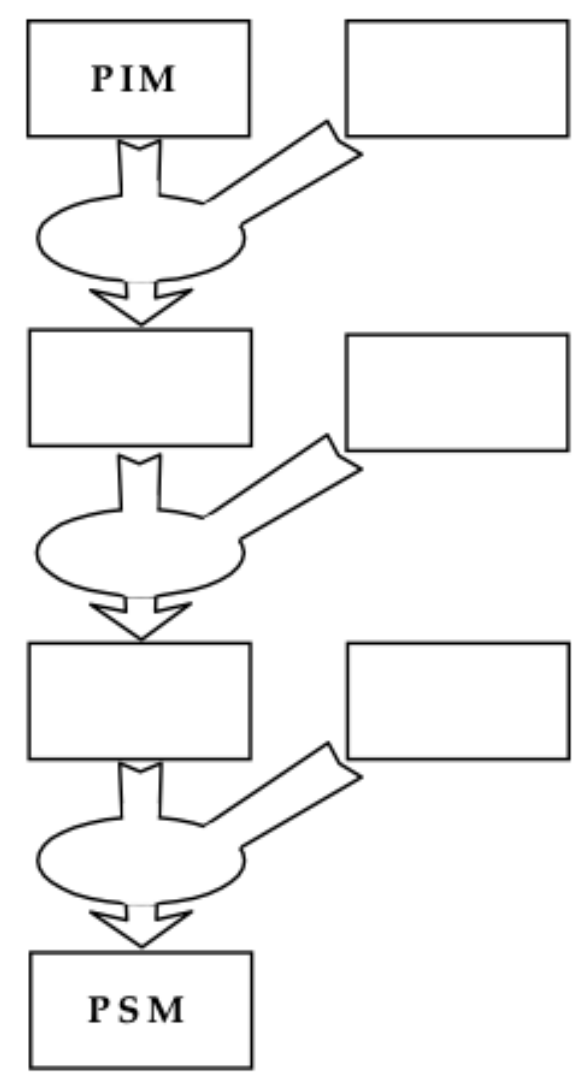

Figura 2.5: Transformação de um modelo independente de plataforma para um modelo específico de plataforma por meio de várias transformações subsequentes [43].

os subprojetos que fazem parte da Fundação Eclipse, existe o projeto de modelagem do Eclipse. 
A abordagem Eclipse é centrada no projeto chamado de Eclipse Modeling e seu objetivo é auxiliar na evolução e divulgação de tecnologias de desenvolvimento baseadas em modelos. Este projeto foi criado com a intenção de unir todos os outros que se classificam nessa categoria sob um único projeto maior, beneficiando a comunidade Eclipse como um todo.

O projeto Eclipse Modeling é formado por diversos outros projetos, entre eles podemos listar:

- EMF: Eclipse Modeling Framework é tanto um framework de modelagem quanto uma estrutura para geração de código com o objetivo de gerar outras ferramentas. Em outras palavras, o objetivo do EMF é construir ferramentas e aplicações a partir de modelos descritos no formato XMI, assim como abordagem da OMG. O meta-metamodelo utilizado pelo EMF é chamado Ecore e ele tem o mesmo papel que o MOF na abordagem MDA.

- ATL: É um projeto que define uma linguagem de transformação de modelos e ferramentas que se integram à IDE Eclipse e que visam auxiliar o usuário no desenvolvimento de transformações de modelos. A ATL tem a mesma função do padrão QVT definido pela OMG na abordagem MDA [31].

- Xtext: O Xtext faz parte do projeto TMF (Textual Modeling Framework) e tem o objetivo de auxiliar na criação de linguagens textuais específicas de domínio (DSL). Esse projeto é baseado nos outros projetos do EMF e, consequentemente, também utiliza meta-metamodelos Ecore [15]. Com o Xtext é possível gerar editores para linguagens textuais que oferecem syntax highlighting e auxílios aos usuários como auto-completar, por exemplo.

- GMF: Outro projeto importante da abordagem Eclipse é o Graphical Modeling Framework que busca fornecer componentes generativos, ferramentas e infraestrutura de execução para facilitar o desenvolvimento de editores gráficos de modelos baseados no EMF. Este projeto se baseia no projeto GEF (Graphical Editing Framework), que é um framework para criação de editores gráficos no Eclipse.

- JET: Sigla para Java Emitter Templates, é um projeto com foco na implementação de geradores de código a partir de modelos. Essa geração é um fator chave no desenvolvimento orientado a modelos pois permite a automação de tarefas repetitivas como citado no Seção 2.1.

Embora a abordagem Eclipse se utilize de alguns conceitos e tecnologias divergentes da abordagem MDA, também existem projetos que se dedicam a implementar as especificações da OMG, algumas vezes com pequenas alterações. Como exemplos de especificações 
da MDA no projeto Eclipse, podemos citar o "Operational QVT" e "Declarative QVT" que fazem parte do projeto M2M (Model to Model) no qual também pode ser encontrado projeto ATL.

\subsection{Considerações finais}

Neste capítulo foram descritas as motivações por trás do uso de abordagens de desenvolvimento de software orientado a modelos, as duas principais abordagens utilizadas tanto na indústria quando na academia foram caracterizadas. Observa-se que a OMG utiliza as especificações do MOF e UML e a abordagem Eclipse que utiliza os padrões Ecore e EMF em seu processo.

Para o desenvolvimento deste projeto, buscou-se utilizar primariamente a abordagem Eclipse, porém como o protótipo que foi desenvolvido possibilita modelagem com UML, espera-se que ele também possa ser utilizado por usuários que trabalhem com a abordagem da OMG.

A ocorrência de ferramentas de modelagem na $W e b$ tem aumentado e esse fato será melhor descrito na Seção 3.4, porém, é necessário se atentar para critérios de acessibilidade nestas ferramentas para que elas possam ser utilizadas universalmente. O Capítulo 3, a seguir, expõe alguns conceitos relevantes referentes à acessibilidade na $W e b$. 


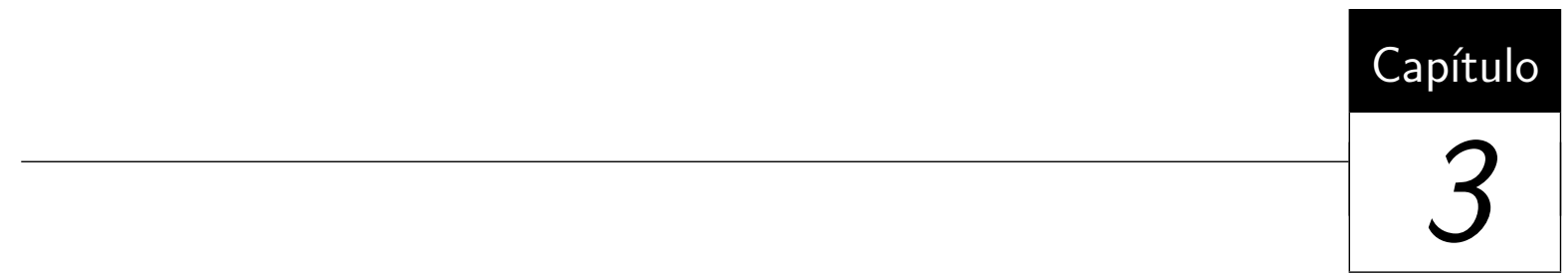

\section{Acessibilidade na Web}

\subsection{Considerações iniciais}

Quando a World Wide Web foi concebida por Tim Berners-Lee em 1990, sua intenção era construir um repositório de conhecimento humano universalmente acessível [69]. Porém, o projeto propunha uma forma de navegação com a intenção principal de se navegar em documentos de texto, como é o caso de artigos científicos sobre Física de alta energia no CERN (Organização europeia para investigação nuclear), lugar no qual a $W e b$ teve seu início.

Com o passar do tempo, notou-se que a Web era uma ótima forma de distribuição de informações e sua evolução foi exponencial [35]. Além de textos, hoje é muito comum encontrarmos grande quantidade de imagens, sons e vídeos em páginas na $W e b$. Em paralelo, as formas de interação com páginas da Web também evoluíram bastante: ao invés de apenas links para navegar entre uma página de texto e outra, hoje existem diversas outras maneiras de se interagir. Por exemplo, é possível realizar operações como Arrastar e Soltar (Drag and Drop), Duplo clique, Parar sobre (Halt over) e além disso, a forma como os dados são apresentados pode ser diferente. Utilizando-se de técnicas mais modernas como AJAX é possível buscar dados e fazer requisições ao servidor sem interromper a interação do usuário e apresentar as novas informações de maneira não intrusiva, resultando em um fluxo de trabalho muito mais próximo do que se está habituado em aplicações Desktop [13].

No entanto, à medida que esta evolução ocorre, a característica de acesso universal idealizada por Berners-Lee nem sempre recebe a devida atenção [41]. Essa é uma frente 
de trabalho da W3C, instituição da qual Tim Berners-Lee é diretor, formada por mais de 300 membros, entre eles empresas, universidades e outras instituições que têm como objetivo trabalharem juntas para a definição de padrões e recomendações para a $W e b$.

Entre esses padrões e recomendações, existe um esforço para tornar a Web mais acessível para todos. O termo acessibilidade $W e b$ significa que pessoas com deficiências podem tomar conhecimento, entender, navegar e interagir com a $W e b$ e, consequentemente, elas podem contribuir para seu desenvolvimento [65].

De acordo com os primeiros resultados do Censo 2010, divulgados pelo IBGE em novembro de 2010, 45,6 milhões de brasileiros diziam possuir algum tipo de deficiência. Isto significa uma parcela equivalente a aproximadamente $23,9 \%$ da população nacional [29]. No censo anterior, realizado em 2000, havia 24,6 milhões de pessoas com algum tipo de deficiência, o que representa 14,5\% da população nacional em 2000 [28]. Em ambos os estudos são considerados todos os tipos de deficiência, sejam elas físicas/sensoriais ou mentais. Houve um crescimento de quase 10 pontos percentuais no intervalo de 10 anos. É importante considerar que a pesquisa realizada pelo IBGE sobre portadores de deficiência nos censos foi realizada por amostragem, ou seja, foram levantadas questões sobre a existência de pessoas com deficiência apenas em uma amostra de todos os domicílios visitados pelos agentes do censo [20].

Como mencionado na Seção 1.2, a computação é uma área em que deficientes possuem certa facilidade para trabalhar pelo fato de que grande parte do trabalho de desenvolvimento de software, que é a programação, é um trabalho de escrita. Com o auxílio de leitores de tela, um deficiente visual pode utilizar o teclado ou até mesmo interfaces de entrada em braille para programas e escutar o que está escrevendo.

Um exemplo de um desenvolvedor de software deficiente visual é o atual funcionário do Google Peter Lundblad. Peter é um dos principais colaboradores da ferramenta de controle de versões Subversion ${ }^{1}$, utiliza um teclado simples com leitor de tela para desenvolver programas, e quando precisa ler trechos de código mais extensos, utiliza um mostrador em braille [8].

Um problema similar ao do acesso a modelos visuais citado na Seção 1.2 ocorreu com a introdução de interfaces gráficas no passado, nas quais formulários podiam ser feitos arrastando e soltando componentes com o mouse. Para permitir acesso a programadores deficientes visuais, foram introduzidas linguagens de script que permitiam a inserção de elementos sem a necessidade do uso de mouse [55].

\footnotetext{
${ }^{1} \mathrm{http}: / /$ subversion.apache.org/
} 


\subsection{Web Accessibility Initiative}

A W3C, por meio da WAI ( Web Accessibility Initiative), trabalha em diversos padrões e recomendações que têm por objetivo melhorar a acessibilidade de sites. No entanto, por focar seus esforços em conformidade com suas recomendações, o W3C promove uma visão mais técnica e mensurável da acessibilidade. Porém, nem sempre ao atingir um bom nível de acessibilidade segundo esses padrões, um site ou aplicação possui uma boa usabilidade [48].

Na Figura 3.1 [64], podemos ver três das principais recomendações da W3C, na forma de documentos com guidelines (diretrizes) e quais áreas ou componentes da Web elas abordam.

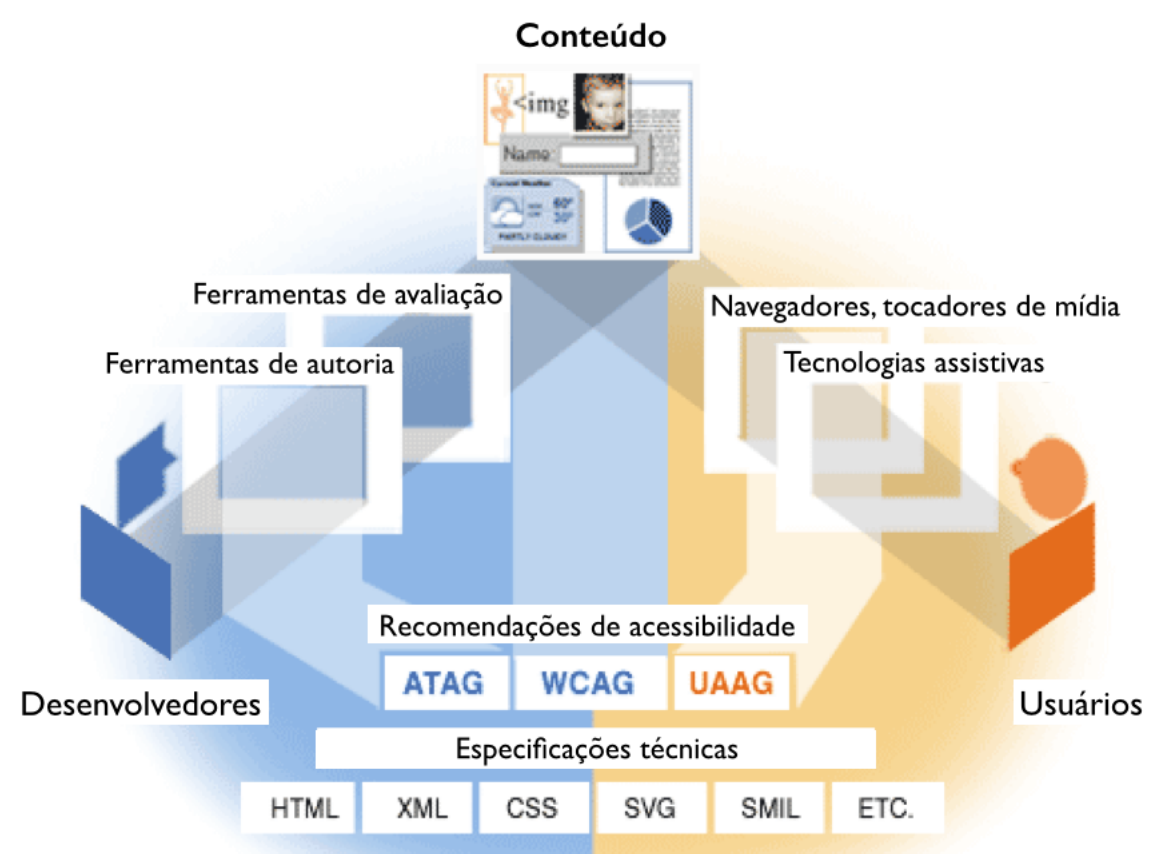

Figura 3.1: Relação entre as recomendações da W3C e seus componentes de atuação [64].

O ATAG tem como alvo as ferramentas de autoria para Web [62], o WCAG tem como objetivo melhorar a acessibilidade do conteúdo e navegação na Web [66] e o UAAG busca definir padrões e recomendações para o desenvolvimento e funcionamento dos softwares pelos quais se acessa a $W e b$ e outras tecnologias assistivas [63]. Uma quarta recomendação que não se encontra na figura e que tem se tornado cada vez mais importante é o WAI-ARIA, que trata de acessibilidade em aplicações Web ricas (RIA) [67]. O conceito de RIAs será explicado na Seção 3.2.4. 


\subsubsection{WCAG}

O WCAG (Web Content Accessibility Guidelines) é um conjunto de recomendações que tem por objetivo tornar o conteúdo de documentos acessível, seja este conteúdo disponibilizado em uma página ou processado em aplicações Web. Para tal, essas recomendações tratam de diversos fatores pertinentes aos conteúdos $W e b$ que podem se tornar barreiras que impedem o acesso, principalmente de pessoas com algum tipo de deficiência, mas também por pessoas utilizando dispositivos limitados como tablets e smartphones.

A W3C afirma que ao tornar o conteúdo de uma página mais acessível para pessoas com deficiência, por exemplo, também se está tornando-o melhor e mais flexível para todos os outros usuários que não possuem deficiências, que possuem deficiências temporárias ou que têm suas habilidades reduzidas devido ao envelhecimento [65].

Por exemplo, para um usuário deficiente visual, o conteúdo de uma imagem não pode ser visto, neste caso a WCAG recomenda a utilização de textos alternativos:

Recomendação 1.1 Alternativas em Texto: fornecer alternativas em texto para qualquer conteúdo não textual, permitindo assim que o mesmo possa ser alterado para outras formas mais adequadas à necessidade do indivíduo, tais como impressão em caracteres ampliados, braille, fala, símbolos ou linguagem mais simples ${ }^{2}$.

Considerando o exemplo da Figura 3.2, temos uma página bastante simples, composta de um cabeçalho, dois trechos de texto e uma imagem entre eles. Um possível código HTML para esta página é o código mostrado na Listagem 3.1. Neste trecho de código a imagem da motocicleta é adicionada ao conteúdo da página com o comando contido na linha 5. No entanto, este código não está em conformidade com a Recomendação 1.1 do WCAG mostrada anteriormente, pois esta imagem não tem um texto alternativo.

\footnotetext{
${ }^{2}$ Tradução realizada em 2 de março de 2009 pelo Prof. Everaldo Bechara e disponível em http://www.ilearn.com.br/TR/WCAG20/
} 


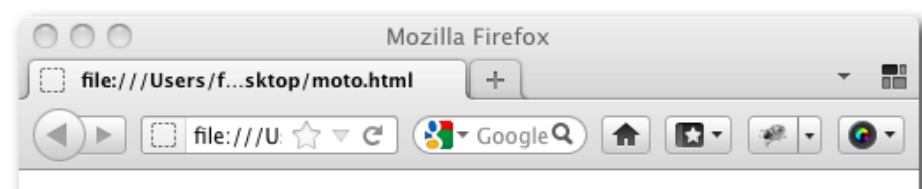

\section{Motocicleta}

Lorem ipsum dolor sit amet, consectetur adipiscing elit. Vestibulum mauris mauris, dictum et fermentum nec, sagittis eu justo.

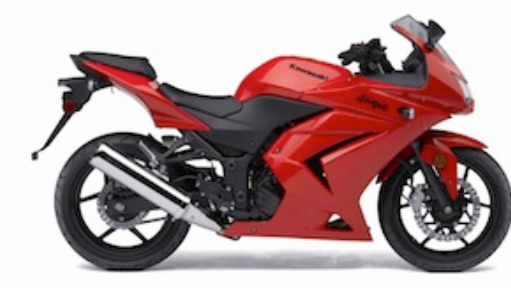

Quisque accumsan aliquam diam, eu pharetra tellus sagittis sed. Vestibulum vel aliquet orci.

Figura 3.2: Código da Listagem 3.1 exibido pelo navegador Firefox.

Listagem 3.1: Trecho de código HTML para inserir uma imagem sem texto alternativo.

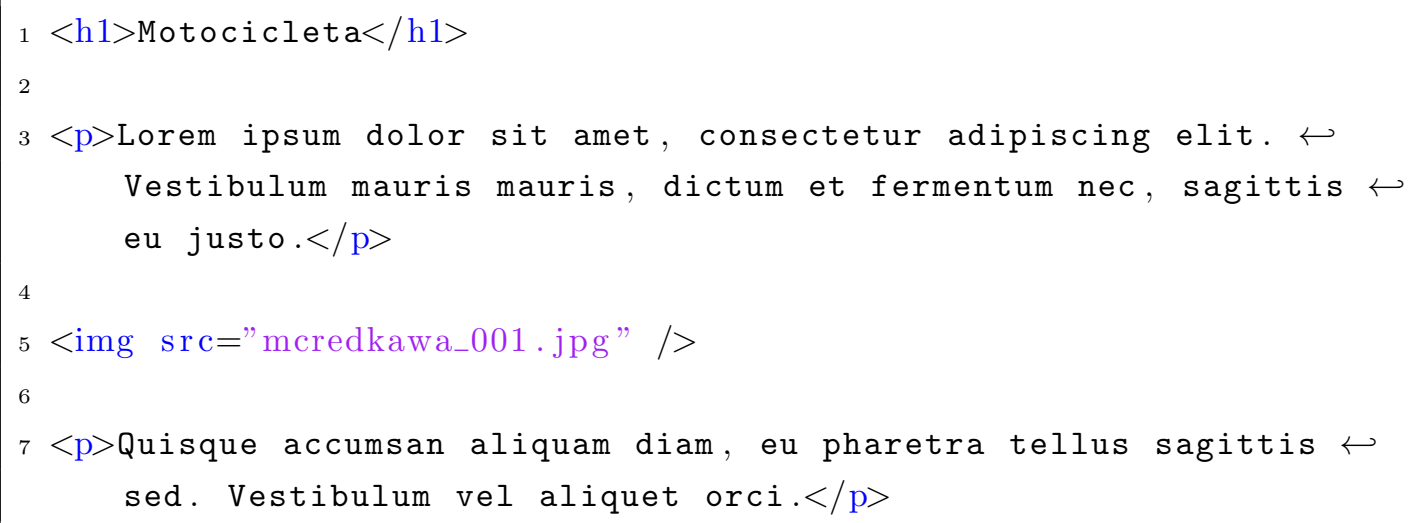

No caso da Listagem 3.1, o leitor de tela iria ler apenas o nome do arquivo da imagem "mcredkawa_001.jpg". No outro cenário, quando a imagem tem um texto alternativo como é o caso da Listagem 3.2, o leitor de tela irá avisar o usuário de que uma imagem foi encontrada e que sua descrição é "motocicleta vermelha". 
Listagem 3.2: Trecho de código HTML para inserir uma imagem com texto

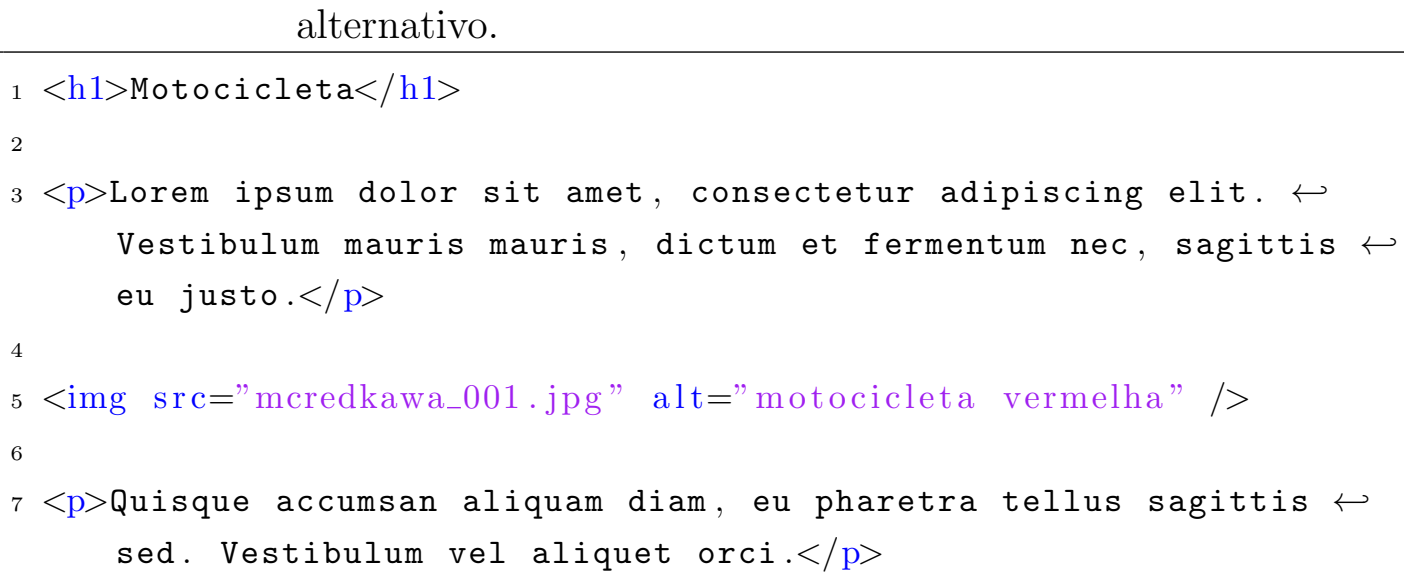

A seguir temos a lista de todos os princípios e suas respectivas recomendações que formam o WCAG 2.0. Cada recomendação é composta por critérios de sucesso que são critérios testáveis em um página $W e b$, e que podem ser verificados para aferir em qual nível de conformidade a página se encontra.

- Princípio 1: perceptível

- Recomendação 1.1: fornecer alternativas textuais para qualquer conteúdo não textual, permitindo que possa ser alterado, se necessário, para outros formatos como impressão com tamanho de fontes maiores, Braille, fala, símbolos ou linguagem mais simples.

- Recomendação 1.2: fornecer alternativas para mídias baseadas no tempo.

- Recomendação 1.3: criar conteúdo que pode ser apresentado de modos diferentes (por exemplo um layout simplificado) sem perder informação ou estrutura.

- Recomendação 1.4: tornar mais fácil aos usuários a visualização e audição de conteúdos, incluindo as separações das camadas da frente e de fundo.

- Princípio 2: operável

- Recomendação 2.1: fazer com que todas as funcionalidades estejam disponíveis no teclado.

- Recomendação 2.2: prover tempo suficiente para os usuários lerem e usarem o conteúdo. 
- Recomendação 2.3: não projetar conteúdo de uma forma conhecida por causar ataques epiléticos.

- Recomendação 2.4: prover formas de ajudar os usuários a navegar, localizar conteúdos e determinar onde se encontram.

- Princípio 3: compreensível

- Recomendação 3.1: tornar o conteúdo de texto legível e compreensível.

- Recomendação 3.2: fazer com que as páginas da Web apareçam e funcionem de modo previsível.

- Recomendação 3.3: ajudar os usuários a evitar e corrigir erros.

- Princípio 4: robusto

- Recomendação 4.1: maximizar a compatibilidade entre os atuais e futuros agentes do usuário, incluindo as tecnologias assistivas.

Existem três níveis de conformidade com o WCAG e eles são obtidos de acordo com quais critérios de sucesso são satisfeitos por uma página Web. A seguir, temos a lista de todos os níveis de conformidade e seus requisitos:

- Nível de conformidade "A": para atingir este nível de conformidade é preciso que a página $W e b$ satisfaça todos os critérios de sucesso de nível A. Este é o nível de conformidade mais baixo.

- Nível de conformidade "AA": para atingir este nível de conformidade é preciso que a página $W e b$ satisfaça todos os critérios de sucesso de níveis A e AA.

- Nível de conformidade "AAA": para atingir este nível de conformidade é preciso que a página $W e b$ satisfaça todos os critérios de sucesso de níveis A, AA e AAA, ou seja, satisfazer todos os critérios de sucesso e, portanto, é o nível mais alto de conformidade com o WCAG.

\subsubsection{ATAG}

O ATAG contém as recomendações da W3C para os desenvolvedores de ferramentas de autoria para a $W e b$. Essas recomendações têm por objetivo fazer com que ferramentas de autoria, sejam elas aplicações Desktop tradicionais ou aplicações Web de produção de conteúdo como blogs, sistemas de gestão de conteúdo (CMS) e redes sociais, sejam: 1) capazes de auxiliar os seus usuários na criação de conteúdos mais acessíveis e estejam em 
conformidade com o WCAG e 2) possibilitar que pessoas com deficiências sejam capazes de utilizar essas ferramentas.

A criação de conteúdo tem tanta importância quanto a possibilidade das pessoas de acessá-lo, portanto é objetivo da W3C que todas as pessoas sejam capazes de colaborar com o desenvolvimento da $W e b$, não apenas como agentes passivos, mas ativamente produzindo conteúdo.

Atualmente, o ATAG se encontra na versão 1.0, porém o desenvolvimento de sua versão 2.0 foi iniciado em julho de 2011 [68] e atualmente se encontra como uma versão preliminar que virá a substituir o ATAG 1.0 no futuro. A seguir temos as sete recomendações do atual ATAG $1.0^{3}$. Cada uma destas recomendações possui pontos de verificação com diferentes prioridades e, portanto, elas podem ser atendidas total ou parcialmente, dependendo do nível de conformidade que se deseja obter para a ferramenta.

- Recomendação 1: apoiar práticas de autoria acessíveis.

- Recomendação 2: gerar marcação padrão.

- Recomendação 3: apoiar a criação de conteúdo acessível.

- Recomendação 4: prover maneiras de verificar e corrigir conteúdo inacessível.

- Recomendação 5: integrar soluções de acessibilidade na aparência e funcionamento.

- Recomendação 6: promover acessibilidade nos mecanismos de ajuda e documentação.

- Recomendação 7: assegurar-se de que a ferramenta de autoria é acessível para autores com deficiências.

Assim como o WCAG, o ATAG também possui três níveis de conformidade, sendo eles:

- Nível de conformidade "A": Para obter este nível, é necessário satisfazer todos os pontos de verificação de prioridade 1 e os pontos de prioridade relativa. Este é o nível mais baixo de conformidade.

- Nível de conformidade "Duplo-A": Para obter este nível é necessário satisfazer todos os pontos de verificação com prioridades 1, 2 e também os pontos de prioridade relativa.

\footnotetext{
${ }^{3}$ Tradução livre realizada pelo autor deste documento em 26/01/2012.
} 
- Nível de conformidade "Triplo-A": Para obter este nível de conformidade é necessário satisfazer todos os pontos de verificação com prioridades 1, 2, 3 e todos os pontos de prioridade relativa. Este é o nível de conformidade mais alto pois atende a todos os pontos de verificação do ATAG 1.0.

\subsubsection{UAAG}

Outro conjunto de recomendações da W3C é o UAAG (User Agent Accessibility Guidelines), estas recomendações foram criadas com foco em desenvolvedores de navegadores $W e b$, softwares de reprodução de mídia e tecnologias assistivas, conhecidos como aplicações cliente, para que eles possam desenvolver aplicações sem barreiras (fatores que impedem a realização de determinadas tarefas) e, consequentemente, tornar mais acessível o acesso à $W e b$. As aplicações clientes são os sistemas de software por meio dos quais os usuários acessam a $W e b$. O navegador Mozilla Firefox ${ }^{4}$ é um exemplo de uma aplicação cliente para Web, assim como o Google Chrome $^{5}$, Safari da Apple ${ }^{6}$ e Internet Explorer ${ }^{7}$.

Além disso, a UAAG também fornece ferramentas que permitem aos usuários avaliarem a acessibilidade de aplicações cliente. Os softwares que estiverem em conformidade com a UAAG promovem a acessibilidade por meio de sua interface e também da habilidade de se comunicar com outras tecnologias, em especial com tecnologias assistivas como leitores de tela.

A seguir temos as doze recomendações que compõem a $\mathrm{UAAG}^{8}$. Cada uma delas é composta por pontos de verificação com prioridades variando de 1 a 3 , sendo 1 as mais importantes e 3 as menos importantes.

- Recomendação 1: apoiar a independência de entrada e saída dos dispositivos;

- Recomendação 2: garantir acesso do usuário a todo o conteúdo;

- Recomendação 3: permitir que seja configurável para não exibir determinados conteúdos que podem reduzir a acessibilidade;

- Recomendação 4: garantir ao usuário controle sobre o que é "renderizado";

- Recomendação 5: garantir controle sobre o comportamento da interface ao usuário;

\footnotetext{
${ }^{4}$ http://www.firefox.com

${ }^{5}$ http://www.google.com/chrome

${ }^{6}$ http://www.apple.com/br/safari/

${ }^{7}$ http://windows.microsoft.com/pt-BR/internet-explorer/products/ie/home

${ }^{8}$ Tradução livre realizada pelo autor deste documento em 26/01/2012.
} 
- Recomendação 6: implementar Interfaces de Programação de Aplicativos (APIs) interoperáveis;

- Recomendação 7: observar convenções dos sistemas operacionais;

- Recomendação 8: implementar especificações que beneficiem a acessibilidade;

- Recomendação 9: prover mecanismos de navegação;

- Recomendação 10: orientar o usuário;

- Recomendação 11: permitir configuração e personalização;

- Recomendação 12: prover documentação e ajuda acessíveis.

Os níveis de conformidade com o UAAG são similares aos utilizados pelo ATAG citados anteriormente, é possível ter os seguintes níveis de conformidade:

- Nível de conformidade "A": para obter este nível, é necessário satisfazer todos pontos de verificação de prioridade 1 .

- Nível de conformidade "Duplo-A": para obter este nível é necessário satisfazer todos os pontos de verificação com prioridades 1 e 2 .

- Nível de conformidade "Triplo-A": para obter este nível de conformidade é necessário satisfazer todos os pontos de verificação com prioridades 1, 2 e 3 .

\subsubsection{WAI-ARIA}

Embora muitas pessoas confundam o termo RIA com Web 2.0, suas definições são diferentes. O termo RIA (Rich Internet Applications), em português, Aplicações de Internet Ricas, foi cunhado pela empresa Macromedia em um white paper [6] em março de 2002, embora o conceito já existisse anteriormente com diferentes nomes.

Ele é utilizado para descrever aplicações $W e b$ que se assemelham a aplicações Desktop, enquanto que o termo Web 2.0 é utilizado para designar aplicações $W e b$ que facilitem o compartilhamento de informações e a colaboração entre os usuários, possuam design centrado no usuário, nas quais eles são os principais geradores de conteúdo e não apenas consumidores de informação. As redes sociais são um exemplo de aplicações da Web 2.0.

As RIAs normalmente também se mostram como um grande desafio à acessibilidade. Em geral, a maioria os frameworks que auxiliam no desenvolvimento da interface e interação como Capuccino ${ }^{9}$, Google Web Toolkit ${ }^{10}$ e PhoneGap ${ }^{11}$, por exemplo, não foram

\footnotetext{
${ }^{9}$ http://cappuccino.org/

${ }^{10}$ http://code.google.com/webtoolkit/

${ }^{11}$ http://phonegap.com/
} 
desenvolvidos com critérios de acessibilidade em mente. Portanto, determinadas formas de interação, como objetos que se escondem ou aparecem podem não ser interpretados corretamente pelos softwares e como consequência, usuários que possuem algum tipo de necessidade especial podem não ter meios para reconhecer e, consequentemente, interagir com esses objetos.

Em função disso, a W3C por meio de sua iniciativa de acessibilidade $W e b$, iniciou a formulação de um conjunto de normas e recomendações para desenvolvimento de aplicações ricas acessíveis. O documento é chamado WAI-ARIA, que é a sigla para Web Accessibility Initiative - Accessible Rich Internet Applications e atualmente se encontra em fase final de desenvolvimento dentro da W3C; visa fornecer maneiras tanto para os desenvolvedores de aplicações $W e b$ quanto para desenvolvedores de tecnologias assistivas, para que padrões sejam adotados entre eles em benefício dos usuários. Portanto, seria possível, por exemplo, uma aplicação fornecer informações para o navegador e para tecnologias assistivas sobre como os objetos complexos de uma página $W e b$ se comportam.

O WAI-ARIA tem um formato diferente das recomendações citadas anteriormente, ela é formada por papéis (roles), semântica e estados. Os papéis são atributos adicionados à marcação HTML de uma página que servem para descrever qual a função de determinado elemento. Com isso é possível indicar a função de determinadas regiões de uma página $W e b$, por exemplo, que determinado elemento é uma barra de menus ou um item de menu. Um exemplo de seu uso pode ser visto no código da Listagem 3.3 que será melhor explicada adiante. Além disso, é possível definir estados de cada elemento para que tecnologias assistivas sejam capazes de determinar quando um elemento dinâmico sofreu alterações.

A Tabela 3.1 descreve como são organizados os papéis do WAI-ARIA, de acordo com suas categorias. Por meio desses papéis é possível adicionar semântica aos elementos mais comuns de uma aplicação Web.

Além dos papéis, a recomendação define estados e propriedades para cada um de seus papéis, tornando possível por exemplo, indicar se um botão se encontra no estado pressionado ou não, ou se determinada região é uma região atualizável e de que forma o usuário deve ser alertado no caso de uma atualização. A Listagem 3.3 mostra um elemento de botão e como as definições do WAI-ARIA são utilizadas para melhorar sua acessibilidade. O fato de utilizar o papel "button" faz com que tecnologias assistivas sejam capazes de diferenciar esse elemento de um link comum e fornecer instruções para o usuário como, por exemplo: "Pressione espaço para ativar". Além disso, o atributo "aria-pressed" indica o estado atual do botão, sendo que "true" significa que o botão está ativado e "false" indicaria que o botão está desativado. 
Tabela 3.1: Categorias do WAI-ARIA e seus respectivos papéis.

\begin{tabular}{|l|l|}
\hline Categorias & Valores atribuídos aos papéis \\
\hline \hline Abstratos & $\begin{array}{l}\text { command, composite, input, landmark, range, roletype, } \\
\text { section, sectionhead, select, structure, widget, window }\end{array}$ \\
\hline Widgets & $\begin{array}{l}\text { alert, alertdialog, button, checkbox, dialog, grid- } \\
\text { cell, link, log, marquee, menuitem, menuitemcheckbox, } \\
\text { menuitemradio, option, progressbar, radio, scrollbar, } \\
\text { slider, spinbutton, status, tab, tabpanel, textbox, ti- } \\
\text { mer, tooltip, treeitem, combobox, grid, listbox, menu, } \\
\text { menubar, radiogroup, tablist, tree, treegrid }\end{array}$ \\
\hline Marcadores & $\begin{array}{l}\text { grticle, columnheader, definition, directory, document, } \\
\text { group, heading, img, list, listitem, math, note, pre- } \\
\text { sentation, region, row, rowheader, separator, toolbar }\end{array}$ \\
\hline & $\begin{array}{l}\text { main, navigation, banner, complementary, contentinfo, form, } \\
\text { main, search }\end{array}$ \\
\hline
\end{tabular}

Listagem 3.3: Trecho de código que mostra um botão utilizando os atributos de papel e estado do WAI-ARIA.

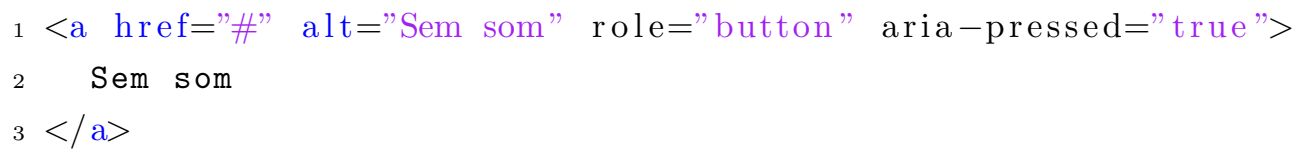

\subsection{Regulamentação}

Com o grande uso de tecnologias de informação e comunicação (TIC) diversos países têm levantado questões sobre como as leis existentes se aplicam à Web. Como consequência disso há um número crescente de regulamentações sendo elaboradas ao redor do mundo no que diz respeito a aspectos de acessibilidade e inclusão de todos os cidadãos nesse meio de comunicação.

No Brasil, foram criadas algumas leis e decretos que tratam de acessibilidade. Embora nenhuma delas trate especificamente de acessibilidade na $W e b$, alguns de seus artigos tratam de acessibilidade e remoção de barreiras em meios de comunicação, sejam eles de massa ou não. A seguir encontram-se as principais regulamentações nacionais a respeito da acessibilidade e alguns de seus trechos que podem ser aplicados à Web ou que definem termos da área. 
- Lei 10.098 de 19 Dezembro de 2000: estabelece normas e critérios gerais para promover a acessibilidade para portadores de deficiência e mobilidade reduzida e estipula providências a serem tomadas por órgãos públicos e privados [1]. Alguns dos seus artigos são relacionados com acessibilidade na $W e b$ :

Art. $2^{\underline{O}}$ Para os fins desta Lei são estabelecidas as seguintes definições:

II - barreiras: qualquer entrave ou obstáculo que limite ou impeça o acesso, a liberdade de movimento e a circulação com segurança das pessoas, classificadas em:

d) barreiras nas comunicações: qualquer entrave ou obstáculo que dificulte ou impossibilite a expressão ou o recebimento de mensagens por intermédio dos meios ou sistemas de comunicação, sejam ou não de massa;

Art. 17. O Poder Público promoverá a eliminação de barreiras na comunicação e estabelecerá mecanismos e alternativas técnicas que tornem acessíveis os sistemas de comunicação e sinalização às pessoas portadoras de deficiência sensorial e com dificuldade de comunicação, para garantir-lhes o direito de acesso à informação, à comunicação, ao trabalho, à educação, ao transporte, à cultura, ao esporte e ao lazer.

Art. 19. Os serviços de radiodifusão sonora e de sons e imagens adotarão plano de medidas técnicas com o objetivo de permitir o uso da linguagem de sinais ou outra subtitulação, para garantir o direito de acesso à informação às pessoas portadoras de deficiência auditiva, na forma e no prazo previstos em regulamento.

Art. 21. O Poder Público, por meio dos organismos de apoio à pesquisa e das agências de financiamento, fomentará programas destinados:

I - à promoção de pesquisas científicas voltadas ao tratamento e prevenção de deficiências;

II - ao desenvolvimento tecnológico orientado à produção de ajudas técnicas para as pessoas portadoras de deficiência;

III - à especialização de recursos humanos em acessibilidade.

- Decreto № 5.296, de 2 dezembro de 2004: regulamenta as leis 10.048, de 8 de novembro de 2000 e 10.098, de 19 de dezembro de 2000. Este decreto também define a que se refere o termo portador de deficiência no que diz respeito ao atendimento prioritário em serviços públicos e instituições financeiras [2]. A seguir encontram-se as transcrições de alguns trechos do decreto em questão: 
Art. $5^{\mathrm{O}}$ Os órgãos da administração pública direta, indireta e fundacional, as empresas prestadoras de serviços públicos e as instituições financeiras deverão dispensar atendimento prioritário às pessoas portadoras de deficiência ou com mobilidade reduzida.

$\S 1^{\mathrm{O}}$ Considera-se, para os efeitos deste Decreto:

I - pessoa portadora de deficiência, além daquelas previstas na Lei no 10.690, de 16 de junho de 2003, a que possui limitação ou incapacidade para o desempenho de atividade e se enquadra nas seguintes categorias:

a) deficiência física: alteração completa ou parcial de um ou mais segmentos do corpo humano, acarretando o comprometimento da função física, apresentando-se sob a forma de paraplegia, paraparesia, monoplegia, monoparesia, tetraplegia, tetraparesia, triplegia, triparesia, hemiplegia, hemiparesia, ostomia, amputação ou ausência de membro, paralisia cerebral, nanismo, membros com deformidade congênita ou adquirida, exceto as deformidades estéticas e as que não produzam dificuldades para o desempenho de funções;

b) deficiência auditiva: perda bilateral, parcial ou total, de quarenta e um decibéis $(\mathrm{dB})$ ou mais, aferida por audiograma nas frequências de $500 \mathrm{~Hz}, 1.000 \mathrm{~Hz}, 2.000 \mathrm{~Hz}$ e $3.000 \mathrm{~Hz}$;

c) deficiência visual: cegueira, na qual a acuidade visual é igual ou menor que 0,05 no melhor olho, com a melhor correção óptica; a baixa visão, que significa acuidade visual entre 0,3 e 0,05 no melhor olho, com a melhor correção óptica; os casos nos quais a somatória da medida do campo visual em ambos os olhos for igual ou menor que $60 \mathrm{o}$; ou a ocorrência simultânea de quaisquer das condições anteriores;

d) deficiência mental: funcionamento intelectual significativamente inferior à média, com manifestação antes dos dezoito anos e limitações associadas a duas ou mais áreas de habilidades adaptativas, tais como:

1. comunicação;

2. cuidado pessoal;

3. habilidades sociais;

4. utilização dos recursos da comunidade;

5. saúde e segurança;

6. habilidades acadêmicas;

7. lazer; e 
8. trabalho.

e) deficiência múltipla - associação de duas ou mais deficiências; e

II - pessoa com mobilidade reduzida, aquela que, não se enquadrando no conceito de pessoa portadora de deficiência, tenha, por qualquer motivo, dificuldade de movimentar-se, permanente ou temporariamente, gerando redução efetiva da mobilidade, flexibilidade, coordenação motora e percepção.

Art. $8^{\mathrm{O}}$ Para os fins de acessibilidade, considera-se:

I - acessibilidade: condição para utilização, com segurança e autonomia, total ou assistida, dos espaços, mobiliários e equipamentos urbanos, das edificações, dos serviços de transporte e dos dispositivos, sistemas e meios de comunicação e informação, por pessoa portadora de deficiência ou com mobilidade reduzida;

II - barreiras: qualquer entrave ou obstáculo que limite ou impeça o acesso, a liberdade de movimento, a circulação com segurança e a possibilidade de as pessoas se comunicarem ou terem acesso à informação, classificadas em:

d) barreiras nas comunicações e informações: qualquer entrave ou obstáculo que dificulte ou impossibilite a expressão ou o recebimento de mensagens por intermédio dos dispositivos, meios ou sistemas de comunicação, sejam ou não de massa, bem como aqueles que dificultem ou impossibilitem o acesso à informação;

V - ajuda técnica: os produtos, instrumentos, equipamentos ou tecnologia adaptados ou especialmente projetados para melhorar a funcionalidade da pessoa portadora de deficiência ou com mobilidade reduzida, favorecendo a autonomia pessoal, total ou assistida;

Art. 47. No prazo de até doze meses a contar da data de publicação deste Decreto, será obrigatória a acessibilidade nos portais e sítios eletrônicos da administração pública na rede mundial de computadores (internet), para o uso das pessoas portadoras de deficiência visual, garantindo-lhes o pleno acesso às informações disponíveis.

Art. 65. Caberá ao Poder Público viabilizar as seguintes diretrizes:

I - reconhecimento da área de ajudas técnicas como área de conhecimento;

II - promoção da inclusão de conteúdos temáticos referentes a ajudas técnicas na educação profissional, no ensino médio, na graduação e na pós-graduação;

III - apoio e divulgação de trabalhos técnicos e científicos referentes a ajudas técnicas; 
IV - estabelecimento de parcerias com escolas e centros de educação profissional, centros de ensino universitários e de pesquisa, no sentido de incrementar a formação de profissionais na área de ajudas técnicas;

- Portaria № 3, de 7 de Maio de 2007: estabelece a criação do "Modelo de Acessibilidade em Governo Eletrônico - e-MAG" e a constituição de sua coordenação, que é responsável pelo desenvolvimento de políticas e fiscalização de sua implantação, que é compulsória para órgãos da administração pública [4]. A seguir temos a transcrição de alguns trechos da portaria:

Art. $1^{\mathrm{O}}$ O planejamento, implantação, desenvolvimento ou atualização de portais e sítios eletrônicos, sistemas, equipamentos e programas em Tecnologia da Informação e Comunicação - TIC no âmbito da Administração Pública Federal direta, autárquica e fundacional reger-se-á por políticas, diretrizes e especificações que visem assegurar de forma progressiva a acessibilidade de serviços e sistemas de Governo Eletrônico.

$\S 1^{0}$ As políticas, diretrizes e especificações técnicas de acessibilidade serão sistematizadas na forma de um modelo denominado "Modelo de Acessibilidade em Governo Eletrônico - e-MAG", de adoção compulsória pelos órgãos e entidades integrantes do Sistemas de Administração dos Recursos de Informação e Informática - SISP, de que trata o Decreto $\mathrm{n}^{\mathrm{0}}$ 1.048, de 21 de janeiro de 1994, a partir da data da publicação desta Portaria.

Art. $4^{\mathrm{O}}$ Compete à Coordenação do e-MAG:

I - coordenar a elaboração e atualização das políticas, diretrizes e especificações técnicas que compõem o e-MAG, bem como as alterações e os acréscimos em razão de sua revisão e atualização;

V - promover a fiscalização e adotar as medidas executivas necessárias ao cumprimento do disposto no Documento de Referência do e-MAG, comunicando e acionando, para providências, os órgãos de controle interno, quando necessário.

Art. $5^{\mathrm{o}}$ À Secretaria de Logística e Tecnologia da Informação do Ministério do Planejamento, Orçamento e Gestão, como órgão central do SISP, incumbe a coordenação executiva das atividades de implantação, manutenção e disseminação do e-MAG, competindo-lhe:

III - supervisionar técnica e normativamente os órgãos e entidades integrantes do SISP na aplicação das políticas, diretrizes e especificações técnicas do e-MAG; 
IV - elaborar e divulgar orientações técnicas, inclusive na forma de manuais e materiais instrucionais;

V - manter e operar em colaboração com a Coordenação do e-MAG, sítio eletrônico na internet para publicações relacionadas ao e-MAG e outros serviços conexos ao tema;

Art. $6^{\mathrm{O}}$ A proposta do e-MAG denominada Documento de Referência, a ser elaborada pela sua Coordenação, será atualizada periodicamente, submetida a processo de consulta pública e publicada no Diário Oficial da União e no sítio eletrônico de que trata o inciso V do art. $5^{\mathrm{o}}$ desta Portaria.

- Convenção sobre os Direitos das Pessoas com Deficiência (2007): convenção elaborada pelas Nações Unidas que foi ratificado pelo Congresso Nacional em 09/07/2008. Esta convenção tem o objetivo de promover e assegurar que os direitos humanos e liberdades fundamentais possam ser aplicados igualmente e sem qualquer tipo de discriminação a pessoas com deficiência. Esta convenção abriu para assinaturas em 30 de março de 2007 e teve 82 países signatários para a Convenção e 44 países signatários para seu Protocolo Opcional o que representou o maior número de assinaturas obtidas por uma convenção no seu primeiro dia de abertura [60].

- Decreto Legislativo № 186, de 9 de julho de 2008 aprova o texto da Convenção sobre os Direitos das Pessoas com Deficiência e também do Protocolo Facultativo [5].

- Decreto № 6.949, de 25 de agosto de 2009: publica oficialmente a Convenção sobre os Direitos das Pessoas com Deficiência fazendo com que seu conteúdo passe a valer a partir desta data [3].

Em outros lugares do mundo, também existem diversas abordagens para essa questão. Em alguns casos são criadas leis que obrigam que qualquer serviço provido pelo governo seja acessível, como é o caso do Brasil. Em outros casos, o direito de acesso a tecnologias de informação e comunicação é estabelecido como direito humano ou civil, ou ainda, obrigando que empresas desenvolvam seus produtos com acessibilidade.

Nos Estados Unidos da América, por exemplo, existe a Section $508^{12}$ que é uma emenda à lei Rehabilitation Act de 1973 que tinha como objetivo obrigar que agências federais e órgãos públicos tornassem seus sistemas de informação acessíveis a pessoas com deficiências. Esta lei norte-americana foi promulgada em 1998 e tem o mesmo propósito da e-MAG que entrou em vigor no Brasil em 2007.

\footnotetext{
${ }^{12} \mathrm{http}: / /$ www.section508.gov/
} 


\subsection{Trabalhos sobre modelagem na Web e alternativas para deficientes visuais}

Nesta seção, são apresentados os trabalhos encontrados na literatura que propiciaram insights (inspirações) para a estratégia proposta na ferramenta AWMo. De fato, não foram encontrados até o momento trabalhos relacionados com a técnica proposta neste mestrado. Assim, a seguir, são descritas as características principais dos trabalhos estudados, confrontando-os com a AWMo desenvolvida.

Foram encontrados na literatura trabalhos que se dedicam a levar para a $W e b$ ferramentas para desenvolvimento orientado a modelos para a Web tais como o GEMSjax [16], que é uma implementação Web da ferramenta GEMS (Generic Eclipse Modeling System). O GEMS é um projeto que surgiu para unir as experiências sobre ferramentas de metamodelagem visual da comunidade GME, na universidade de Valderbilt e as comunidades Eclipse tais como EMF e GMF. A GEMSjax utiliza o Google Web Toolkit para criar uma interface $W e b$ capaz de ser utilizada para modelagem e metamodelagem.

O ambiente SLIM é outro exemplo desse tipo de ferramenta. Ele é um ambiente para modelagem colaborativa síncrona e seus diagramas são desenvolvidos com SVG (Scalable Vector Graphics) e técnicas da Web 2.0, como Comet para comunicação com pouca latência com o servidor. O principal objetivo do SLIM é possibilitar a colaboração entre pessoas distantes geograficamente [59]. A Figura 3.3 ilustra a interface do SLIM; nela podemos notar os elementos UML à esquerda, uma região para edição de propriedades dos elementos à direita e a região para o desenho do modelo no centro da tela.

Foram encontradas também soluções que não são Web como o Eclipse Modeling Framework [70], a ferramenta COMA (COllaborative Modeling Architecure tool) com foco em colaboratividade [51] e aplicações comerciais como a MagicDraw Teamwork Server ${ }^{13}$.

No entanto, as ferramentas citadas não são acessíveis. Muitas vezes o deficiente visual conseguirá navegar pela interface da aplicação, seja Web ou Desktop, porém o conteúdo de que trata essas ferramentas continua inacessível, por ser intrinsecamente ligado ao sentido da visão, o que impede esses usuários de trabalhar de maneira independente.

Nesse sentido, a AWMo buscou tornar não só a sua interface acessível, que é uma prática comum e com critérios e recomendações bem difundidas, como visto no Capítulo 3, mas principalmente fornecer uma forma alternativa de acesso ao conteúdo antes exclusivamente visual.

Por outro lado, existem trabalhos que abordam a exploração não visual de informações representadas graficamente como é o caso de Metatla et al. (2007) [39] na qual é utilizada uma representação hierárquica para diagramas relacionais de maneira que eles podem ser

\footnotetext{
${ }^{13}$ https://www.magicdraw.com/teamwork_server
} 


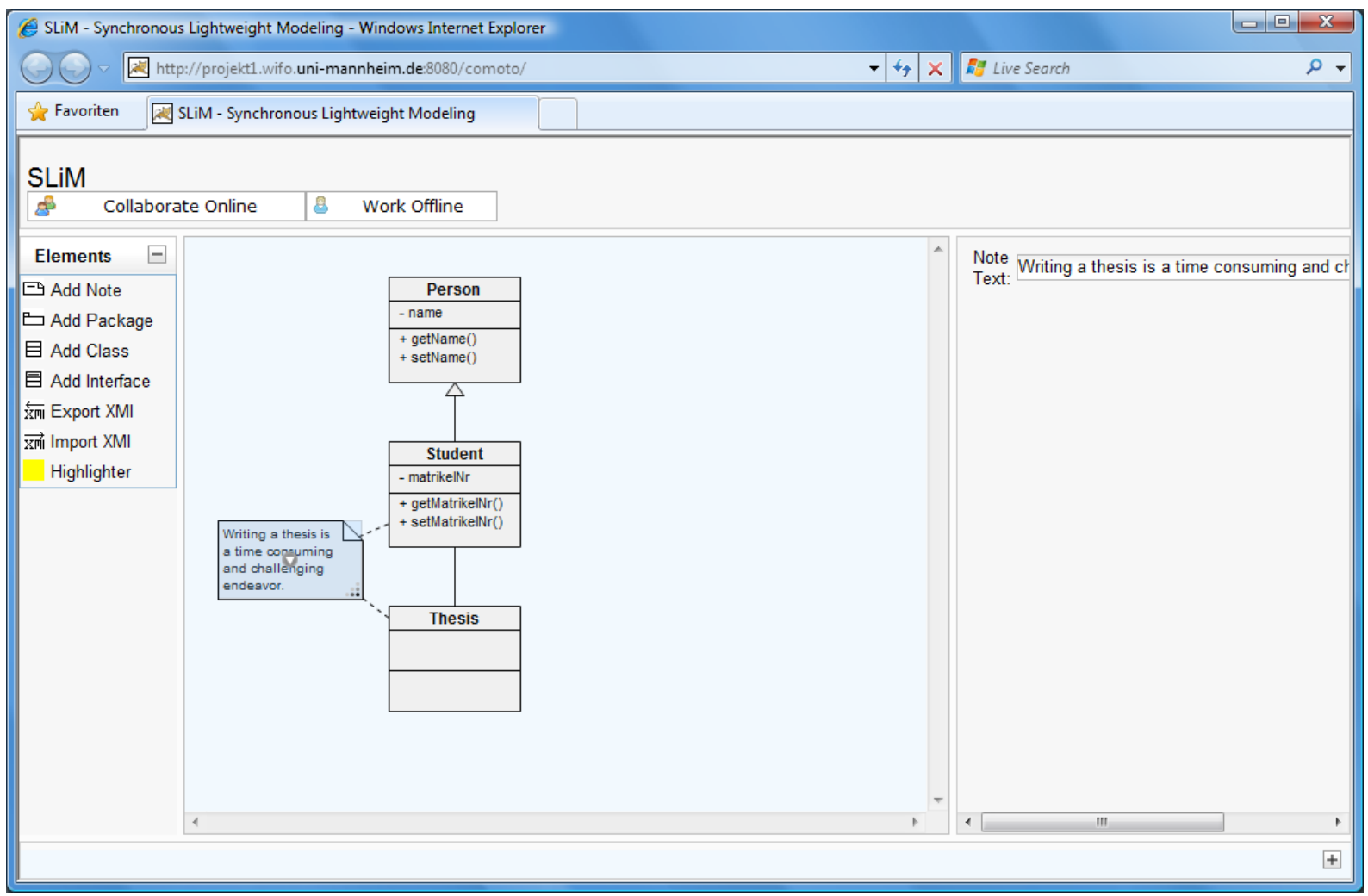

Figura 3.3: Captura de tela de um modelo UML sendo desenvolvido no ambiente SLIM em um navegador $W e b[56]$.

explorados por meio de interfaces de áudio. Ainda o mesmo autor também desenvolveu um trabalho em que são comparadas estratégias para construção de diagramas em interfaces que utilizam apenas áudio [40] e também o sistema chamado PLUMB [11] que foi desenvolvido com o intuito de ensinar grafos para deficientes visuais. O PLUMB define uma interface de áudio e sua entrada é feita por meio de um dispositivo de caneta em um computador do tipo tablet. Durante seu uso, o usuário recebe indicações sonoras distintas quando seu ponteiro está sobre um nó e quando seu ponteiro está sobre uma aresta do grafo.

Além disso, são encontrados trabalhos que abordaram o uso e ensino de UML para deficientes visuais. King et al. (2004) desenvolveram uma forma de visualização e navegação de diagramas UML. Este projeto buscou abordar quatro dos doze diagramas da UML e explorou paradigmas não textuais, utilizando um joystick para navegação e leitores de tela para que o usuário escutasse as informações contidas no diagrama. No entanto, este projeto permite apenas a visualização de diagramas da UML e não sua alteração ou a criação de novos diagramas. Sem a possibilidade de editar ou criar novos diagramas o acesso de deficientes visuais é apenas parcial, eles são capazes de acessar os diagramas e entender as informações que ele busca transmitir mas são incapazes de participar de sua construção ou colaborar em atividades de modelagem. Este fator foi levado em con- 
sideração no planejamento da AWMo e por esse motivo, decidiu-se focar em apenas um diagrama da UML, o diagrama de classe, mas possibilitar sua manipulação (as operações CRUD - criação, recuperação - read, atualização - update, e remoção - delete), ao invés de apenas leitura.

\subsection{Considerações finais}

Além de ser imposto pelo governo, em muitos casos, fazer com que determinada página ou aplicação Web seja acessível, essa imposição governamental é de tamanha importância, que aumenta a esfera de seu alcance especialmente nos cenários do mundo dos negócios. De acordo com a W3C, alguns estudos de caso relatam que com a acessibilidade, um produto ou página $W e b$ atinge uma gama maior de usuários e que páginas acessíveis apresentam resultados melhores em mecanismos de busca e custo de manutenção, por exemplo [69]

Também foram encontrados na literatura trabalhos que tratam de acessibilidade em um contexto mais amplo de RIA (Rich Internet Applications. As RIAs ou Aplicações de Internet Ricas são aplicações Web que se assemelham à aplicações Desktop [6].

O trabalho de Jeschke et al. (2009) demonstra o uso de práticas de desenvolvimento centradas no usuário e baseadas em modelo com o objetivo simplificar o processo de desenvolvimento de aplicações $W e b$ acessíveis [30].

Velasco et al. (2008) desenvolveram um framework com o objetivo de suprir deficiências de sistemas de avaliação de acessibilidade tradicionais e ao mesmo tempo suportar conceitos mais amplos de Web Compliance aplicados a RIA. A ferramenta foi utilizada em produção em portais $W e b$ de larga escala [61].

Embora estes trabalhos não tenham foco especificamente em ferramentas de modelagem, eles tratam de diversos desafios relacionados ao desenvolvimento de aplicações de Internet ricas que auxiliaram no planejamento e desenvolvimento do protótipo apresentado neste trabalho.

No Capítulo 4, a seguir, será detalhada a ferramenta desenvolvida, considerando-se os critérios de acessibilidade descritos nesse capítulo. 


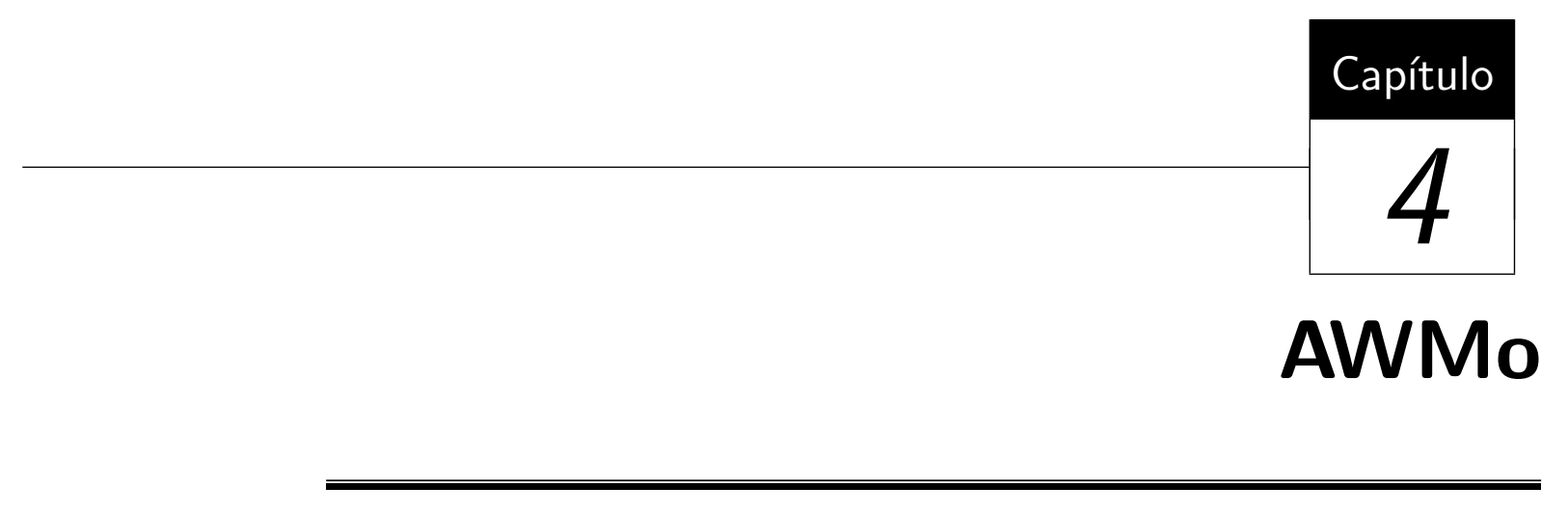

Neste capítulo é apresentado o protótipo da ferramenta desenvolvido, que foi batizado de AWMo, sigla para Accessible Web Modeler. Serão descritos detalhes de sua arquitetura, da linguagem textual e de sua operação.

\subsection{Considerações Iniciais}

A obtenção de requisitos para o desenvolvimento do protótipo foi realizada com especialistas nos domínios de MDD e acessibilidade Web. Além disso, as experiências passadas do grupo de pesquisa foram imprescindíveis para definições arquiteturais e de tecnologia.

O processo de desenvolvimento utilizado foi bastante similar ao método de desenvolvimento ágil Scrum [53], no entanto, houve apenas uma fase. Para gestão do desenvolvimento foi utilizada a ferramenta Redmine ${ }^{1}$ que pode ser vista na Figura 4.1.

Os tickets são utilizados para dividir o desenvolvimento em unidades menores de trabalho e foram úteis tanto para manter o foco durante o desenvolvimento de cada funcionalidade como também ajudaram a acompanhar o progresso do projeto.

A Figura 4.2 ilustra os cenários de uso para a ferramenta proposta. Os usuários deficientes visuais que não conseguirem interagir com a visão gráfica poderão utilizar a visão textual e com interação por meio do teclado e leitores de tela, sendo capazes de realizar as mesmas tarefas que podem ser realizadas por meio da visão gráfica.

Mais detalhes sobre a arquitetura da AWMo podem ser encontrados na Seção 4.2, a seguir.

\footnotetext{
${ }^{1}$ http://redmine.org
} 


\begin{tabular}{|c|c|c|c|c|c|}
\hline$\checkmark \#$ & Status $\triangle$ & Priority & Subject & $\%$ Done & Assignee \\
\hline \multicolumn{6}{|c|}{ Gechada $(8)$} \\
\hline $\mathbf{2 1 8}$ & Fechada & Normal & Atualizar gramática textual & & Filipe Grillo \\
\hline 219 & Fechada & Normal & Criar estrutura do banco de dados & & Filipe Grillo \\
\hline$\bigcirc \mathbf{2 2 0}$ & Fechada & Normal & Criar a visão do editor textual & & Filipe Grillo \\
\hline $\mathbf{2 2 1}$ & Fechada & Normal & Criar visão do editor visual & & Filipe Grillo \\
\hline$\bigcirc \mathbf{2 2 3}$ & Fechada & Normal & Criar página de Ajuda & & Filipe Grillo \\
\hline $\mathbf{2 2 4}$ & Fechada & Normal & Validar acessibilidade & & Filipe Grillo \\
\hline 226 & Fechada & Normal & Modificar Layout & & Filipe Grillo \\
\hline$\bigcirc 265$ & Fechada & Normal & Criar tradutores de formatos & & Filipe Grillo \\
\hline
\end{tabular}

Figura 4.1: Tickets criados para o desenvolvimento do protótipo da AWMo.

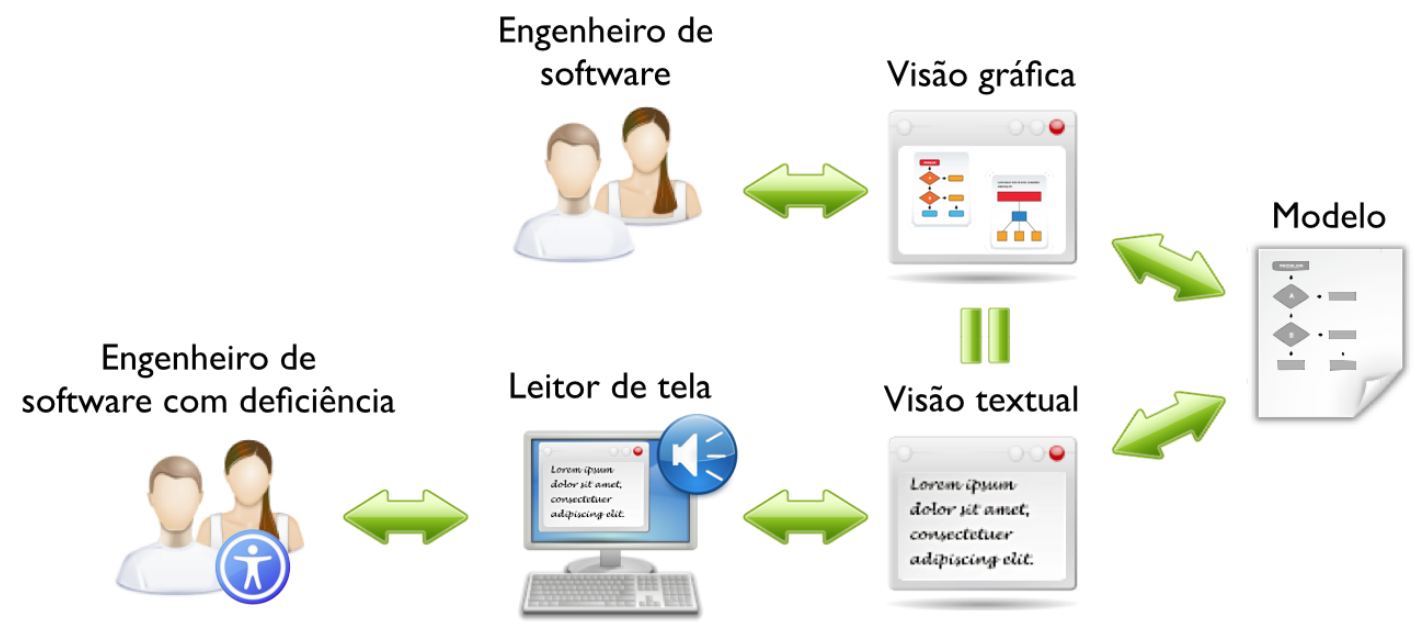

Figura 4.2: Cenários de uso previstos para a ferramenta, considerando-se a colaboração entre usuários desenvolvedores de software, sejam eles com ou sem deficiências visuais.

\subsection{Arquitetura}

A AWMo foi desenvolvida utilizando a linguagem Java e o framework de aplicação JSF (JavaServer Faces) [9] com uma arquitetura MVC (Model-view-controller) [18]. A Figura 4.3 ilustra a organização dos componentes entre as camadas de visualização, controle e os modelos.

Na camada de modelos, além dos Beans que são utilizados para fazer a comunicação com o servidor por meio de mapeamento utilizando a biblioteca Hibernate, existe uma biblioteca contendo toda a infraestrutura da gramática textual da AWMo gerada pelo Xtext.

O Xtext provê um conjunto de ferramentas que permitem a definição de gramáticas com a notação EBNF (Extended Backus-Naur Form) e a geração de recursos para editores textuais, tais como parser da linguagem, validadores e geradores de código. O Xtext 
pode também gerar um metamodelo Ecore e classes EMF (Eclipse Modeling Framework) a partir da gramática da linguagem. Isto torna possível a manipulação programática dos modelos e metamodelos [15].

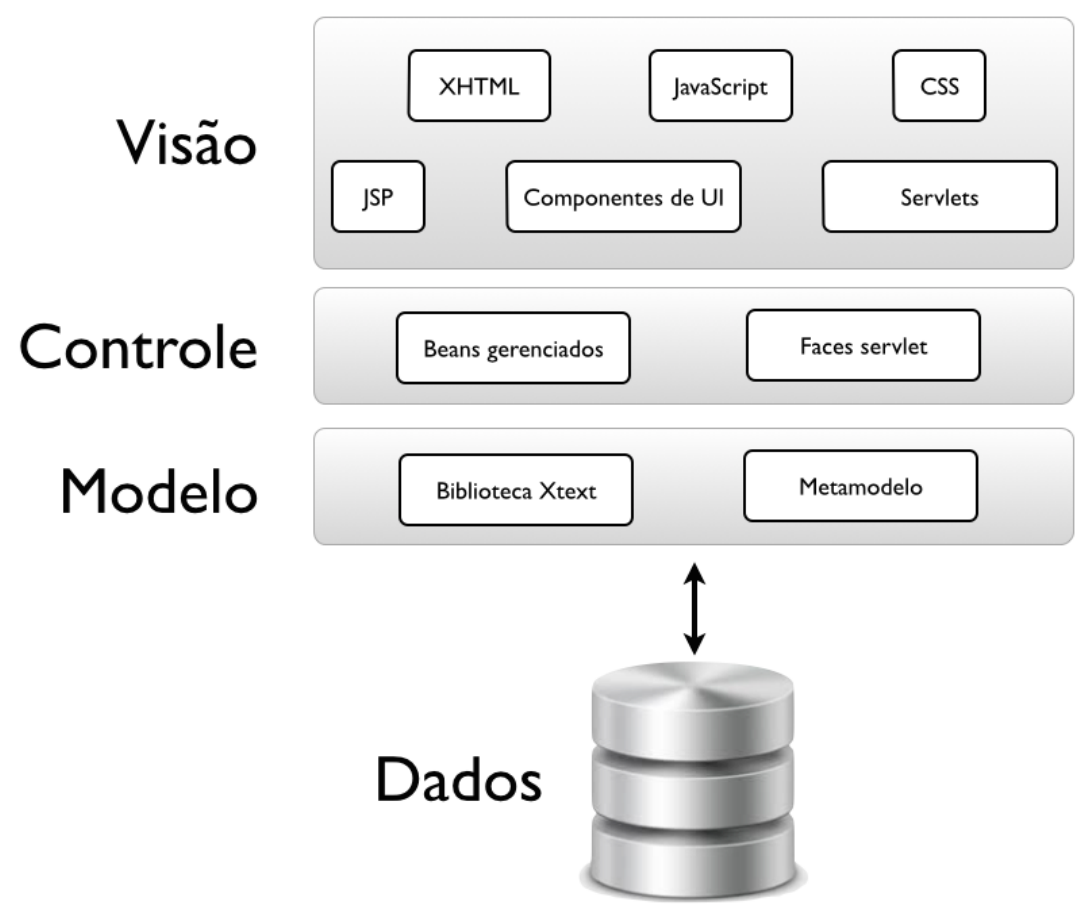

Figura 4.3: Visão de alto nível da arquitetura utilizada na AWMo com o conceito de MVC (Model-View-Controller) e as tecnologias empregadas em cada uma das camadas.

A Figura 4.4 ilustra o funcionamento da AWMo em todas as suas etapas de uso. No caso de um usuário abrindo um modelo com a visão gráfica, as informações são buscadas no banco de dados e são criados objetos Java pelo Hibernate e seus mapeamentos. Posteriormente os objetos Java são convertidos para JSON com o uso da biblioteca GSON e por sua vez, o JSON é consumido por um código JavaScript na página que monta o diagrama utilizando a biblioteca jsUML2².

Ao salvar um modelo a partir da visão gráfica, um código JavaScript percorre o modelo como ele está representado pela jsUML2 gerando uma representação em JSON que é enviada para o servidor. Com o uso da biblioteca GSON a representação em JSON é convertida em objetos Java e por fim, os objetos Java são convertidos em dados relacionais para serem armazenados no banco de dados MySQL.

No caso de um usuário abrindo um diagrama com a visão textual as informações são buscadas no banco de dados e são criados objetos Java pelo Hibernate ${ }^{3}$ e seus mapeamentos. Posteriormente os objetos Java são convertidos para a notação textual definida pela

\footnotetext{
${ }^{2}$ http://www.uco.es/ in1rosaj/tool_jsUML2.html

${ }^{3}$ http://hibernate.org/
} 
gramática desenvolvida com o Xtext e então esta notação textual é exibida para o usuário em um editor de texto na página. No sentido oposto, ao salvar um diagrama utilizando a visão textual, a representação textual existente na tela é enviada para o servidor, o parser gerado pelo Xtext valida se a sintaxe e semântica estão corretas e disponibiliza o acesso por meio de classes EMF. Essas classes EMF são percorridas gerando objetos Java para serem armazenados no banco de dados pelo Hibernate.

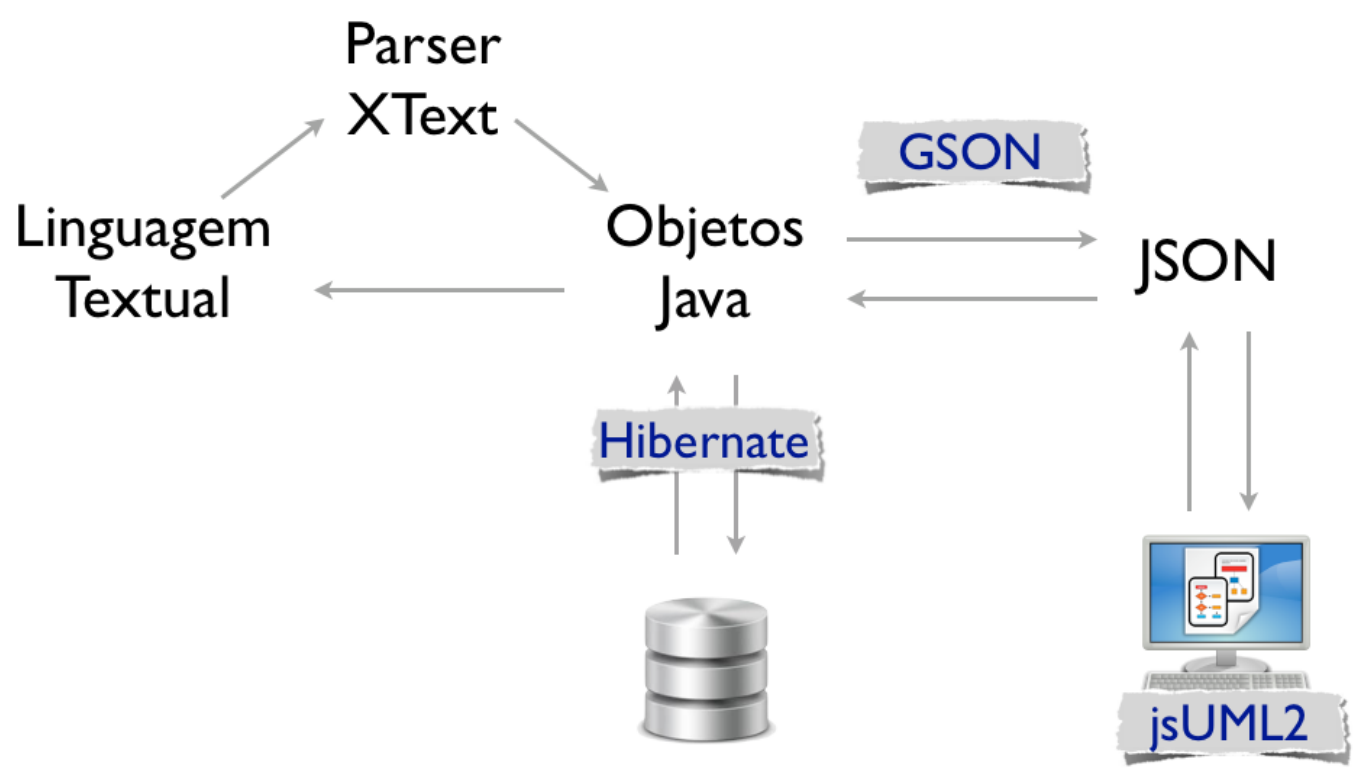

Figura 4.4: Modelo de funcionamento da AWMo, mostrando os passos, ferramentas e bibliotecas utilizadas para transformação dos modelos para ambas as visões disponíveis.

A estrutura de dados da AWMo combina a informação textual que é utilizada por ambas as visões da ferramenta tais como nome das classes, nome de atributos, métodos e seus tipos com as informações espaciais que são utilizadas apenas pela visão textual da ferramenta que são as coordenadas X e Y de cada classe no espaço do diagrama.

\subsection{Linguagem textual}

A linguagem textual representa uma peça central na abordagem proposta pela AWMo pois é por meio dessa linguagem que os engenheiros de software com deficiência visual são capazes de interagir com os modelos.

Em sua versão atual, a AWMo possibilita apenas a edição de diagramas de classe da UML e portanto a única linguagem textual desenvolvida até o momento serve especificamente para esse fim. 
Na Listagem 4.1 temos a definição completa da gramática que define a linguagem da AWMo. Esta gramática livre de contexto está representada em notação EBNF (Extended Backus-Naur Form).

Nas linhas 1 e 3 temos instruções para o Xtext, sendo que a definição da gramática em si é iniciada na linha 5. A partir desta definição o Xtext é capaz de gerar toda a infraestrutura da linguagem textual, as quais precisam ser extraídas em uma biblioteca isolada para que possa ser incluída na ferramenta Web da AWMo.

A gramática define um elemento que é o diagrama de classes: 'ClassDiagram' na linha 5. O 'ClassDiagram' é composto por dois conjuntos de elementos: classes e relações, que são declaradas nas linhas 9 e 12 respectivamente. Sendo que antes de cada um desses conjuntos existem as palavras-chave 'Classes' e 'Relações'.

A definição dos elementos do tipo classe, chamados 'ClassElement' pode ser vista das linhas 15 a 23. Nota-se que as classes devem possuir a palavra-chave 'classe' seguida de um nome que a identifica e ela pode ou não possuir uma classe-pai que se especifica com o uso da palavra-chave opcional 'herda'. Uma classe é composta por um conjunto de atributos (linha 18) e um conjunto de métodos (linha 20).

Os atributos tem sua definição nas linhas 25 a 27. Eles são compostos pela palavra-chave 'atributo', uma definição de visibilidade que remete a uma enumeração de possíveis valores (public, private, protected), um nome que o identifica, o caractere ':' como separador entre o nome e a definição do tipo de dados que remete à regra 'ComplexType'.

Os métodos, por sua vez, tem sua definição entre as linhas 29 e 31 e são compostos pela palavra-chave 'metodo', uma definição de visibilidade, da mesma forma que os atributos, um nome que o identifica, um conjunto de parâmetros entre parêntesis que é opcional, e o separador ':' seguido da definição do tipo de dado que remete à regra 'ComplexType'.

Os parâmetros são definidos entre as linhas 33 e 35. Eles devem possuir um nome que o identifica, o separador de tipo ':' e a declaração do tipo, que da mesma forma que nos atributos e métodos é do tipo 'ComplexType'. Além disso, um parâmetro pode ser seguido de outro parâmetro se separados por vírgula ','.

A definição de 'ComplexType' (linhas 41 a 43) pode ser composta de um tipo simples que remete a uma enumeração de possíveis valores (string, int, float e boolean) ou por um 'ClassElement', ou seja, uma classe definida no conteúdo do próprio diagrama que se está declarando.

Por fim, as definição das relações (linhas 37 a 39) é composta pela palavra-chave 'relacao' seguida pelo tipo da relação que remete a uma enumeração, definida entre as linhas 47 e 51, cujos possíveis valores são 'associacao', 'agregacao' e 'composicao'. Em seguida a especificação de uma classe existente no diagrama um indicador de cardinalidade que pode assumir os valores '*', 'n' ou '1' (linha 45), uma segunda classe existente no 
diagrama e um segundo indicador de cardinalidade. Essa regra pode utilizada para definir um relacionamento entre duas classes dentro de um diagrama de classes da UML.

Listagem 4.1: Gramática em notação EBNF que define a linguagem da AWMo.

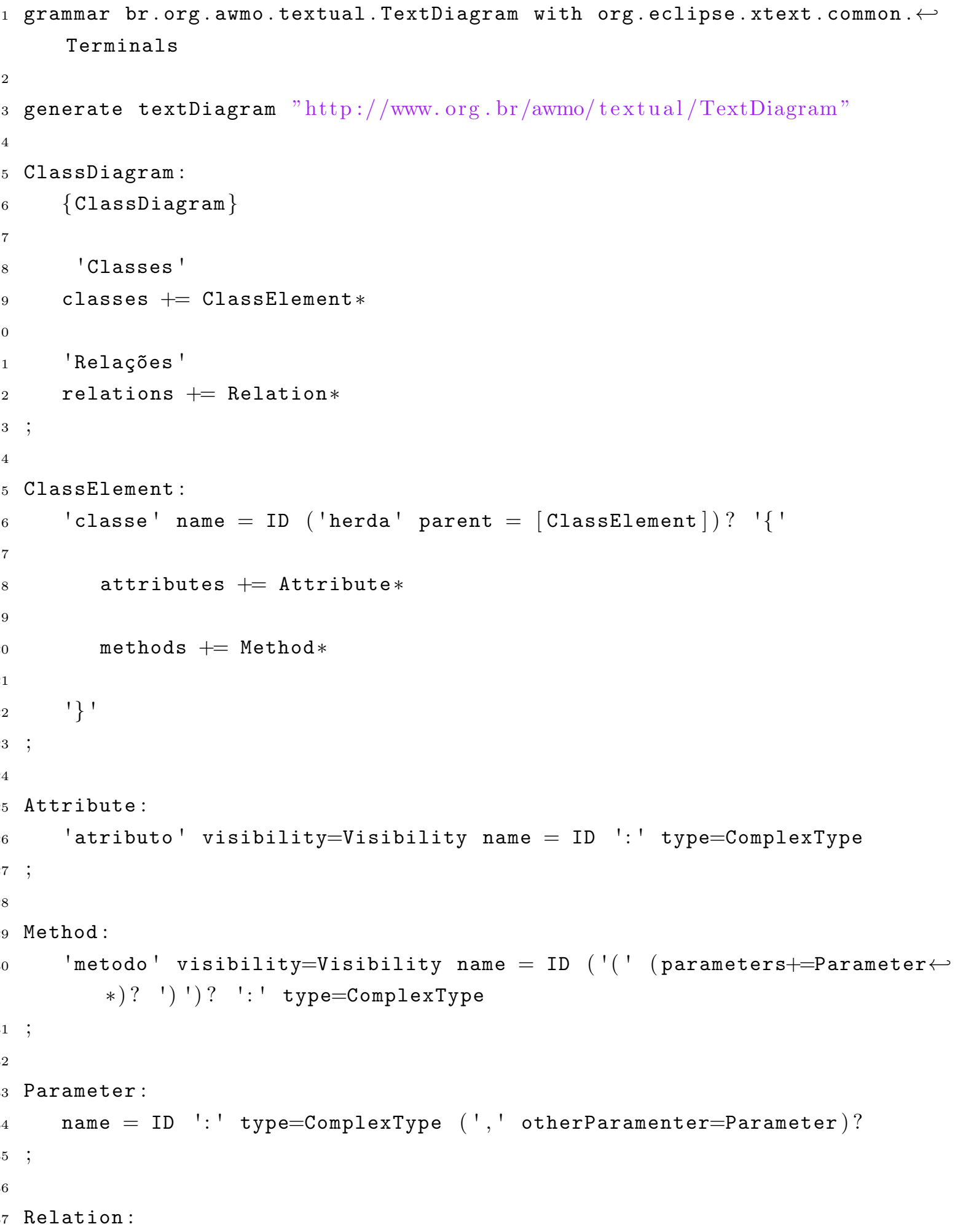




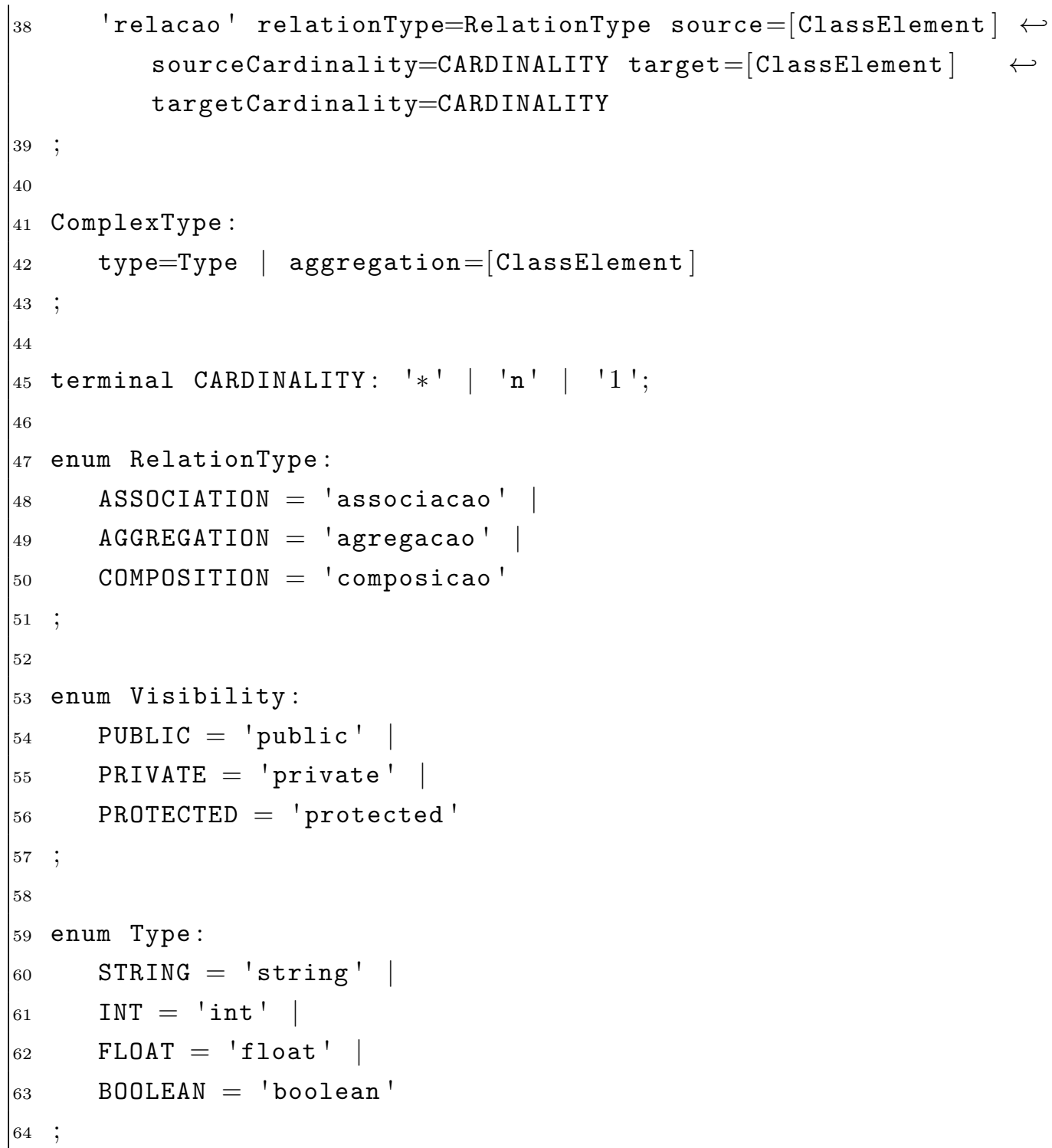

Para o desenvolvimento da linguagem foi utilizado o Eclipse Modeling Tools ${ }^{4}$, uma versão da IDE Eclipse que já é distribuída com os pacotes e ferramentas de modelagem da Fundação Eclipse.

\subsection{Uso da ferramenta}

A principal funcionalidade da AWMo é permitir que tanto deficientes visuais quanto pessoas com visão possam construir modelos de software de maneira colaborativa e incremental, ou seja, é possível que um modelo seja criado inicialmente por um usuário da visão textual e posteriormente seja editado pela visão gráfica e vice-versa.

\footnotetext{
${ }^{4}$ http://www.eclipse.org/modeling
} 
O conceito chave de prover duas visões diferentes para a edição do mesmo modelo é que ambas as visões permitem que os usuários realizem as mesmas tarefas e alcancem os mesmos resultados. Dessa forma, se um usuário deficiente visual criar um novo diagrama de classes na AWMo, editá-lo e salvá-lo, um usuário com visão poderá abrir o mesmo diagrama na visão gráfica e continuar o trabalho ou realizar alterações nele que, por sua vez, serão novamente acessíveis na visão textual e vice-versa [25].

Isso é possível pois a AWMo utiliza uma estrutura de dados única para os modelos que permite que eles sejam editados em ambas as visões existentes na ferramenta e posteriormente são convertidos para esse modelo único para ser salvo no banco de dados.

A Figura 4.5 ilustra a tela do editor textual da AWMo. Nota-se no menu que é possível alternar entre o modo visual e o modo gráfico de edição (por meio das opções de Menu à esquerda "Textual view" e "Graphical view") para o mesmo diagrama que encontra-se aberto (na área central da tela).

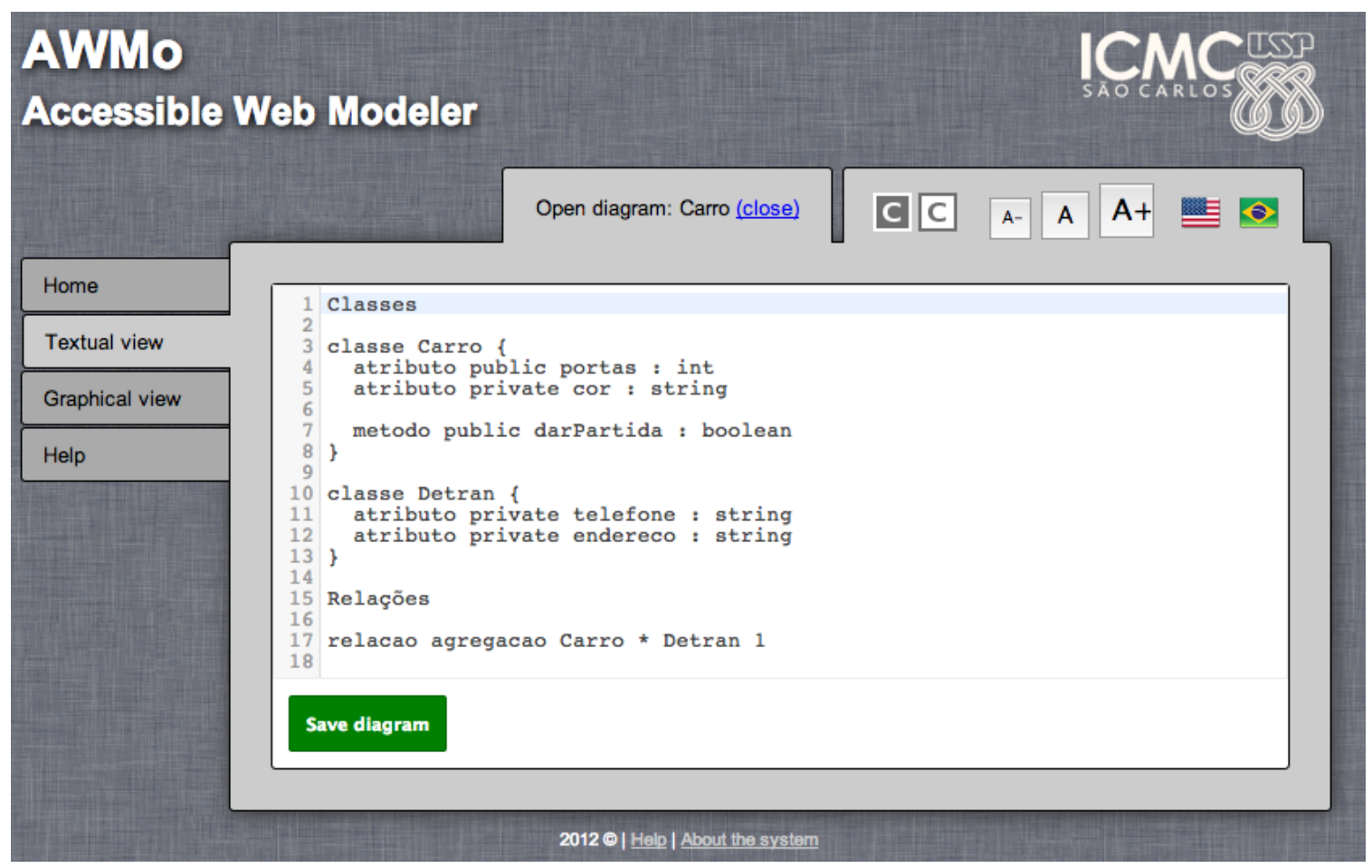

Figura 4.5: Captura de tela da AWMo com um modelo chamado Carro, aberto para edição na visão textual.

A Listagem 4.2 mostra um diagrama de classes simples que ilustra a relação de composição entre duas classes: Carro e Motor.

Listagem 4.2: Exemplo de um diagrama criado com a linguagem textual da AWMo.

1 Classes

2 


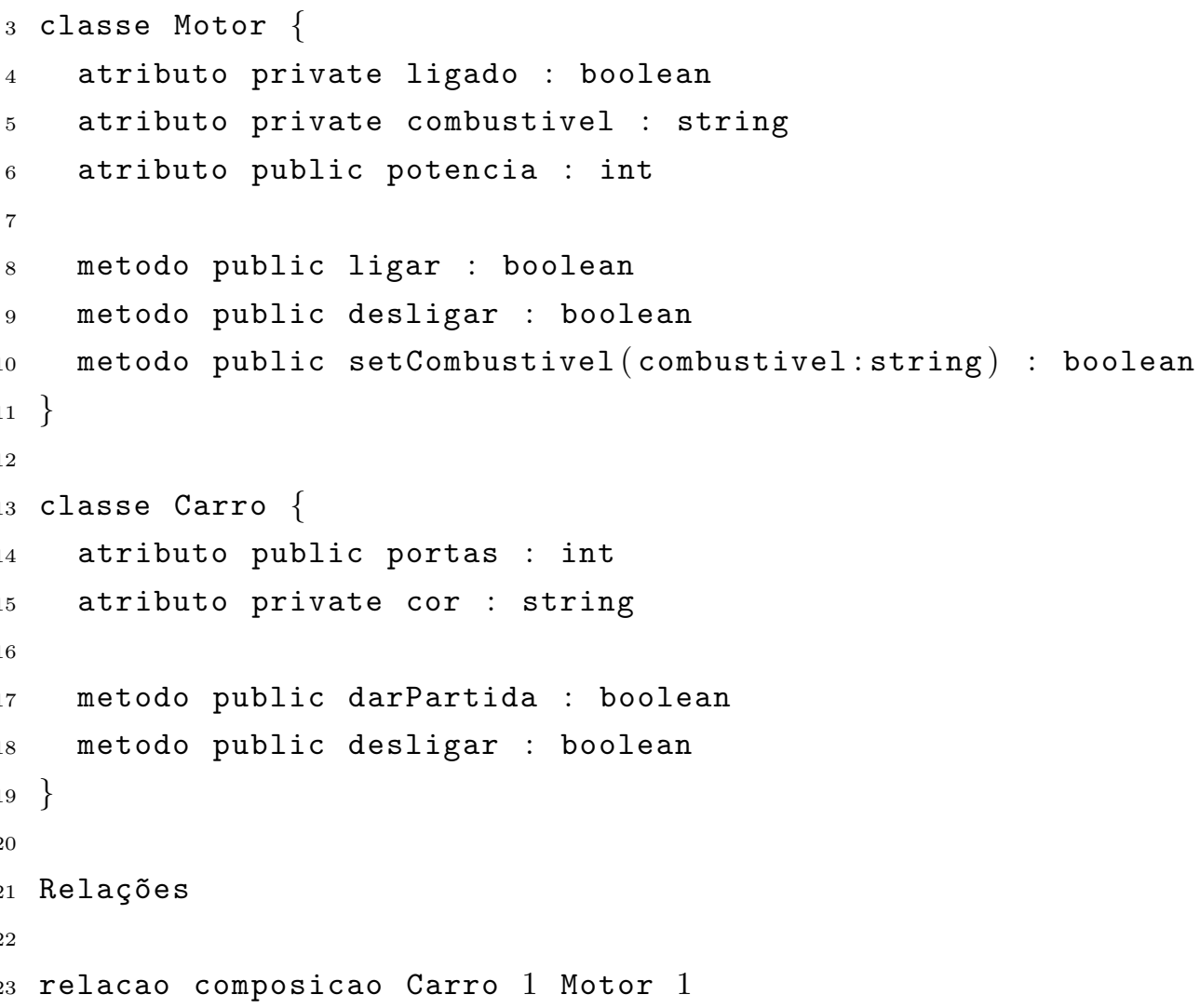

Por meio do uso da visão gráfica o mesmo diagrama seria exibido conforme mostrado na Figura 4.6.

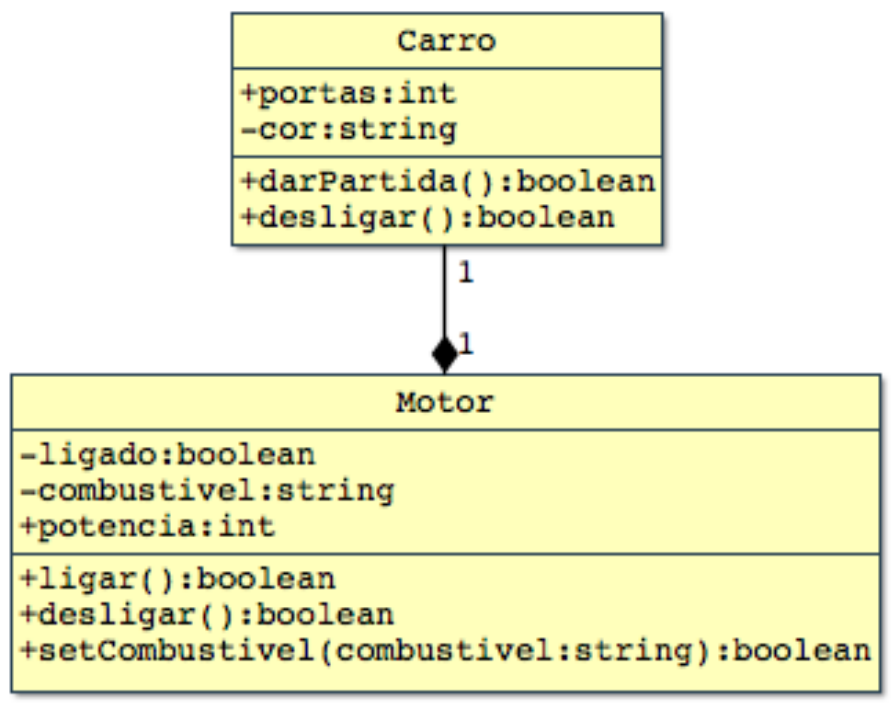

Figura 4.6: Exemplo do diagrama da listagem 4.2 como exibido pela visão gráfica da AWMo. 


\subsubsection{Navegação}

A Navegação dentro da AWMo é realizada com o auxílio de dois componentes principais: o menu à esquerda e a barra de contexto no topo da aplicação.

Quando não existe nenhum diagrama aberto para edição, a AWMo apresenta apenas o menu lateral esquerdo com as opções: Início e Ajuda. A primeira opção leva para a página principal da ferramenta, na qual podem ser encontrados os diagramas existentes e novos diagramas podem ser criados. A segunda opção do menu leva para uma página de ajuda.

A Figura 4.7 mostra a aparência da AWMo quando não existe um diagrama aberto para edição. Nela podemos ver o menu lateral esquerdo em seu estado inicial.

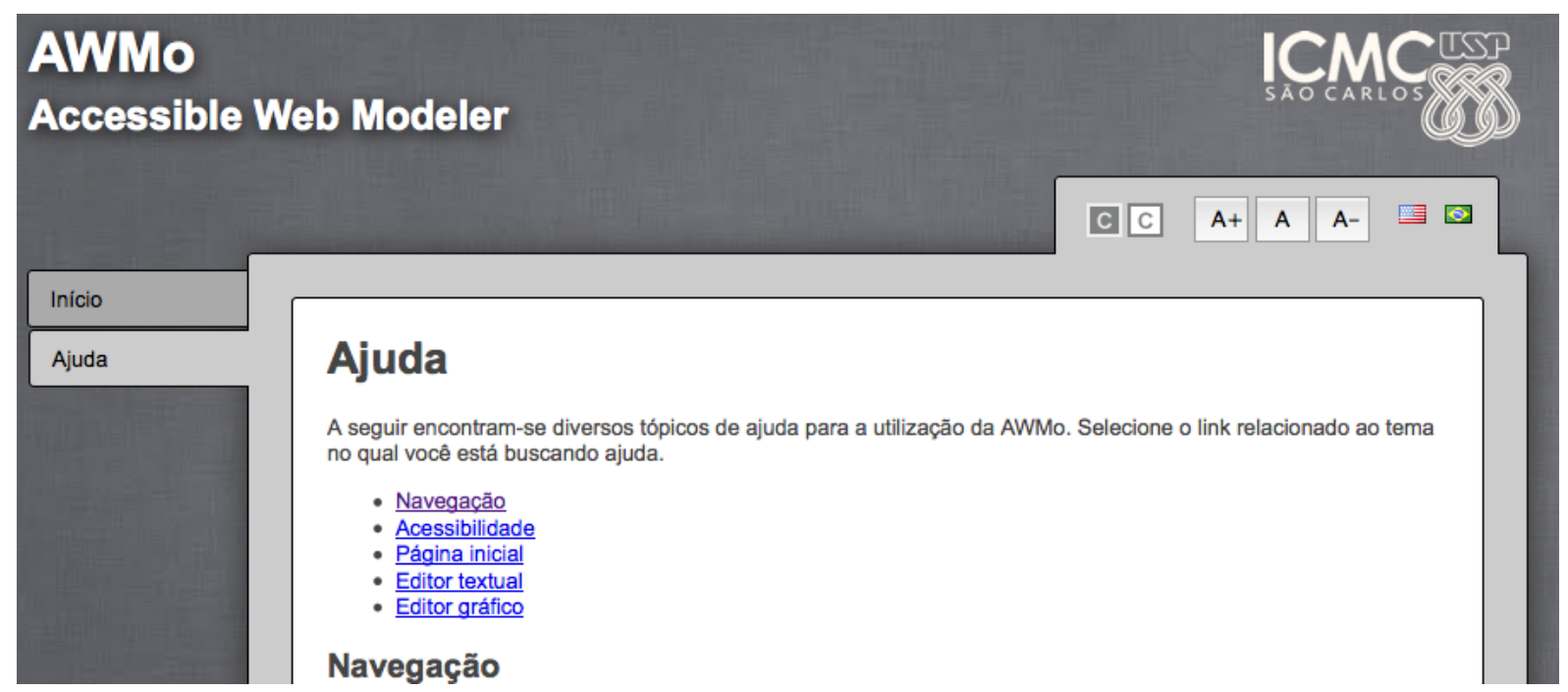

Figura 4.7: Captura de tela mostrando a aparência da AWMo quando não existe um diagrama sendo editado.

Quando um diagrama é aberto para edição, esta informação é mostrada em uma barra de contexto no topo da aplicação, ao lado da barra de ferramentas de acessibilidade. Na barra de contexto é informado o nome do diagrama que se encontra aberto e existe um link que possibilita ao usuário fechar o diagrama atual.

Além disso, duas novas opção são exibidas no menu lateral esquerdo: "Visão Textual" que abre a interface do editor textual para o diagrama que se encontra atualmente aberto e "Visão Gráfica" que abre a interface do editor gráfico para o diagrama que se encontra aberto. A Figura 4.8 mostra a aparência da AWMo com a barra de contexto no topo e as novas opções no menu lateral esquerdo.

Nota: A visão gráfica da AWMo se encontra em uma versão preliminar e portanto ainda não pode ser utilizada completamente. Todo o conteúdo dos diagramas desenvolvidos com 


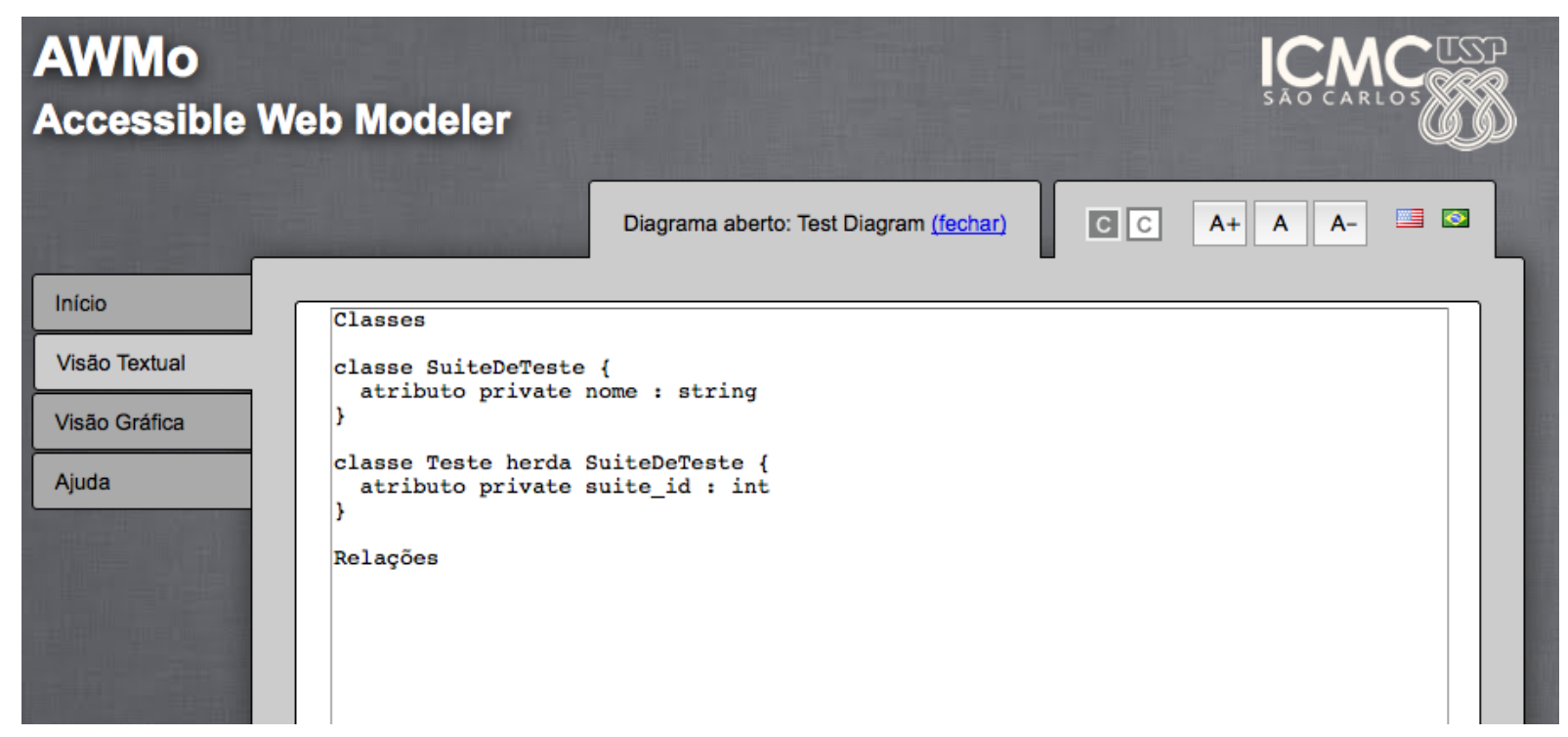

Figura 4.8: Captura de tela mostrando a aparência da AWMo com um diagrama aberto para edição.

visão textual é exibido na visão gráfica, porém a formatação e as ferramentas de edição e criação ainda precisam ser desenvolvidas.

\subsubsection{Acessibilidade}

Durante o desenvolvimento da AWMo, uma arquitetura de referência foi utilizada para assegurar que o projeto fosse iniciado com uma base sólida e seguindo critérios de acessibilidade citados no Capítulo 3 [17]. Dentre os benefícios referentes à acessibilidade obtidos ao se utilizar a arquitetura de referência, podemos citar:

- Descrições textuais para imagens e conteúdos sonoros;

- Garantia de entendimento do conteúdo quando utilizado sem cores como no caso do alto contraste, por exemplo;

- Visibilidade do estado atual do sistema; e

- Página de ajuda, com informações para auxiliar os usuários na utilização da ferramenta.

Além disso, essa arquitetura de referência também fornece à AWMo algumas ferramentas de acessibilidade embutidas. A barra de ferramentas de acessibilidade mostrada na Figura 4.9 pode ser encontrada na parte superior direita da interface da AWMo.

As funcionalidades existentes são, da esquerda para a direta: Ativar alto contraste, Desativar alto contraste, Diminuir tamanho de fonte, Fonte em tamanho normal, Aumentar tamanho de fonte, Alterar idioma para Inglês e Alterar idioma para Português. 


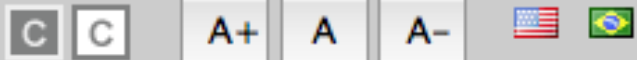

Figura 4.9: Captura de tela parcial mostrando a barra de ferramentas de acessibilidade da AWMo.

As ferramentas descritas visam facilitar o uso da aplicação por pessoas com diferentes capacidades visuais e também usuários que sejam fluentes apenas em Inglês ou Português, atingindo assim uma gama maior de usuários.

\subsection{Considerações finais}

A AWMo é uma ferramenta que apresenta inovação ao unir duas grandes áreas de pesquisa como as de acessibilidade na $W e b$ e desenvolvimento orientado a modelos. Sua abordagem textual e conversão automática entre as visões textual e gráfica permitem que ela seja utilizada por equipes compostas tanto por pessoas com deficiência visual quanto por pessoas com visão. Um ponto importante durante o projeto da ferramenta foi a facilidade de uso, propiciando um trabalho inclusivo, com autonomia para todos os envolvidos: pessoas com e sem deficiência. Assim, as pessoas com visão não precisam, necessariamente, aprender a linguagem textual para operá-la, se utilizarem a visão gráfica, com a qual estão habituados com o uso de outras ferramentas.

A versão atual da AWMo é capaz de exibir todo o conteúdo criado por meio da interface textual e permite que o usuário manipule os elementos existentes na interface gráfica com interações como: drag $\mathscr{E}$ drop para alterar a posição de uma classe no espaço do diagrama, adição e remoção de atributos e métodos. Porém, na visão gráfica não é possível adicionar novas classes ou relacionamentos ao diagrama e não é possível salvar nenhuma das alterações realizadas no diagrama.

Esse fato deve-se exclusivamente a uma restrição de tempo para a implementação do protótipo e necessidade do cumprimento de cronograma relacionado a esse projeto de mestrado. Por questões de tempo, foi decidido investir principalmente na interface textual para que fosse possível estudar o principal objetivo da ferramenta que é permitir o acesso aos deficientes visuais. No entanto, estudos de viabilidade realizados mostraram que a implementação do retorno dos dados da interface gráfica para o banco de dados é possível e não traria grandes dificuldades.

A AWMo foi publicada como uma ferramenta de código aberto sob a versão simplificada da licença BSD para permitir que seja distribuída e modificada e que novos pesqui- 
sadores e desenvolvedores de software possam colaborar com sua evolução. O projeto da AWMo está hospedado no GitHub em: https://github.com/awmo/awmo.

Além disso, um manual técnico foi publicado contendo instruções para instalação, uso e desenvolvimento da AWMo [23]. 



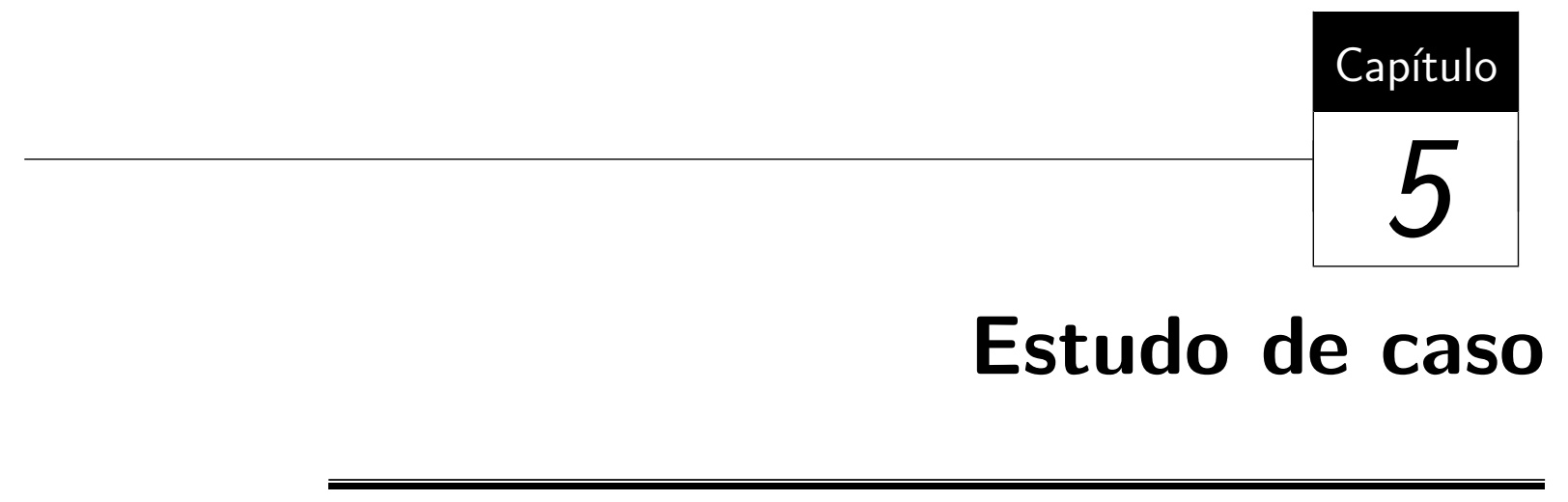

Este capítulo apresenta o estudo de caso conduzido para avaliar a efetividade da ferramenta proposta neste trabalho ao cumprir o objetivo a que se propõe: permitir acesso a diagramas e modelos de software para deficientes visuais. São apresentados o protocolo que guiou a execução dos estudos, os resultados obtidos e, por fim, discussões e considerações finais.

\subsection{Considerações iniciais}

Estudos de caso são estudos empíricos que buscam investigar fenômenos contemporâneos em seu contexto [71]. O protocolo de um estudo de caso é utilizado como documentação para os procedimentos planejados e decisões tomadas ao longo do planejamento, execução e posterior análise dos dados do estudo de caso [52].

Para entender a relação dos usuários com a técnica de interação proposta para modelos de software, foram conduzidas entrevistas presenciais e observação da utilização da AWMo por sujeitos pré-selecionados, enquanto realizavam algumas tarefas definidas na ferramenta.

Nesse sentido, foram encontrados trabalhos na literatura que relatam a condução de estudos de casos e experimentos similares ao proposto neste trabalho.

No caso de Freire et al. (2010), foi realizado um estudo de caso para avaliar um protótipo de uma lousa digital construído para permitir o acesso de deficientes visuais. A ideia explorada foi a mediação, ou seja, desenvolver um ambiente no qual mediadores podem inserir informações e um ambiente no qual os usuários com deficiência visual possam 
acessá-las. Neste caso específico, o conteúdo se refere a descrições textuais para desenhos feitos sobre a lousa. O estudo de caso foi realizado com um estudante em uma aula experimental de geografia sobre a atmosfera e utilizou, de maneira informal, a técnica think aloud. Posteriormente foi conduzida uma entrevista para conhecer melhor o participante e identificar suas impressões e problemas em relação ao protótipo [19].

Shinohara e Tenenberg (2007) realizaram um estudo de caso com uma estudante de ensino superior com cegueira congênita. Neste estudo a participante, Sara, foi incumbida de realizar uma série de doze tarefas nas quais ela deveria interagir com algum equipamento ou objeto a fim de estudar sua interação com artefatos tecnológicos. Os pesquisadores optaram por um design de pesquisa que utilizou apenas um sujeito e uma análise em profundidade dos dados coletados através de observações. As principais técnicas utilizadas para coleta de dados foram Technology tours, Personal History e Guided Speculation [54].

Kaczmirek e Wolff (2007) elaboraram um conjunto de doze recomendações para a elaboração de surveys cujo público alvo fossem deficientes visuais. Para tal, o trabalho leva em consideração o conhecimento dos processos cognitivos e padrões de acessibilidade [32]. Embora este trabalho não se utilize de questionários que serão respondidos de maneira autônoma pelos participantes, as recomendações se mostraram muito importantes durante a preparação do material de apoio para a condução de entrevistas e observações de estudo.

Um trabalho que se assemelha mais com a proposta deste estudo foi reportado por Hillen e Evers (2007). Os autores conduziram um estudo de caso composto por uma fase de entrevista semiestruturada e uma fase de observação, com o intuito de avaliar um protótipo de uma aplicação chamada NavAccess. O objetivo da NavAccess era facilitar o uso de páginas $W e b$ em geral e funcionava com um crawler que buscava o conteúdo e informações da página para auxiliar a navegação do usuário [27].

O objetivo deste estudo de caso foi avaliar a viabilidade da proposta da AWMo para permitir acesso a modelos de software para deficientes visuais e investigar se a técnica proposta é apropriada para ser utilizada em ambientes reais, tais como empresas que trabalham com desenvolvimento de software e empregam profissionais com deficiência visual.

\subsection{Questões de pesquisa}

As questões de pesquisa são as questões que se busca responder por meio da análise do estudo de caso. Para este trabalho temos as seguintes questões de pesquisa:

1. A ferramenta AWMo permite o acesso aos diagramas de classe da UML para deficientes visuais? 
2. A linguagem textual da AWMo impõe alguma barreira para a utilização da abordagem proposta?

3. Qual o maior desafio enfrentado na questão do acesso e desenvolvimento de modelos visuais por usuários com deficiência visual?

\subsection{Estratégia de seleção}

O problema que a AWMo visa superar é a barreira que existe devido à dificuldade do acesso a modelos de software para deficientes visuais. Portanto, para a condução deste estudo foi necessária a participação de indivíduos que possuíssem conhecimento em desenvolvimento de software e que também fossem deficientes visuais. Portanto, o conjunto de usuários selecionados era bastante limitado.

Foram convidados os sujeitos que atenderam aos seguintes critérios:

- Fosse deficiente visual; e

- Trabalhasse com desenvolvimento de software ou fosse estudante e estivesse frequentando algum curso relacionado, que aborde programação e desenvolvimento de software.

\subsection{Coleta de dados}

A coleta de dados se deu de duas maneiras distintas. De acordo com a definição de Lethbridge et al. (2005), podemos separar as técnicas de coleta de dados em três graus: primeiro grau, na qual o pesquisador está em contato direto com os sujeitos e os dados são coletados em tempo real. Segundo grau, na qual o pesquisador indiretamente coleta dados sem interagir diretamente com os sujeitos. E terceiro grau, quando o pesquisador se utiliza da análise independente de artefatos ou documentos já existentes [36].

Neste estudo, foram utilizadas entrevistas presenciais como uma técnica de coleta de dados de primeiro grau e observação do sujeito ao utilizar a AWMo para realizar um conjunto de tarefas pré-estabelecidas, como uma técnica de coleta de dados de segundo grau.

\subsubsection{Entrevistas}

Foram realizadas duas sessões de entrevistas, uma antes da observação do uso da AWMo, para coletar informações sobre o participante e sua experiência com desenvolvimento e modelagem de software e outra, posteriormente ao uso da ferramenta, para obter 
informações sobre a experiência do usuário durante a utilização. Daqui em diante serão chamadas de entrevistas pré-uso e pós-uso, respectivamente.

Ambas as entrevistas foram realizadas de maneira semiestruturada, ou seja, foram utilizados guias com as questões e pontos que deveriam ser abordados durante a entrevista; porém, a ordem destas questões não precisava necessariamente ser seguida de maneira linear. Essa abordagem semiestruturada possibilita ao entrevistador incluir ou remover perguntas de acordo com o rumo da entrevista, tornando-a assim oportunística, o que é bastante útil para se aumentar ou aprofundar o entendimento [34].

As questões que foram utilizadas como guia para a entrevista pré-uso encontram-se no Apêndice A e as questões de guia para a entrevista pós-uso encontram-se no Apêndice C das notas publicadas na biblioteca do ICMC-USP [24].

As entrevistas planejadas buscam respostas mais amplas e nas quais os entrevistados tenham a liberdade de colaborar com mais informações e por isso buscou-se trabalhar com questões abertas em detrimento de questões fechadas e com conjuntos de respostas pré-definidos que podem inibir os entrevistados de elaborarem suas respostas. Esta escolha torna o processo de análise dos dados mais trabalhoso pois ao invés de simplesmente contar ou tabular os dados, é necessária uma análise interpretativa das respostas [34].

Durante as entrevistas, o áudio foi gravado para consultas posteriores, pois ao se realizarem anotações em tempo real, consome-se muito tempo e em razão da quantidade de informação ser muito grande, acaba-se perdendo detalhes que podem ser interessantes. A gravação em áudio foi realizada com o conhecimento e consentimento do participante.

\subsubsection{Observação}

Para a coleta de dados em segundo grau, ou seja, com pouca interferência do pesquisador, foi utilizado um computador instrumentado para a gravação da interação do usuário com a AWMo. Nesta parte do estudo, o usuário recebeu uma série de tarefas pré-estabelecidas para que as executasse utilizando a interface da AWMo.

Para gravação foi utilizada a ferramenta Morae, que auxilia na execução de testes de usabilidade. Foi desenvolvida pela TechSmith¹.

Com o uso da Morae foram gravadas as seguintes informações durante a execução das tarefas:

- Tela do computador e os programas que estavam sendo executados durante o procedimento;

- Interação do usuário com o mouse;

\footnotetext{
${ }^{1}$ http://www.techsmith.com/morae.html
} 
- Webcam mostrando o rosto do usuário ao longo do processo;

- Áudio do computador para capturar o que o usuário estava falando e possíveis perguntas que pudessem vir a ser realizadas para o pesquisador em caso de dúvidas, por exemplo;

A Morae é composta por 3 componentes: o Recorder que é o software responsável pela captura do experimento, o Observer que possibilita que pesquisadores acompanhem o experimento remotamente em tempo real e o Manager que é utilizado para visualizar e analisar os dados após a coleta.

Embora seja possível conduzir estudos utilizando apenas o Recorder e o Manager, escolheu-se utilizar o Observer, mesmo tendo em vista que o estudo foi conduzido por apenas um pesquisador durante as sessões, pois o uso do Observer possibilita a adição de marcadores e comentários à captura, enquanto o estudo está sendo executado. A configuração utilizada para execução contou com o uso de dois computadores em uma mesa, um para o sujeito, executando o Recorder, e outro para o pesquisador, executando o Observer e conectado ao primeiro computador.

A Figura 5.1 mostra a configuração utilizada durante a execução do estudo piloto e que também foi utilizada na execução do estudo final.

Com esta configuração, o pesquisador está sempre à disposição para auxiliar em quaisquer dúvidas ou questões que o sujeito possa vir a ter e ainda é capaz de fazer anotações e adicionar marcadores diretamente no experimento que está sendo capturado, sem interromper o sujeito.

As tarefas que foram realizadas pelos participantes podem ser encontradas no Apêndice B das notas publicadas na biblioteca do ICMC-USP [24].

Do mesmo modo que nas entrevistas, os dados foram gravados com a autorização e conhecimento dos participantes.

\subsubsection{Medições e métricas}

Com o objetivo de coletar dados qualitativos, foram extraídas algumas métricas da fase de observação do experimento, com base nas tarefas que os participantes realizaram, utilizando a AWMo.

Para que o fluxo do trabalho não fosse interrompido, as medições foram realizadas em um momento posterior ao da coleta, utilizando os registros em vídeo, gravados com a ferramenta Morae. As medições que foram extraídas das gravações são:

- Falhas por tarefa: medidas a partir dos vídeos, o número de ações incorretas realizadas pelo usuário ao longo de cada objetivo que podem vir a resultar em um erro se não corrigida. 


\section{CAPÍTULO 5. ESTUDO DE CASO}

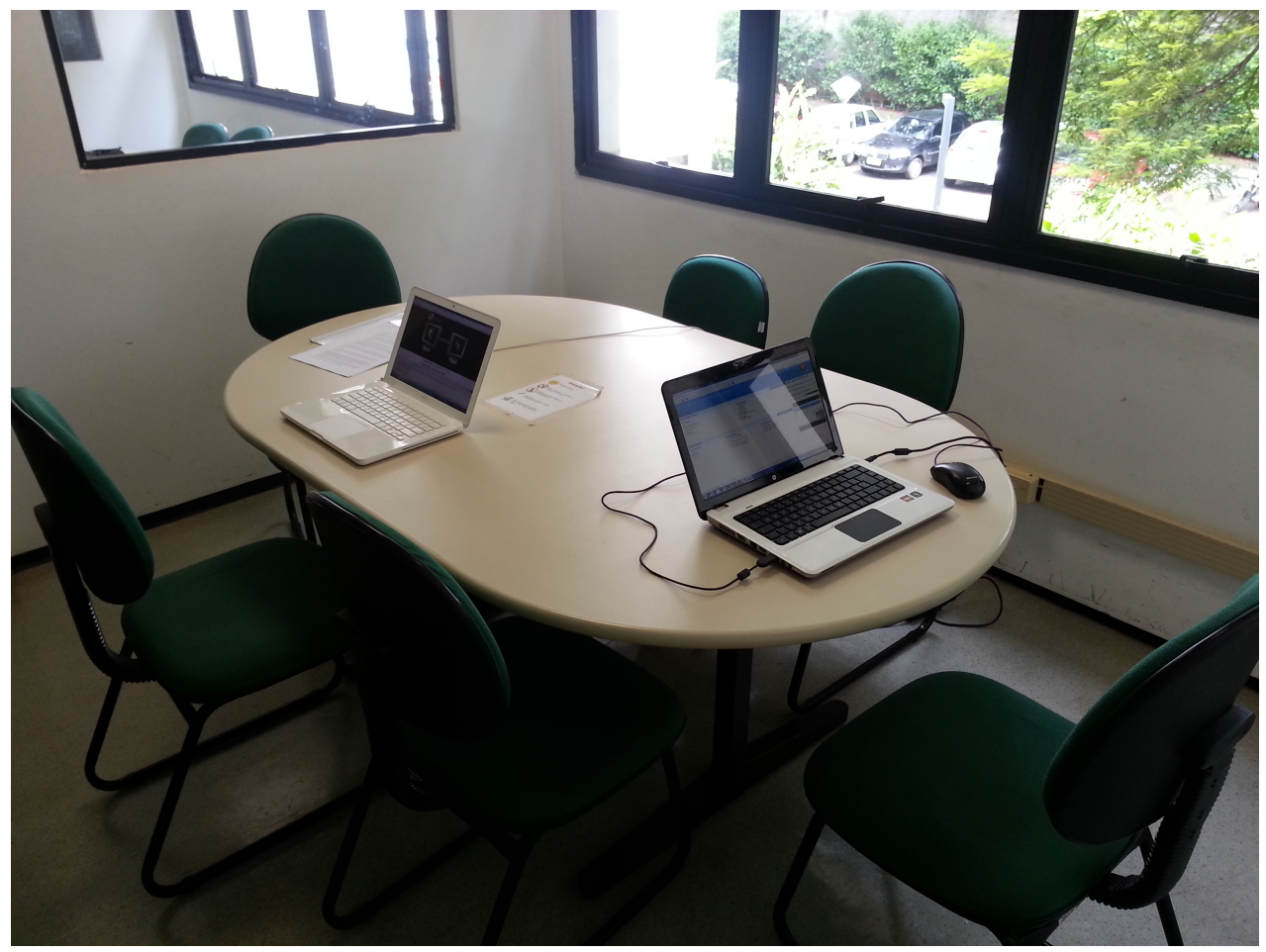

Figura 5.1: Foto da configuração do ambiente do experimento como foi conduzido durante a execução piloto. O computador à direita, utilizado pelo sujeito executa o Morae Recorder e o computador à esquerda, utilizado pelo pesquisador executa o Morae Observer.

- Erros por tarefa: medidos a partir dos vídeos, o número de vezes em que a AWMo exibiu mensagens de erro para o usuário ao decorrer da realização de cada tarefa.

- Tempo por tarefa: medido o tempo que o usuário utilizou para realizar cada uma das tarefas.

\subsection{Triangulação}

Triangulação é o processo de se abordar o objeto de estudo por diferentes ângulos. Essa técnica é muito importante quando se está realizando um estudo qualitativo, pois o material coletado em geral é muito rico e extenso, porém menos preciso do que dados quantitativos [52].

De acordo com Stake (1995), existem quatro tipos de triangulação que podem ser realizadas em um estudo de caso: triangulação de dados, triangulação de observadores, triangulação metodológica e triangulação teórica [57].

Neste trabalho foram utilizados três tipos de triangulação: 
- Triangulação metodológica: com o objetivo de validação e de aumentar a confiabilidade dos dados coletados, foram combinadas uma estratégia qualitativa (entrevista) com uma estratégia quantitativa (métricas na observação). Embora essa abordagem quantitativa não seja suficiente para que conclusões sejam estatisticamente válidas, elas colaboram para a validade dos dados coletados, seja sustentando os dados das entrevistas ou expondo possíveis divergências.

- Triangulação de dados: do mesmo modo que na triangulação metodológica, a triangulação de dados se deu pela coleta de dados de duas fontes diferentes, nas entrevistas, de maneira direta e por meio de gravações da Morae, de maneira indireta. O uso de fontes de dados distintas provê oportunidade para se obter insights que poderiam ser mais difíceis de se obter quando se utiliza apenas uma forma de coleta de informações [34].

- Triangulação de observador: durante a fase de análise dos dados, todo o material coletado durante as entrevistas e observações de uso da ferramenta foi analisado pelo autor com o auxílio de um segundo pesquisador. Dessa forma, para que refletissem de maneira mais fiel os fatos, buscou-se evitar que as análises fossem influenciadas pelas opiniões pessoais dos pesquisadores.

Com o uso das triangulações citadas e analisando os dados das três etapas (entrevista pré-uso, uso da ferramenta e entrevista pós-uso) de maneira cruzada, esperou-se mitigar o risco de que a informação fosse mal interpretada ou mal compreendida.

\subsection{Ameaças à validade}

Para assegurar a melhor qualidade dos resultados deste estudo, as principais ameaças à sua validade foram tratadas e monitoradas ao longo de sua execução. Essas ameaças e as ações que poderiam ser realizadas para mitigá-las ou possíveis soluções alternativas são listadas nas Tabelas 5.1 e 5.2. 
Tabela 5.1: Ameaças à validade interna.

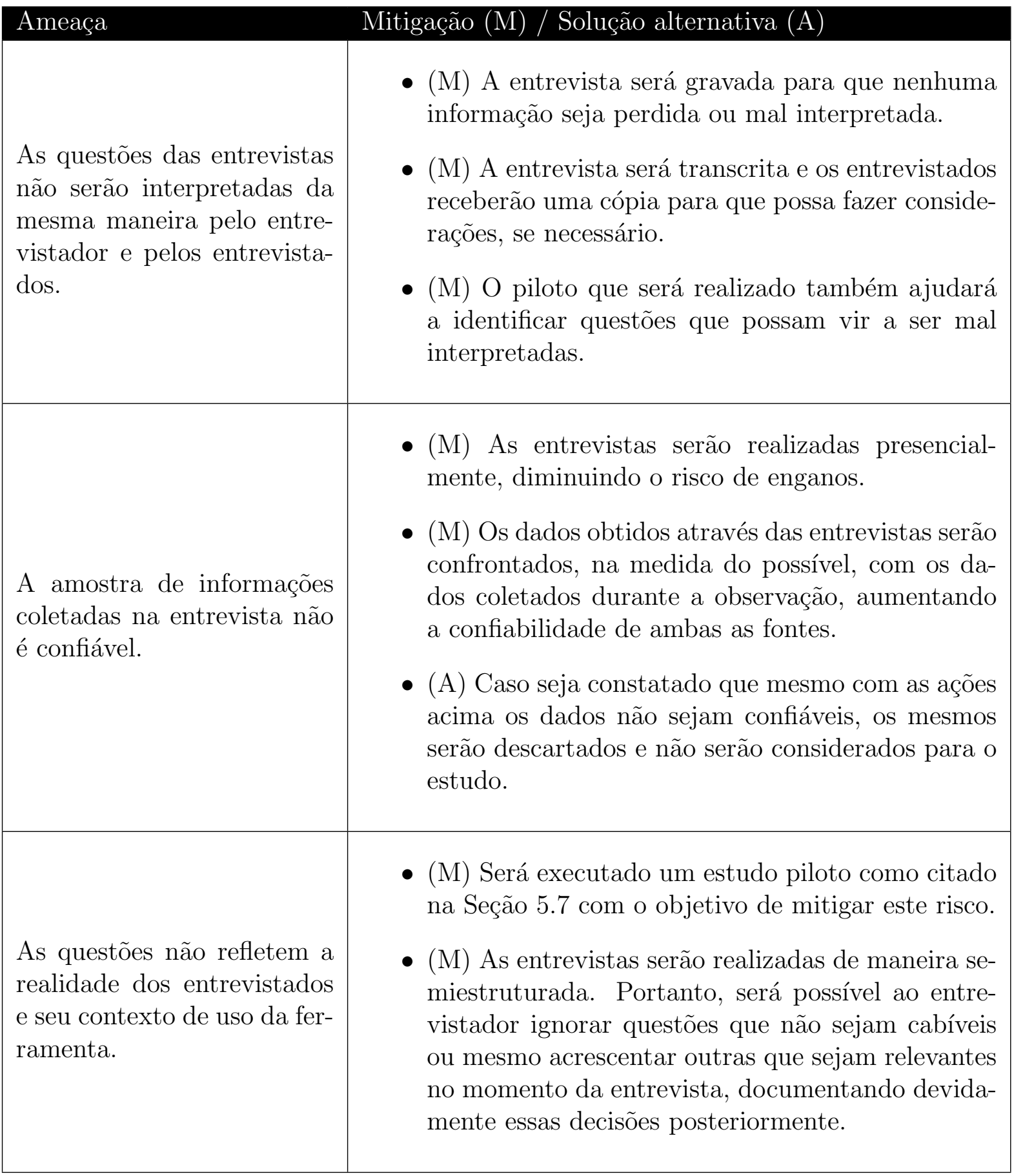


Tabela 5.2: Ameaças à validade externa.

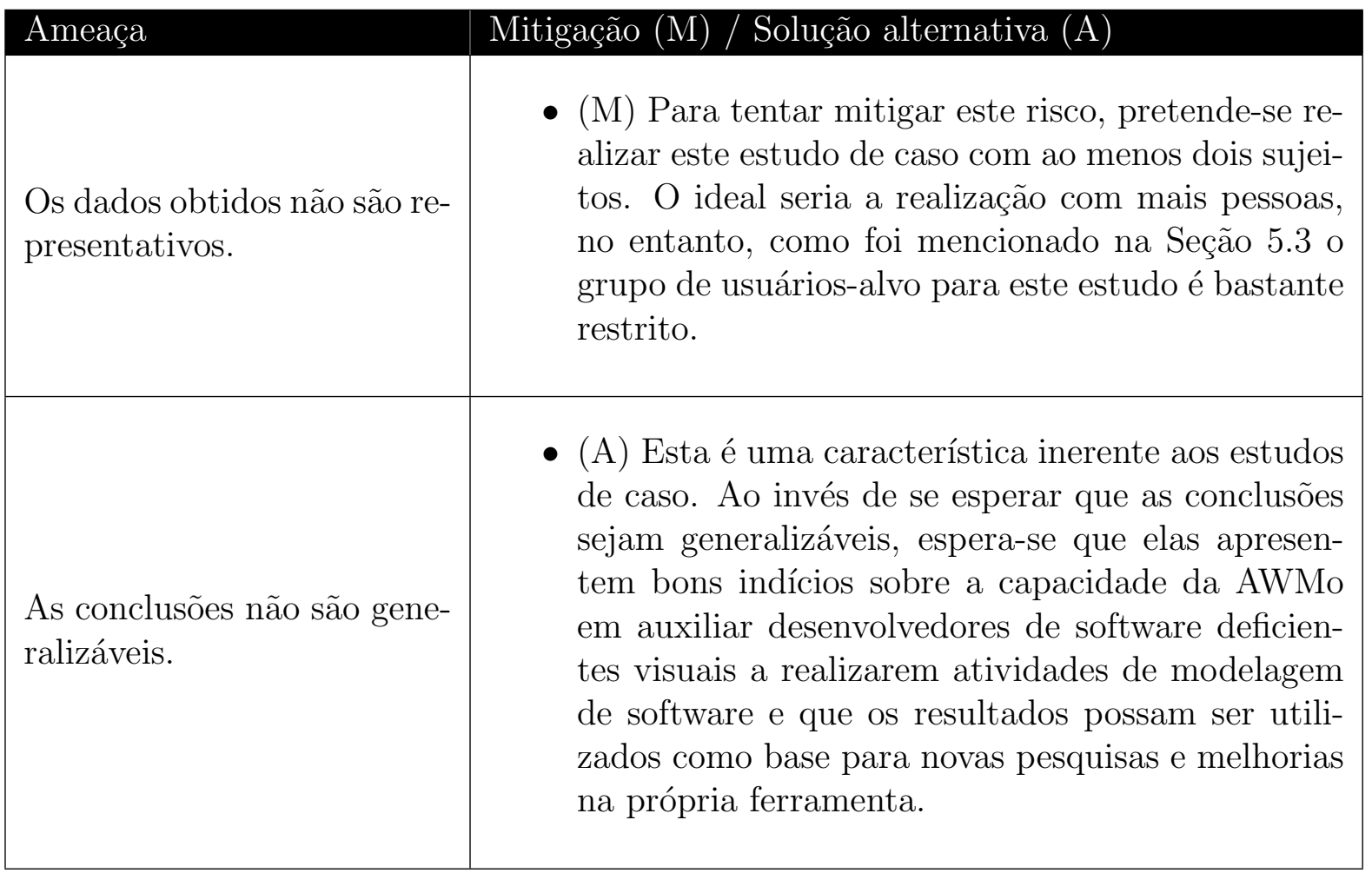

\subsection{Piloto}

Um estudo piloto foi conduzido para avaliar se as questões de entrevista e as tarefas que foram requisitadas eram adequadas para se coletar os dados pretendidos e se seriam suficientes para se atingir os objetivos estabelecidos.

O estudo piloto contou com a participação de Marvin. Marvin é um nome fictício que foi atribuído pelo autor, com o objetivo de preservar a identidade do participante.

Marvin é natural do interior de São Paulo, possui 41 anos de idade e apenas 10\% de visão em ambos os olhos, em função de cicatrizes em suas retinas. É formado em matemática e atualmente está no terceiro ano de um curso de bacharelado em sistemas de informação.

Com o objetivo de facilitar o uso de computadores, ele utiliza as fontes levemente ampliadas, o que torna a leitura mais fácil e ao mesmo tempo não atrapalha o uso em telas pequenas, como é o caso de seu netbook. Além disso, é comum que aproxime bastante o rosto da tela do computador. Também utiliza os ícones em tamanho grande e mantém poucos itens na área de trabalho. Por possuir visão parcial, não faz uso de leitores de tela.

Marvin utiliza computadores desde 1984, desde o CP 500². Em relação à programação de computadores, teve seu primeiro contato aos 18 anos durante um curso técnico de

\footnotetext{
${ }^{2} \mathrm{http}: / /$ museudocomputador.org.br/cp500.php
} 
processamento de dados, com linguagens de programação como Basic e COBOL, porém deixou de praticar programação durante o período em que cursou graduação em matemática, utilizando apenas um pouco de linguagem C. Há cerca de três anos começou a estudar linguagens de programação para Web por conta própria.

Mais recentemente, no curso de sistemas de informação, Marvin teve contato com Java, PHP e SQL.

Em relação a modelos e diagramas da UML, teve contato ao longo do curso de sistemas de informação nas disciplinas como banco de dados (modelos entidade-relacionamento) e programação orientada a objetos, na qual o conteúdo em Java era ilustrado com diagramas de classe da UML e também chegou a construir alguns diagramas utilizando a ferramenta Blue $J^{3}$.

Ao longo da execução do estudo piloto foram coletados 18 minutos de áudio durante a pré-entrevista, 67 minutos de vídeo durante a fase de observação, enquanto Marvin utilizava a AWMo e, posteriormente, foram capturados 16 minutos de áudio durante a pós-entrevista.

Com base na execução do estudo piloto, foi identificado que a pré-entrevista foi capaz de coletar dados sobre o sujeito e suas experiências passadas com modelagem de maneira satisfatória. A estratégia de conduzir a entrevista de maneira semiestruturada se mostrou bastante útil à medida que questões que foram adicionadas pelo pesquisador ao longo da entrevista ajudaram a conhecer melhor o sujeito. Outro aspecto importante foi o fato de que algumas das questões planejadas não refletiam a realidade de Marvin, por exemplo, a questão: "Na sua opinião, qual o principal problema de acesso a esses diagramas?" para qual o sujeito respondeu:

"...eu acho que o fato deles serem diagramas facilitou." e "A não ser que você tenha que fazer um diagrama muito complexo e talvez tenha que diminuir o diagrama, não sei como funciona isso aí. Eu fiz diagramas simples, bem simplesinhos."

Isto ocorreu devido ao fato de Marvin possuir $10 \%$ de visão, então diagramas visuais não são, na realidade, uma barreira para ele. Podem exigir mais esforço para leitura e, especialmente se o diagrama for complexo, a imagem resultante pode ser muito grande. Isso mostrou que esta questão foi criada com foco em sujeitos que são completamente cegos, que são os usuários que supostamente terão maior benefício com o uso da AWMo. Sob esta perspectiva o curso da entrevista foi alterado durante sua execução para melhor se adaptar à realidade de Marvin.

Na primeira versão do protocolo foi definido um conjunto de 4 objetivos para o usuário executar ao utilizar a AWMo durante a fase de observação do estudo. No entanto, durante o estudo piloto foi possível perceber que as descrições dos objetivos causaram confusão

\footnotetext{
${ }^{3}$ http://www.bluej.org/
} 
no sujeito. Parte disso em função de alguns nomes que foram utilizados de maneira inconsistente entre as descrições e o diagrama já existente na AWMo, neste caso chamado de "Conta corrente". O objetivo 3 foi o que apresentou os maiores problemas. Neste objetivo foi solicitado que o usuário realizasse duas ações inteiramente distintas no mesmo diagrama e Marvin concluiu apenas uma delas, precisando ser lembrado da segunda parte do objetivo pelo pesquisador.

A lista dos 4 objetivos propostos inicialmente para o piloto pode ser vista a seguir.

Objetivo 1 - Ajuste a AWMo de acordo com suas preferências (Tamanho de fonte, contraste e idioma).

Objetivo 2 - Abrir o diagrama "Conta corrente" já existente na AWMo e entender seu conteúdo.

Objetivo 3 - Realizar alterações no diagrama: O engenheiro responsável pela modelagem do diagrama da conta corrente cometeu alguns enganos. Sua tarefa é corrigir estes problemas: a Pessoa, dona de uma conta, pode ser tanto uma pessoa física quanto uma pessoa jurídica (empresa). Represente essa informação no diagrama de classes. (Se possível, utilize o relacionamento de herança). Além disso, o cliente não deseja que as operações de Poupança sejam controladas pelo sistema nesta primeira versão, portanto, remova a poupança desta versão do diagrama de classes. (Remova também as relações da Poupança com as outras classes onde for cabível).

Objetivo 4 - Crie um novo diagrama e chame-o de Carro. Em seguida abra o diagrama para edição no modo textual e insira as classes Carro e Motor. Sendo que Carro possui os atributos "cor" e "modelo" e o Motor possui os atributos "potência" e "cilindros". Represente o fato de que um carro é composto por um motor. Crie os métodos que achar necessário.

Para melhorar os objetivos, alguns dos nomes foram padronizados e o objetivo 3 foi dividido em dois distintos, resultando em um novo conjunto de 5 objetivos que englobam as mesmas ações do primeiro conjunto, porém de uma maneira mais simples de serem compreendidas. O novo conjunto de tarefas pode ser visto a seguir.

Objetivo 1 - Ajuste a AWMo de acordo com suas preferências (Tamanho de fonte, contraste e idioma) utilizando as funcionalidades de acessibilidade existentes na própria AWMo. Se necessário pode-se utilizar de configurações do navegador e/ou sistema operacional para tornar a utilização da ferramenta o mais confortável possível.

Objetivo 2 - Abrir o diagrama "Sistema Bancário" já existente na AWMo e entender seu conteúdo e explicá-lo com suas palavras ao pesquisador. 
Objetivo 3 - Ainda no diagrama Sistema Bancário: O engenheiro responsável pela modelagem do sistema bancário se esqueceu que o banco em questão atende tanto a pessoas físicas quanto a pessoas jurídicas. Sua tarefa é corrigir este problema: a Pessoa, dona de uma conta, pode ser tanto uma pessoa física quanto uma pessoa jurídica (empresa). Represente essa informação no diagrama de classes. (Se possível, utilize o relacionamento de herança). Implemente os métodos e atributos que julgar necessário.

Objetivo 4 - Ainda no diagrama Sistema Bancário. Na versão atual o modelo do sistema está considerando o funcionamento de contas do tipo Poupança. No entanto, o cliente deseja que a conta Poupança seja desenvolvida apenas no futuro, portanto, remova a Poupança desta versão do modelo. (Remova também as relações da Poupança com as outras classes onde for cabível).

Objetivo 5 - Crie um novo diagrama e chame-o de Automóvel. Em seguida abra o diagrama para edição no modo textual e insira as classes Carro e Motor. Sendo que Carro deve possuir os atributos "cor" e "modelo" e o Motor deve possui os atributos "potência" e "cilindros". Represente o fato de que um carro é composto por um motor. Crie os métodos que achar necessário.

A pós-entrevista foi conduzida de maneira similar à pré-entrevista e permitiu elicitar novos requisitos, tais como: adicionar um link nas mensagens de erro para que o foco do editor de texto seja movido diretamente para a linha com erro em questão e a exibição de número de linha no editor de código para auxiliar a navegação do usuário. Novamente, a entrevista semiestruturada com questões abertas se mostrou útil para se obter um entendimento mais profundo nos tópicos que se mostraram interessantes ao decorrer da entrevista.

Após a condução do piloto, algumas das funcionalidades apontadas por Marvin foram desenvolvidas na AWMo antes da execução do estudo com outros sujeitos, tais como: habilidade de controlar o tamanho da fonte dentro da área de texto do código, utilizando a funcionalidade de aumentar a fonte da barra de acessibilidade da AWMo. Outro caso especial foi o número de linha e a habilidade de ir diretamente para as linhas com erro, que foram desenvolvidas depois do piloto utilizando um plugin para editores de código na Web chamado code mirror ${ }^{4}$. Porém, em um momento posterior, ao validar a acessibilidade deste editor com o leitor de tela NVDA, ele se mostrou inacessível para leitores de tela pois substitui completamente a área de textos por outros elementos HTML que respondem a eventos JavaScript. Por isso, essas últimas funcionalidades tiveram que ser removidas

\footnotetext{
${ }^{4}$ http://codemirror.net
} 
para permitir a continuidade do estudo e necessitam de uma reavaliação mais detalhada posteriormente.

A execução do estudo piloto foi muito importante, não apenas para validar a abordagem com a qual o estudo foi conduzido, mas também por permitir que os pesquisadores coletassem informações valiosas sobre a própria AWMo e que identificassem alguns problemas básicos, tanto na ferramenta quanto no conjunto de objetivos planejados para a fase de observação.

As transcrições das entrevistas realizadas com Marvin podem ser encontradas no Apêndice F das notas publicadas na biblioteca do ICMC-USP [24].

\subsection{Plano de Análise}

Para cada um dos sujeitos analisados neste estudo de caso (Marvin, no piloto e Arthur e Ford nas execuções subsequentes), os arquivos de áudio das entrevistas foram transcritos e o conteúdo das gravações em vídeo (tela e webcam) foram analisados em busca das medições estabelecidas na Seção 5.4 .2 e outras informações relevantes.

Após as transcrições das entrevistas terem sido revistas pelos participantes, os dados foram analisados com o objetivo de responder às questões de pesquisa estabelecidas na Seção 5.2. Nenhum dos nomes ou informações confidenciais dos participantes serão publicados em hipótese alguma e um termo de confidencialidade foi firmado com os participantes para esse fim.

\subsection{Resultados obtidos}

Após a execução do estudo piloto e de terem sido melhorados os pontos observados na Seção 5.7, o estudo foi conduzido com dois outros participantes: Arthur e Ford (novamente os nomes foram alterados com o objetivo de manter a confidencialidade dos participantes).

As Seções 5.9.1 e 5.9.2 apresentam os resultados das execuções dos experimentos com Arthur e Ford, respectivamente, e a Seção 5.9.3 apresenta uma análise comparativa dos resultados dos dois participantes.

No decorrer das análises são feitas referências para o diagrama "Sistema Bancário". Este diagrama era pré-existente na AWMo no início das execuções deste estudo de caso e pode ser encontrado no Apêndice A para consulta. 


\subsubsection{Arthur}

A partir da pré-entrevista foi possível conhecer um pouco mais sobre o Arthur: ele é um homem de 31 anos e está atualmente matriculado no terceiro ano de um curso de ensino a distância de Bacharelado em Sistemas de Informação, oferecido com o apoio de uma universidade federal. Arthur é completamente cego em função de uma doença craniana e perdeu a visão quando tinha 15 anos de idade. Ele utiliza computadores há 7 anos e começou a aprender programação de computadores a 5 anos atrás, sendo familiarizado com as linguagens Java, C\# e JavaScript e outras tecnologias para desenvolvimento Web tais como HTML e CSS.

Para auxiliar o uso de computadores, ele utiliza o leitor de tela NVDA que lê todas as informações exibidas na tela e fornece atalhos de teclado para auxiliar a navegação e interação com o conteúdo.

Arthur já teve contato com diagramas de classe UML no passado, por meio de descrições textuais e de uma abordagem que utiliza planilhas do Excel para sistematizar os diagramas. Quando questionado sobre como foi essa experiência, ele respondeu:

"Através dessas descrições, se o diagrama for complexo, fica complicado você ter uma ideia clara. Eu consigo ter uma noção mas não considero que seja suficiente para eu ter uma ideia clara de como é o diagrama. A questão de você descrever uma imagem, ela ajuda em alguns aspectos, mas em diagramas mais complexos fica difícil, fica muito confuso você ter uma noção clara do que está ali."

E quando questionado sobre o que ele acredita que sejam os principais problemas nesta forma de se acessar os diagramas a resposta foi:

"Primeiro, a falta de praticidade. Porque se você está em uma situação real, onde você está dentro de um projeto e você precisa trabalhar com pessoas que enxergam, por exemplo, você precisa de alguém que descreva para você e isso já é uma perda de tempo em determinados aspectos. Fora que você não consegue expressar o diagrama de uma forma como uma outra pessoa que enxerga... Você não consegue se comunicar com a pessoa através do diagrama, por exemplo, eu posso criar uma descrição de como eu entendo o diagrama, só que para uma pessoa que está acostumada a observar a representação gráfica, ler aquilo não vai ficar muito claro pra ela entender. Então esse é um aspecto, e a questão da leitura também, basicamente eu preciso de alguém que descreva para mim. Eu não consigo pegar o diagrama feito por uma outra pessoa e entender aquilo de uma maneira independente".

Durante a fase de observação foram coletados 51:44 minutos de vídeo enquanto Arthur completava o conjunto de objetivos pré-estabelecidos. O tempo utilizado em cada um dos objetivos pode ser visto na Figura 5.2. 


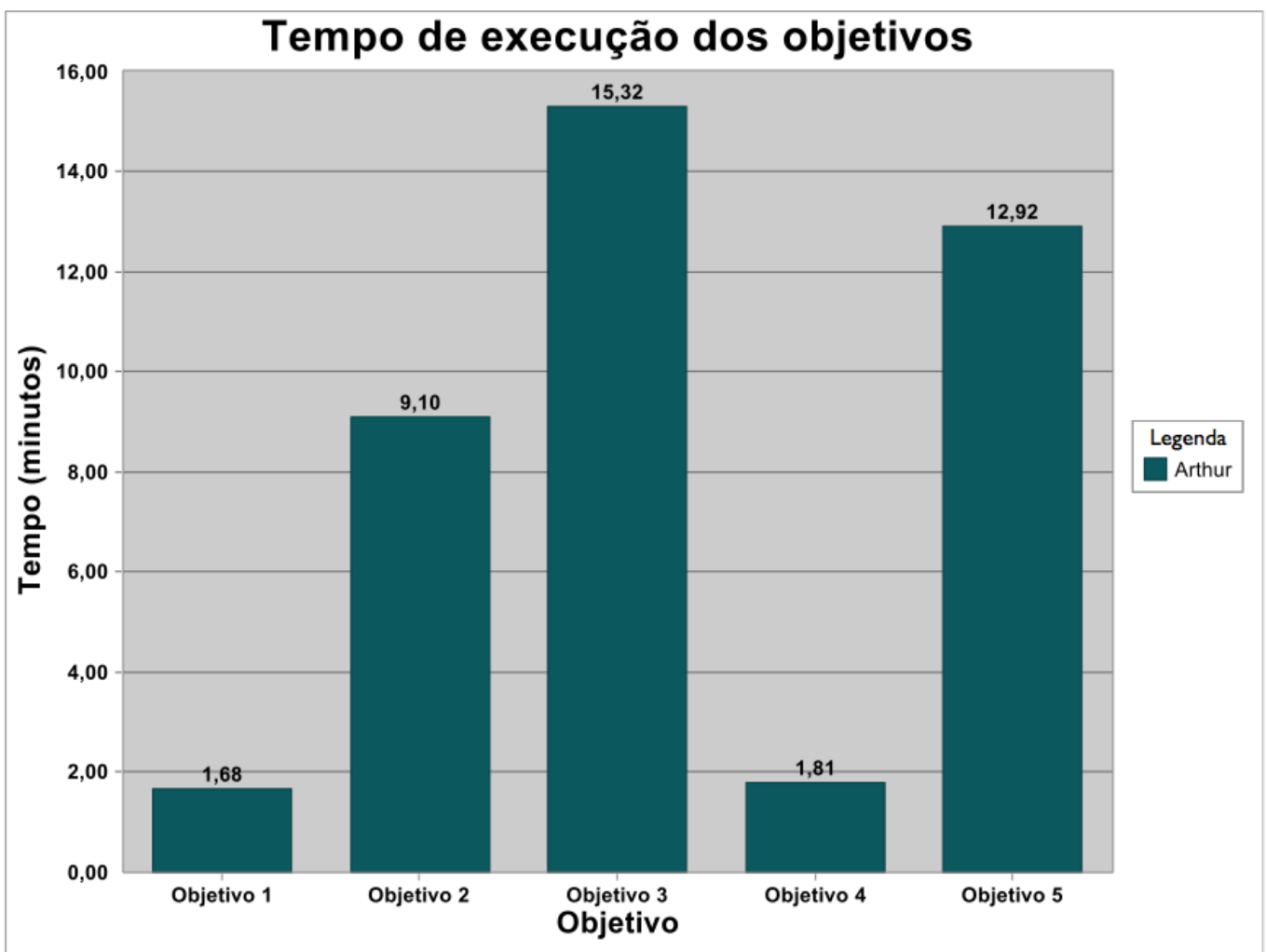

Figura 5.2: Gráfico mostrando a quantidade de tempo utilizado por Arthur para completar cada um dos objetivos propostos neste estudo de caso.

O tempo utilizado para a leitura das instruções dos objetivos, antes de começar a trabalhar para completá-los, não foi contabilizado nos tempos dos objetivos. Todas as consultas posteriores às instruções realizadas após o início da resolução foram contabilizadas na soma do tempo. Além disso, no caso do objetivo 1, Arthur interrompeu a execução para explicar ao pesquisador o funcionamento do leitor de tela e como um problema de acessibilidade encontrado poderia ser resolvido. Durante essa explicação a contagem do tempo estava em pausa na Morae e, portanto, não foi contabilizado no total de tempo utilizado para completar o objetivo 1, por se tratarem de informações adicionais.

O objetivo 1 consistia em permitir que o usuário utilizasse as funcionalidades de acessibilidade da AWMo. No entanto, pelo fato de Arthur ser completamente cego, a única assistência que ele utilizava era o leitor de tela, que estava previamente instalado no computador e, portanto, ele utilizou o tempo deste objetivo para conhecer a ferramenta AWMo, com qual ele estava tendo o primeiro contato. Ele navegou por toda a estrutura da aplicação, aprendendo a localização de menus, botões e outros recursos. Ao decorrer dos objetivos seguintes foi possível perceber que o sujeito começou a adotar diferentes estratégias de navegação para alcançar mais rapidamente o local desejado dentro da AWMo.

O objetivo 2 consistia no tempo utilizado para entender o diagrama "Sistema Bancário" e explicar seu conteúdo para o pesquisador. Aqui Arthur mostrou entender o conteúdo 
consideravelmente rápido, considerando-se que ele possuía conhecimento prévio das estruturas da linguagem textual em si, porém estava tendo contato com este diagrama específico pela primeira vez. Ele levou um total de 9,1 minutos para entender o diagrama e explicá-lo ao pesquisador.

Como esperado, os objetivos 3 e 5 foram os que levaram mais tempo para serem completados, pois eles são complexos e, portanto, a probabilidade de o sujeito cometer algum engano é maior. No entanto, era esperado que o objetivo 4 tomasse mais tempo e fosse complexo para ser resolvido, pois ao remover a conta poupança, Arthur teria de buscar todas as referências à essa classe. Porém, haviam apenas duas referências no diagrama proposto que consistiam em dois métodos na classe Pessoa: AbrirContaPoupança() e FecharContaPoupança() sendo que ambos tinham valores de retorno booleanos. Estes dois métodos são relacionados à classe ContaPoupança porém esse fato não foi mapeado no diagrama por meio de tipo de retorno ou parâmetros de entrada. Neste caso, se os dois métodos tivessem valores de retorno ou parâmetros do tipo ContaPoupança, o interpretador da AWMo teria mostrado erros quando a classe fosse removida, pois os métodos estariam referenciando uma classe que não poderia ser encontrada.

Uma observação importante em relação as tarefas 3 e 5 é o fato de que Arthur encontrou bastante dificuldade com o teclado do computador que ele utilizou durante o estudo, e pode-se notar claramente por meio da gravação de vídeo que grande parte das falhas e erros poderiam ter sido evitadas se o sujeito estivesse utilizando um computador ou teclado com o qual ele estivesse familiarizado. Infelizmente, devido à instrumentação necessária para realizar as gravações, Arthur teve que utilizar um computador fornecido pelo pesquisador e, mesmo com tempo fornecido para que ele pudesse configurar o computador e o leitor de tela de acordo com suas preferências, o teclado não pôde ser alterado por se tratar de um notebook.

A Figura 5.3 mostra o número de falhas que Arthur inseriu ao longo de cada um dos objetivos. Uma vez que os objetivos 3 e 5 são os que envolvem mais edição, foram ao longo do desenvolvimento destas tarefas em que o maior número de falhas foram inseridas. Comparando-se o número de falhas inseridas com o número de vezes que o interpretador mostrou mensagens de erro ao usuário exibidos na Figura 5.4, podemos ver que durante o processo de correção dos erros apontados, em geral, Arthur corrigiu mais de uma falha por vez, isto explica o motivo pelo qual o número de vezes que o interpretador retornou mensagens de erros ao usuário é inferior ao número de falhas inseridas. Além disso, houve situações nas quais Arthur foi capaz de detectar uma falha que ela gerasse uma mensagem de erro, ou seja, antes de salvar o diagrama. 


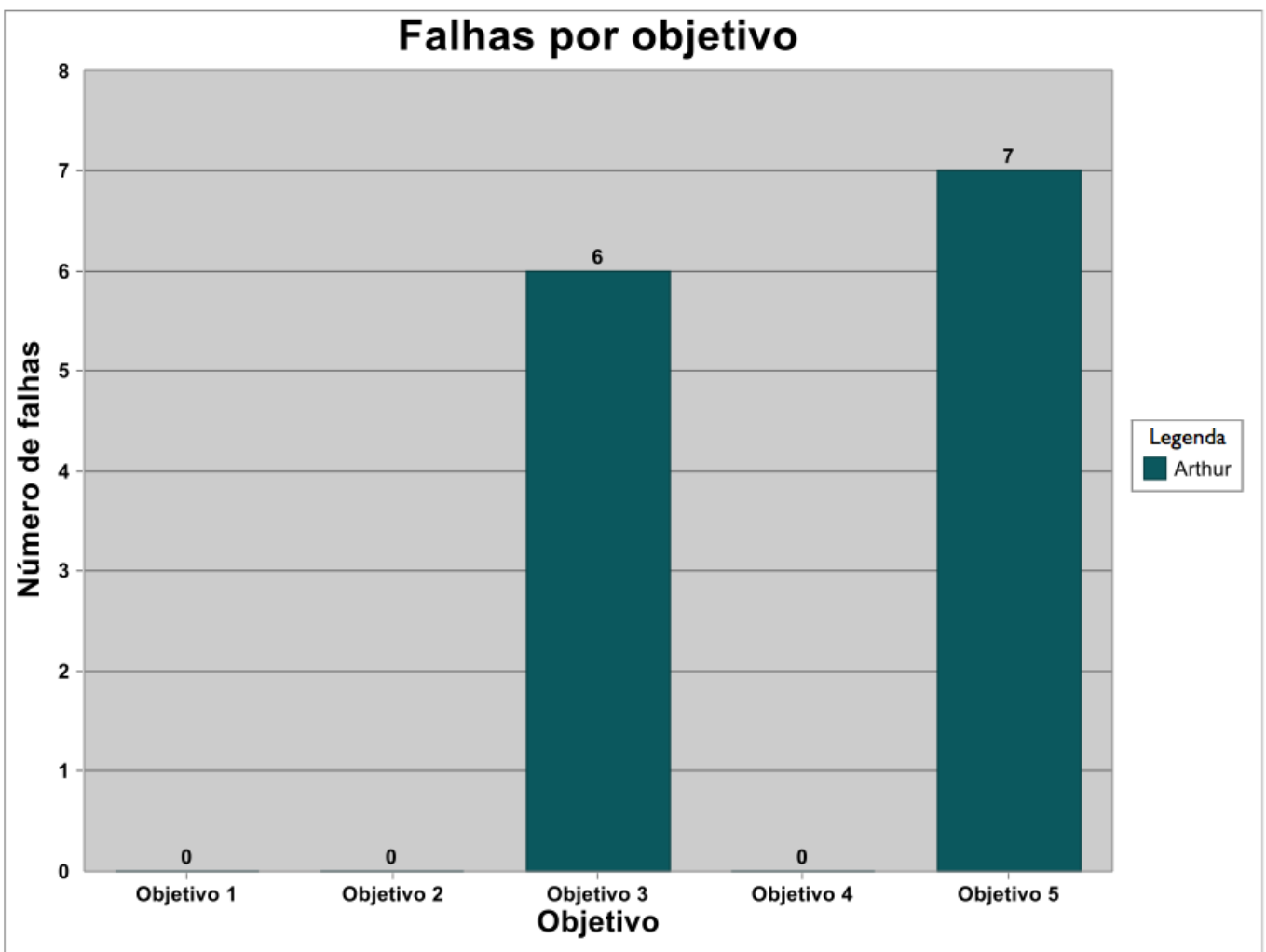

Figura 5.3: Gráfico extraído da gravação de vídeo da fase de observação contendo o número de falhas inseridas por Arthur ao decorrer da execução de cada objetivo.

A Figura 5.5 mostra uma captura de tela retirada da sessão gravada com a ferramenta Morae. A figura exibe uma das situações em que o interpretador da AWMo retornou erros ao sujeito em reposta à ativação do botão "Salvar diagrama".

Após a fase de observação, a pós-entrevista foi conduzida com o objetivo de entender melhor a experiência de uso, as dificuldades que Arthur encontrou e o que contribuiu para que os objetivos fossem completados.

Ao longo da fase de observação do estudo Arthur identificou um problema de acessibilidade nos botões de controle de tamanho de fonte da AWMo, exceto isso, não foram encontradas maiores dificuldades ao utilizar a ferramenta:

"Não achei nada que fosse difícil de trabalhar, achei a interface simples, acessivel, intuitiva. Só sinalizei um problema, que não chega a impedir a utilização que são os botões do menu do topo, não estão rotulados, a função deles está indicada só pelo atributo title e quando você está navegando no modo de leitura da página, o leitor de tela não detecta a funcionalidade do botão, você precisa navegar pelo foco. Mas, tirando isso que também não é nenhum problema que impeça a utilização, o resto eu achei totalmente acessivel e tranquilo de utilizar, mesmo o feedback com relação aos erros de sintaxe da linguagem, são simples de você encontrar na página." 


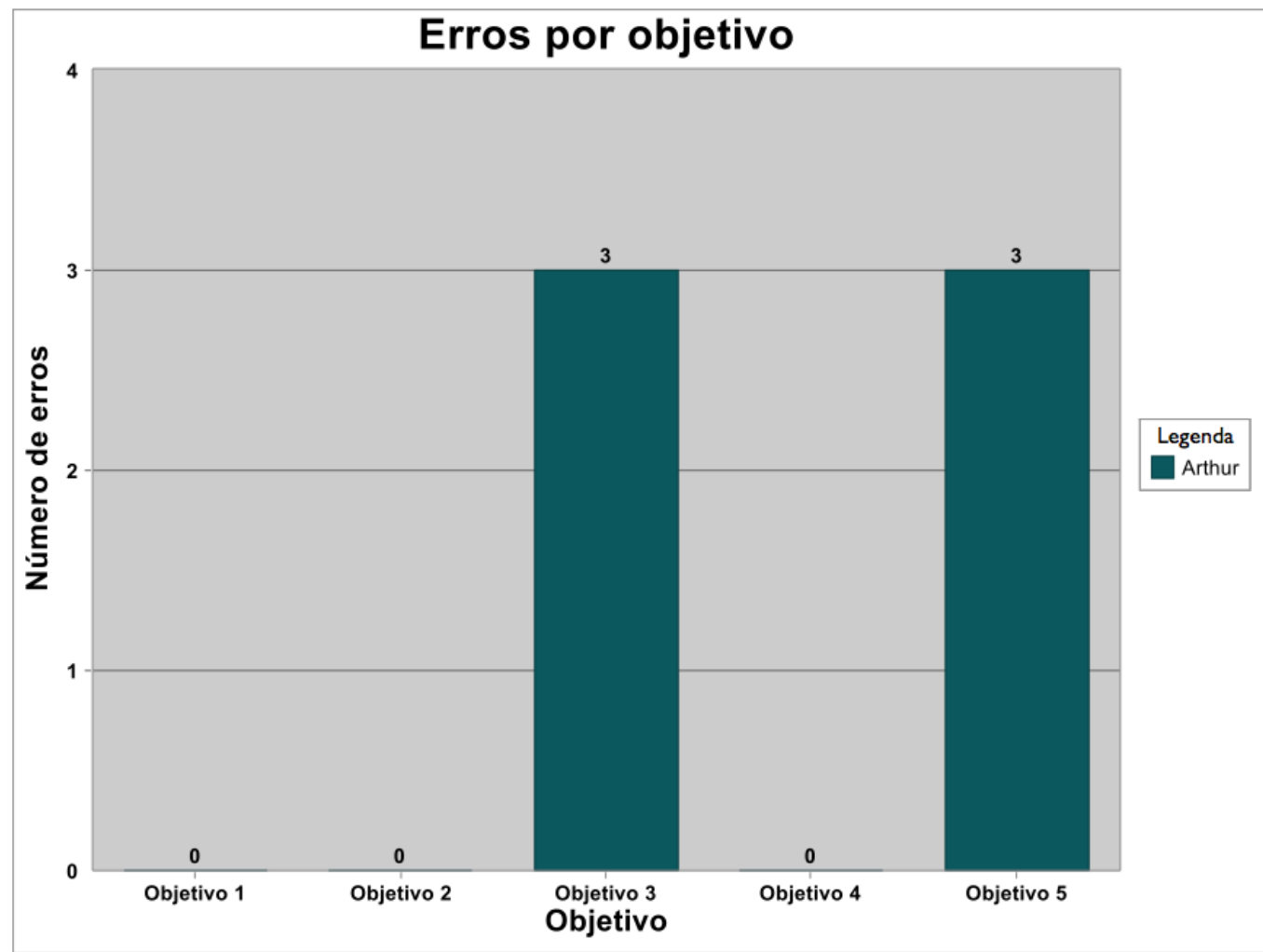

Figura 5.4: Gráfico extraído da gravação de vídeo da fase de observação, contendo o número de vezes em que mensagens de erro foram exibidas para Arthur em cada um dos objetivos propostos.

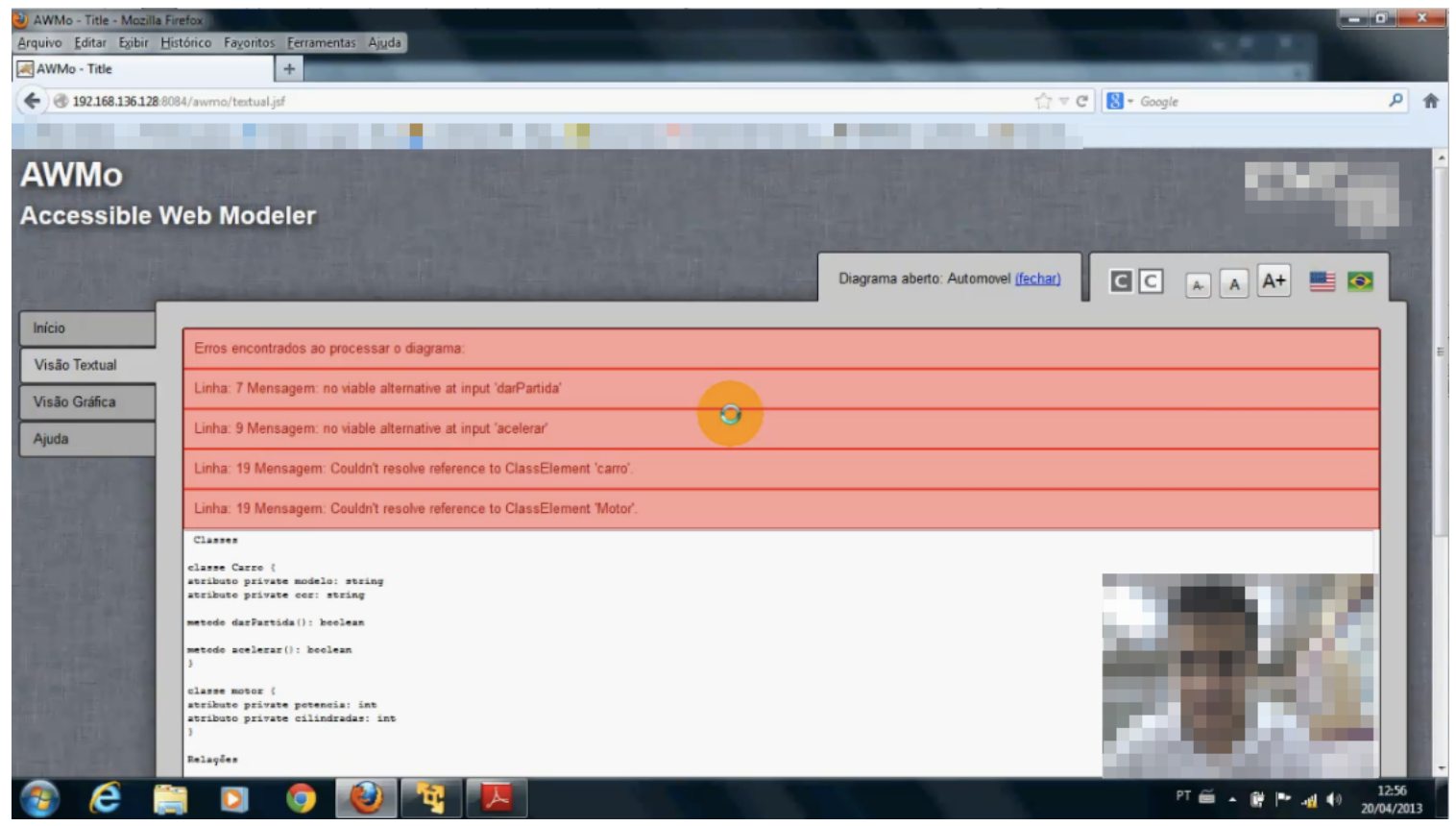

Figura 5.5: Captura de tela de um dos momentos em que o interpretador retornou mensagens de erro para Arthur. Foi aplicado um mosaico sobre o rosto de Arthur para preservar sua identidade. 
Além disso, quando questionado se mudaria algo na AWMo:

"Olha, honestamente, observando a ferramenta, a dificuldade que você tem é a normal que você tem em qualquer página que é o fato de você não conhecer a página. Você precisa primeiro saber onde estão as coisas, estudar primeiro a página para você ter uma representação, ter claro na sua mente como as coisas estão dispostas para você encontrá-las mais rapidamente, mas é o contato inicial. Após isso você já consegue se localizar e fica tranquilo de utilizar. Não vejo nada que devesse melhorar, mais aqueles pontos dos botões e link de abrir que são mudanças básicas e simples de fazer, mas de forma geral eu fiquei satisfeito com a interface."

Com o objetivo de melhor investigar os sentimentos de Arthur a respeito da ferramenta, foi questionado se ele acredita que seria prático utilizar a AWMo diariamente, ao trabalhar com desenvolvimento de software:

"Eu acho que sim, por exemplo, se eu me encontrasse numa equipe de desenvolvimento e fosse trabalhar maciçamente com UML e os demais desenvolvedores se interessassem em aprender a linguagem, que é uma coisa simples e rápida de se fazer, eu acho que seria interessante sim."

No entanto, ele se esqueceu que a AWMo também oferece uma visão gráfica que permitiria que usuários com visão colaborassem com ele sem a necessidade de aprender a linguagem textual. Quando foi lembrado sobre isto pelo pesquisador ele disse: "Exatamente, esse é o ponto."

Alguns pontos que foram levantados como melhorias para serem implementadas na AWMo:

- Adicionar o atributo label nos botões de controle de fonte;

- Melhorar a descrição das ações de abrir o diagrama na lista de diagramas da página inicial.

Por fim, foi questionado se ele, como um desenvolvedor de software, teria interesse em contribuir com o projeto da AWMo, se ela fosse publicada como um projeto de código aberto:

"Eu me interessaria, achei um projeto bacana de utilizar e de colaborar."

\subsubsection{Ford}

Ford é um homem de 35 anos e atualmente é funcionário em um departamento de investimentos corporativos de uma grande instituição financeira. Ele possui glaucoma congênito e nasceu cego. Aos 20 dias de nascido, passou por uma cirurgia que restaurou $30 \%$ de sua visão. Ford viveu com baixa visão durante grande parte de sua vida, porém 
aos 30 anos de idade passou por uma crise que o deixou praticamente cego novamente. Ele é capaz de reconhecer luz e alguns objetos, mas sem formas definidas e é clinicamente considerado cego.

Ele utiliza computadores desde os 9 anos de idade quando ganhou um curso de informática que ensinava MS Logo, mas em casa ia além do conteúdo passado em aula, lendo e aprendendo sozinho e programando algoritmos de geração de números aleatórios e jogos de perguntas e respostas. Posteriormente ganhou um TK85, depois um PC e atualmente é formado em Análise de Sistemas e utiliza um Mac em casa.

Já utilizou as linguagens de programação Basic, dBase, Clipper, VB3, todas as versões de Delphi, VB6, ASP, PHP e Java. Atualmente trabalha com .NET mas disse estar sempre buscando aprender novas linguagens e tecnologias.

Para auxiliar seu uso de computadores ele utiliza o leitor de tela NVDA em $99 \%$ do tempo e ocasionalmente utiliza o alto contraste no Windows quando o leitor de tela falha em ler alguma janela, embora admita que o uso do alto contraste seja bastante raro.

Ford já teve contato com modelos da UML, entidade-relacionamento, DFDs (Data flow diagrams) nos cursos de graduação que frequentou durante a fase de sua vida em que possuía $30 \%$ de visão, portanto aprendeu UML como um vidente e por isso tem memória de como os modelos são representados visualmente e já chegou a utilizar o UML profissionalmente para documentação e comunicação entre as equipes de análise e desenvolvimento. Porém deixou de utilizar os diagramas quando perdeu a visão.

Ao ser questionado se já havia utilizado algum tipo de tecnologia assistiva para UML ele respondeu:

"Não, tecnologia assistiva não. Assim, sempre tentei imaginar alguma coisa assim, inclusive a sua ideia foi sensacional, porque foi até uma coisa que estava comentando com um colega meu, era exatamente isso, né? Pra deficientes seria muito mais fácil uma linguagem declarativa e que fizesse essa conversão, por que aí os videntes poderiam ler os modelos graficamente como eles lêem hoje e a gente teria essa facilidade porque a universidade do Paraná, teve uma aluna lá que fez um projeto sobre como ensinar UML para um deficiente visual a partir do uso de tabelas. Cara, bacana, é super bom para o lado educacional, o deficiente vai entender, mas quando ele sair para o mercado, das duas uma: ou ele vai ter que perder um tempão com alguém da equipe dele falando, cara, olha é isso, e o cara vai documentando na tabela e aí se depois tiver uma mudança de projeto, ele vai ter que ter esse trabalho, ir lá e atualizar, sendo que com uma linguagem declarativa como é o caso do seu projeto, você consegue fazer uma tradução bidirecional. Se alguém for lá na ferramenta e alterar o diagrama, automaticamente atualiza a linguagem e alterando a linguagem, já altera o diagrama. Então, quer dizer, tem uma interação muito maior e muito mais rápida, né?". 
Quando questionado sobre os principais problemas de acesso de diagramas para deficientes visuais:

“...as tecnologias assistivas hoje ainda não conseguem chegar num ponto de transformar realmente qualquer elemento da tela em algo interativo. Então se o cara que desenvolveu lá o Visio tivesse pensado que cada um dos componentes que vai no formulário tem que ter foco, tem que ter interação com o teclado, tem que ter ali um label que descreva o que é aquilo para que o NVDA, o JAWS ou qualquer outro leitor consiga interagir né, a gente não consegue.".

Durante a fase de observação foram coletados 54:14 minutos de vídeo durante o tempo em que Ford completava o conjunto de objetivos propostos por este estudo. A distribuição do tempo utilizado em cada um dos 5 objetivos pode ser vista no gráfico 5.6 .

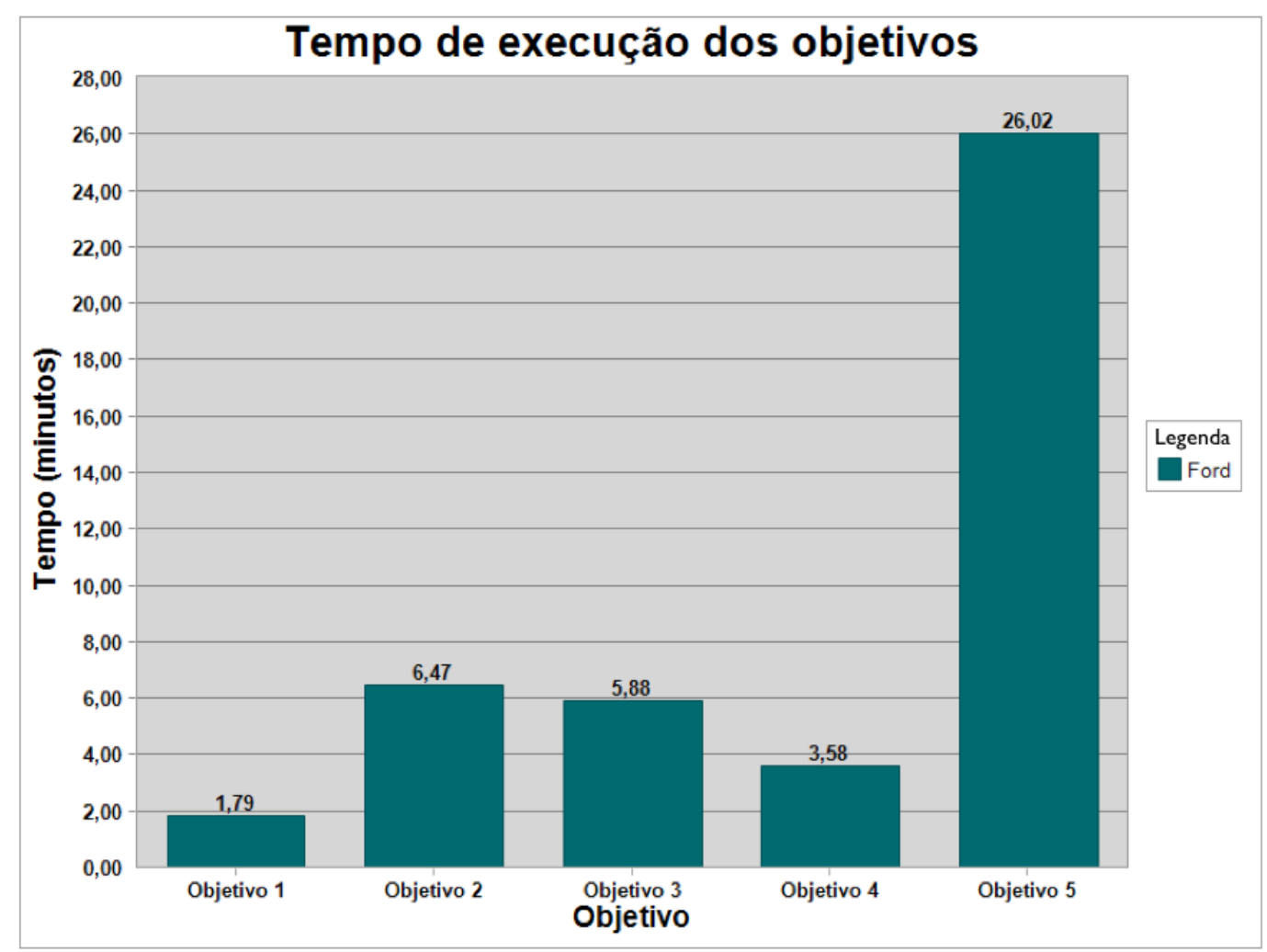

Figura 5.6: Gráfico mostrando a quantidade de tempo utilizado por Ford para completar os objetivos propostos neste estudo de caso.

Da mesma forma que ocorreu com a participação de Arthur descrita na seção anterior, Ford não necessitava de nenhuma das funcionalidades de acessibilidade da AWMo por utilizar unicamente o leitor de tela como tecnologia assistiva para a navegação em sites e aplicações $W e b$ e portanto, utilizou apenas pouco tempo para se familiarizar com a localização dos menus e outros itens da interface. 
No objetivo 2, Ford foi capaz de compreender o modelo "Sistema Bancário" rapidamente, sendo que levou 6,47 minutos para ler e explicar com suas próprias palavras o funcionamento do sistema que se encontrava modelado naquele diagrama.

No objetivo 3 era requisitado que o sujeito especializasse a classe Pessoa, existente no diagrama para tratar tanto pessoas jurídicas quanto pessoas físicas e sugeria-se utilizar o relacionamento de herança. Ford completou este objetivo muito rapidamente cometendo apenas duas falhas iguais que foi esquecer-se de adicionar os modificadores de acesso aos dois atributos da classe "PessoaJurídica" que ele havia criado. No entanto, Ford detectou a falha sozinho e as corrigiu antes de ser alertado sobre o problema pelo interpretador da linguagem textual. No total, Ford levou 5,88 minutos para completar esta tarefa.

Para completar o objetivo 4 Ford utilizou 3,58 minutos sendo que não cometeu nenhuma falha e consequentemente não houve erros. Mesmo com a questão de os métodos relacionados a poupança não estarem relacionados com a classe "Poupança" como explicado na Seção anterior, Ford encontrou e removeu os métodos "AbrirPoupança" e "FecharPoupança" que se encontravam na classe "Pessoa".

Ford encontrou maiores dificuldades no objetivo 5, ele levou um total de 26,02 minutos para completar este objetivo e cometeu 22 falhas ao longo deste tempo que resultaram em 7 retornos com mensagens de erros do interpretador. Grande parte das falhas foram erros de sintaxe como falta de modificador de acesso ou grafia incorreta de tipos básicos de dados $(81,8 \%)$ e as demais foram erros de digitação como troca de letras ou falta de espaço entre duas palavras $(18,2 \%)$. Além disso, para criar o relacionamento de composição entre as classes "Carro" e "Motor" Ford precisou consultar o manual da linguagem textual para se lembrar como esse relacionamento deveria ser declarado. O manual da linguagem estava disponível a qualquer momento na forma de um documento PDF acessível no desktop do computador em que o experimento foi executado e Ford realizou essa consulta de maneira independente, sem qualquer auxílio do pesquisador.

A Figura 5.7 mostra o número de falhas inseridas por Ford distribuídas pelos objetivos propostos e na Figura 5.8 pode-se observar que, assim como no caso de Arthur, falhas foram corrigidas em conjunto, ou seja, a cada vez que o usuário se deparava com mensagens de erros do interpretador da AWMo, mais de uma falha foi corrigida, no caso de Ford foram 3,14 falhas corrigidas em média, a cada vez que foram exibidas mensagens de erro.

Após a fase de observação, a pós-entrevista foi conduzida para entender melhor a experiência de uso da AWMo pela perspectiva de Ford. Ao falar sobre as dificuldades de uso da ferramenta, Ford disse:

"Cara, na verdade, a dificuldade foi lembrar a sintaxe, mas foi a primeira vez que eu usei, então com certeza usando isso no dia a dia se torna um pouco mais fácil. E as mensagens de erro, elas poderiam conter ali a mais, além da linha, que eu acho que facilita 


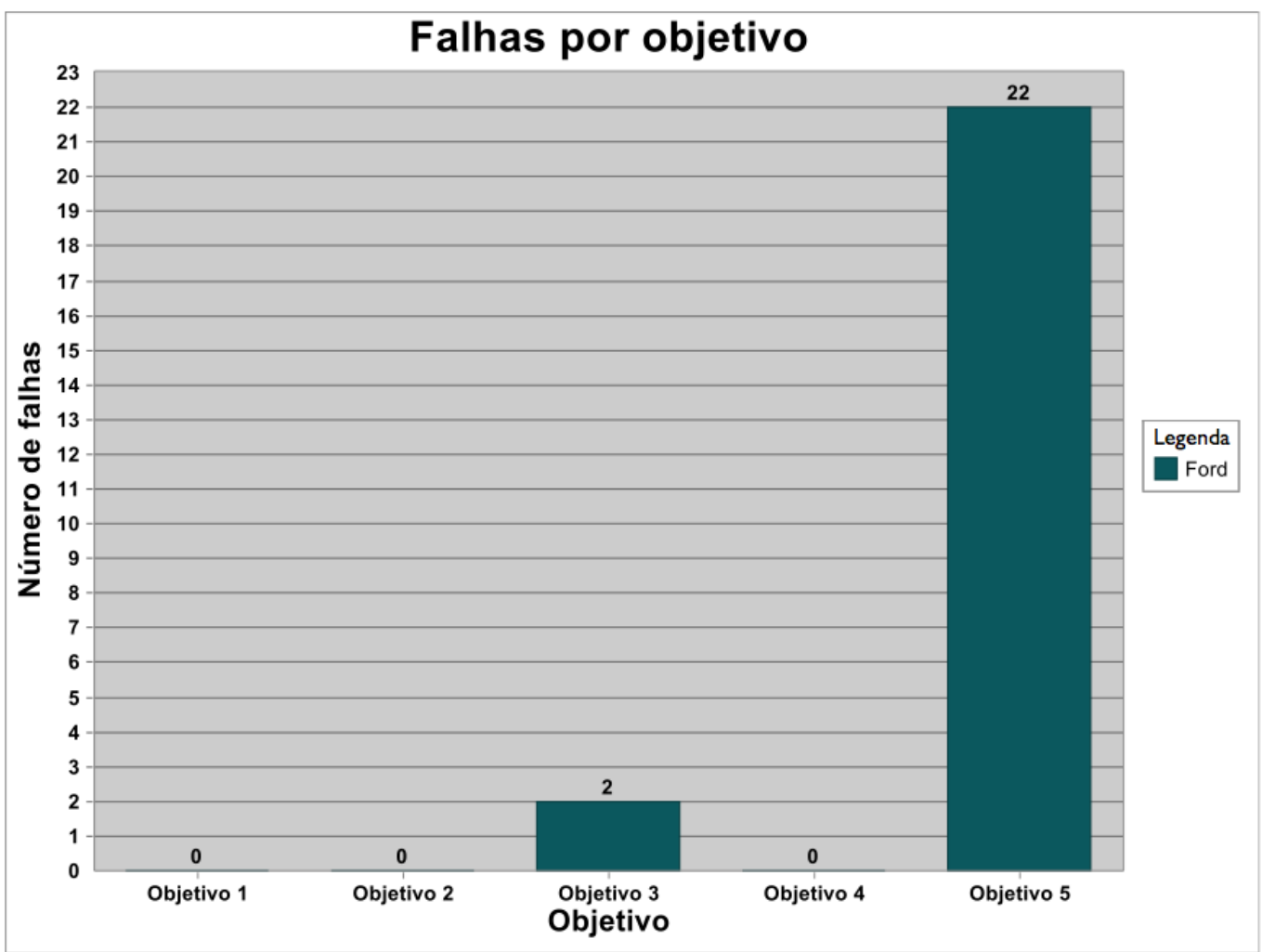

Figura 5.7: Gráfico mostrando o número de falhas inseridas por Ford ao decorrer da execução dos objetivos.

pra você chegar na linha e tudo mais. Seria alguma coisa como, por exemplo, a própria linha mesmo como algumas linguagens fazem na compilação, colocar ali um caractere do lado da onde ele acha que está o problema, né? Ou então, pelo menos a coluna, do tipo: deu problema na linha 11, coluna 5. Porque, quando ele tava lendo rápido, quando ele lia método pra mim, o cérebro tem essa mania de querer adivinhar as coisas, então existe até leitura dinâmica com leitor de tela e quando ele falava método, apesar de estar errado eu entendia certo. Foi aí que eu soletrei pra ver o que é que tava acontecendo."

Quando questionado se mudaria algo na ferramenta ou na linguagem textual Ford respondeu:

"Cara, na linguagem eu achei a estrutura bem bacana, eu achei que ficou bem legal. Porque ela segue uma linha de linguagem orientada a objetos mesmo, então por exemplo, para alguém que desenvolve com .NET hoje, com C\# ou Java, PHP ou com qualquer coisa que hoje em dia tem alguma orientação a objeto, tá bem legal mesmo, tá bem definido.E na ferramenta acho que seria o que já comentei mesmo: alguns facilitadores para a pessoa interagir mais com a sintaxe num primeiro momento, porque depois também vai ficar tão natural que ela vai indo e, por exemplo, Web, pelo menos eu nunca vi, se alguém fez isso, o cara é mais maluco do que eu imaginava, seria fazer uns auto-completes que a gente tem nas IDEs hoje..." 


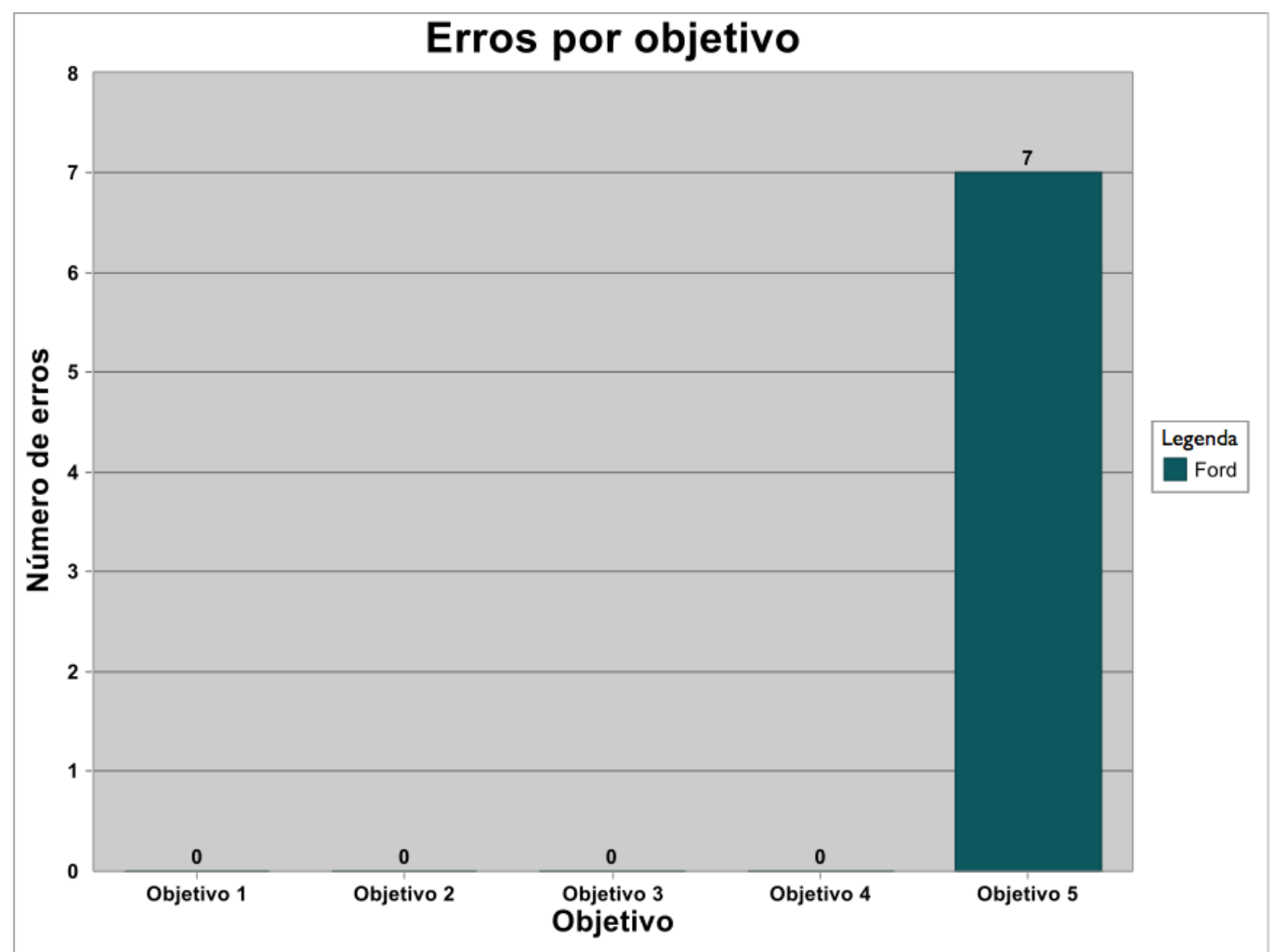

Figura 5.8: Gráfico mostrando o número de vezes em que mensagens de erro do interpretador de texto foram exibidas para Ford em cada um dos objetivos.

Além disso, sobre a questão da acessibilidade da ferramenta, Ford comentou:

“...por você ter feito ela Web, ficou muito legal porque roda em qualquer lugar, né? Isso é um diferencial bacana e o ambiente Web por si só ele já é um ambiente muito mais acessivel. Se você tivesse feito, por exemplo, quando você me falou que era em Java eu já tava imaginando a interface Swing, que é um inferno pra se configurar acessibilidade pra aquilo, não fica bom de jeito nenhum, todo ano eu sofro com aquele imposto de renda. Então, por ter feito ele em Web, você já começou com uma plataforma bem bacana e que estende muito até o próprio uso, porque, dentro de uma empresa, por exemplo, você pode ganhar algumas vantagens, como ter a instalação disso em um único servidor na empresa e a empresa inteira usar, que vai facilitar muito. Ou então, mesmo hoje em dia, né? Tá muito comum ir pra nuvem. Mas pensando no lado da acessibilidade é muito legal porque o ambiente, ele é bem acessivel."

Alguns pontos de melhoria que foram identificados foram:

- Adicionar a coluna em que ocorre o erro nas mensagens de erro do interpretador;

- Adicionar botões para auxiliar o usuário a utilizar estruturas da linguagem como relacionamentos; e 
- Utilizar WAI-ARIA para destacar as mensagens de erro e controlar melhor o foco do cursor para facilitar a navegação.

Por fim, pelo fato de Ford ser um desenvolvedor de software, foi questionado se teria interesse em contribuir para o projeto da AWMo que foi publicada como um software livre:

"Com toda certeza, com toda certeza. E acho que faltam iniciativas desse tipo e toda a iniciativa que vem tem que ser muito apoiada porque é tão difícil olharem pra gente né, que pô, você tem um trabalho de pesquisa, um trabalho de desenvolvimento. Um negócio desse open source eu seria, com certeza, um dos colaboradores, isso aí você pode contar mesmo."

\subsubsection{Análise}

As Figuras 5.9, 5.10 e 5.11 mostram os tempos utilizados, as falhas inseridas e os erros exibidos pelos participantes lado a lado. É possível ver que os comportamentos foram ligeiramente distintos. No objetivo 1 ambos fizeram tempos bastante parecidos, e ambos desempenharam a mesma tarefa: conhecer a localização dos itens de interface e se familiarizar com a AWMo, nenhuma falha ou erro foi cometida neste objetivo por nenhum dos participantes.

No objetivo 2, Ford utilizou um tempo menor, sendo 6,47 minutos contra 9,10 minutos de Arthur. Essa diferença pequena pode ser explicada pelo fato de Ford trabalhar em uma instituição financeira. Embora o sistema utilizado nesse estudo de caso seja fictício, trata-se de um modelo de um software de sistema bancário e, portanto, Ford possuía familiaridade com o assunto modelado. Um outro fator que deve ser levado em consideração é o fato que de Ford aprendeu UML enquanto possuía visão, e portanto tem uma familiaridade maior com seus conceitos do que Arthur, que só teve contato com a UML após ter perdido a visão. Novamente, nenhuma falha ou erro foi realizada neste objetivo, ambos os participantes souberam explicar bem o funcionamento do sistema modelado.

No objetivo 3, novamente Ford utilizou menos tempo e aqui a diferença entre os dois participantes foi maior, 5,88 minutos de Ford contra 15,32 minutos de Arthur. Este objetivo demandava que a classe Pessoa fosse especializada em classes para representar pessoas físicas e pessoas jurídicas. Ford cometeu um número menor de falhas do que Arthur e Ford corrigiu ambas as 2 falhas antes de salvar o diagrama, e portanto, não houve nenhum erro exibido pela AWMo. A quantidade de falhas e erros cometidos ajudam a explicar a diferença no tempo e, novamente, o fato que de Ford ter aprendido UML enquanto possuía visão pode ter influenciado. 


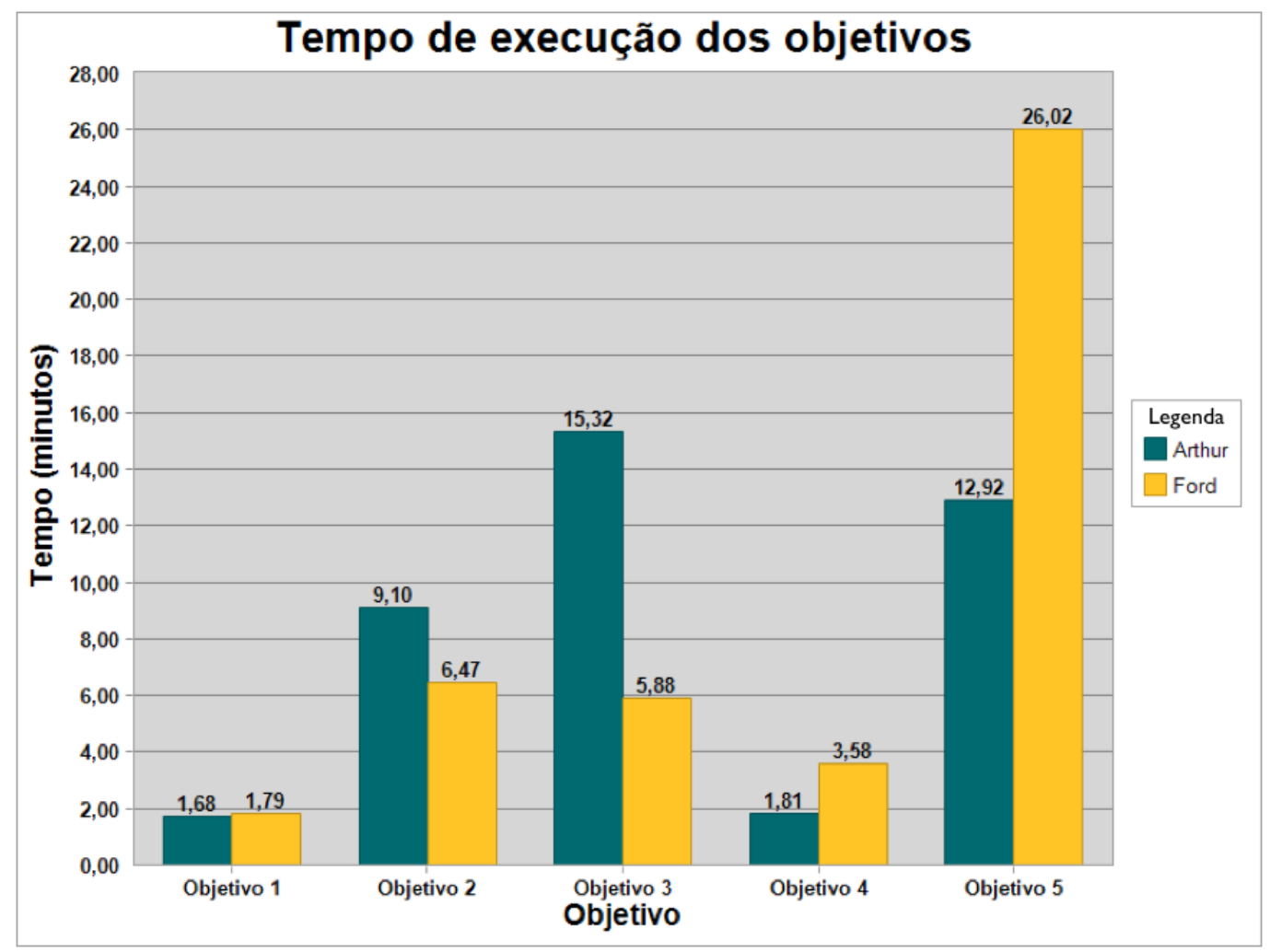

Figura 5.9: Gráfico mostrando a quantidade de tempo utilizado por cada um dos sujeitos para completar os objetivos propostos neste estudo de caso.

No objetivo 4, por outro lado, Ford levou um tempo maior do que Arthur, pois ele removeu os métodos "AbrirPoupança" e "FecharPoupança" que embora não tivessem nenhuma relação sintática direta com a classe poupança que pudesse ser apontada pelo interpretador. Portanto, embora Ford tenha levado mais tempo, é possível afirmar que o resultado obtido por ele foi melhor do que o que foi obtido por Arthur sob uma análise mais minuciosa. Como o critério de sucesso definido foi a ação de salvar o diagrama, ambos os participantes obtiveram sucesso no desempenho do objetivo. No entanto, sob uma análise mais criteriosa é possível afirmar que o resultado obtido por ele foi melhor do que o obtido por Arthur, o que torna inconclusiva a análise da diferença entre os tempos utilizados. Nenhum dos participantes cometeram erros ou falhas.

Por fim, no objetivo 5 nota-se uma maior discrepância entre os resultados. Assim como nos outros casos, ambos os participantes foram capazes de concluir o objetivo com sucesso. No entanto, Ford levou 26,02 minutos para completar o objetivo enquanto Arthur levou apenas 12,92 minutos, ou seja, o tempo de Ford foi 2 vezes maior. Na Figura 5.10 podemos ver que Ford inseriu 22 falhas ao longo da execução do objetivo 5, enquanto Arthur inseriu apenas 7, novamente o número de falhas inseridas por Ford foi cerca de 3 vezes maior e, consequentemente, o número de erros vistos na Figura 5.11 também foi maior: 7 de Ford contra 3 de Arthur. 


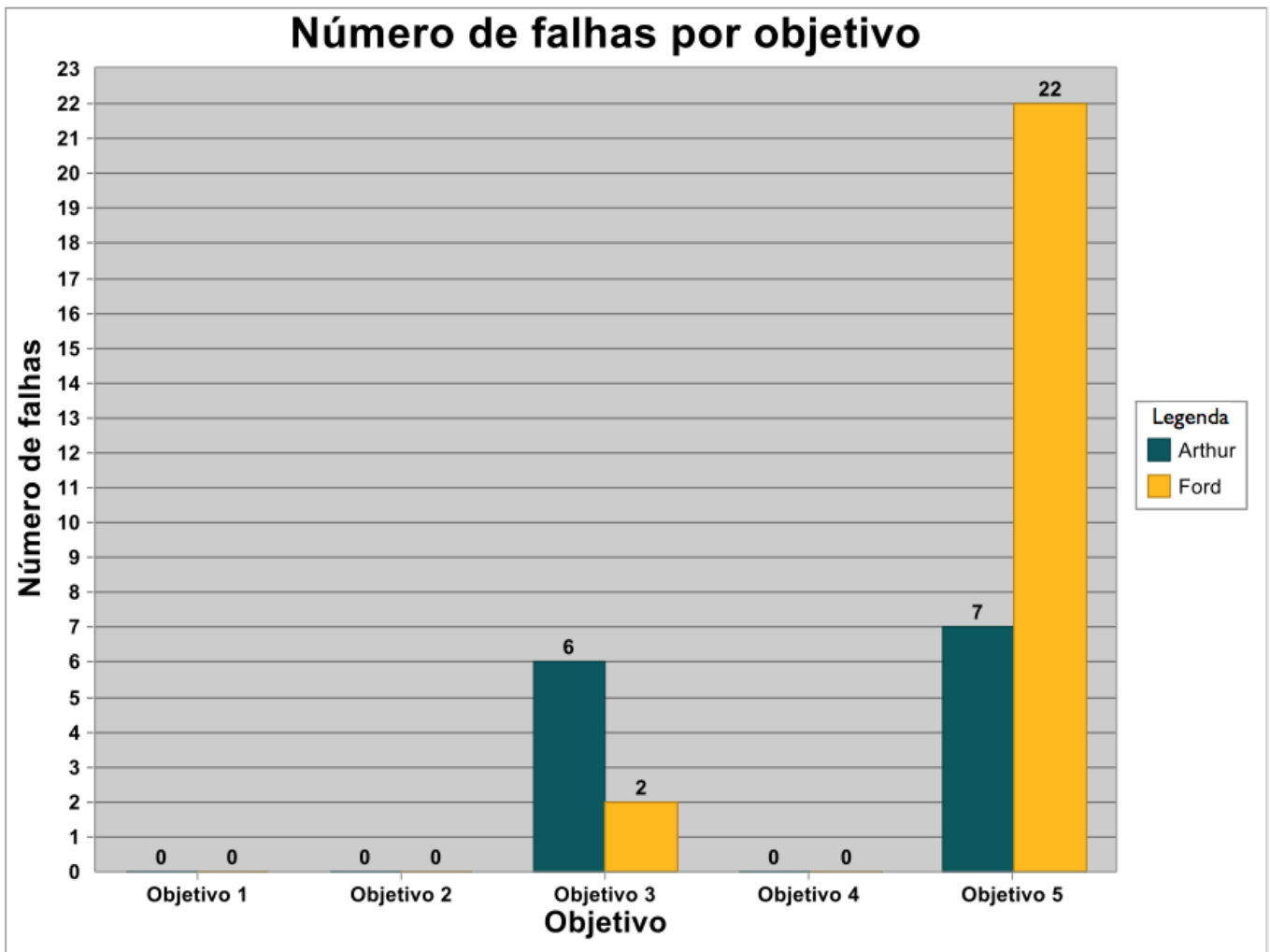

Figura 5.10: Gráfico mostrando o número de falhas inseridas por Arthur e Ford ao decorrer da execução dos objetivos.

O objetivo 5 exigia que os participantes criassem um modelo totalmente novo a partir de especificações simples fornecidas nas instruções do objetivo e, portanto, era necessário que o participante tivesse maior domínio sobre a linguagem textual da AWMo. Em comparação com os objetivos anteriores, quando se está alterando um modelo pré-existente, é mais fácil encontrar exemplos das estruturas da linguagem no próprio modelo em que se está trabalhando, ao passo que para se construir um modelo totalmente novo é necessário lembrar melhor das estruturas da linguagem textual ou utilizar o manual da linguagem para consulta.

As Tabelas 5.3 e 5.4 mostram uma categorização das falhas inseridas por ambos os participantes durante a execução dos objetivos propostos por este estudo de caso. Para tal, foram definidas as seguintes categorias de falhas:

- Gramatical: ocasiões nas quais o participante errou palavras reservadas e tipos de dados ou utilizou incorretamente estruturas da linguagem.

- Lógica: ocasiões nas quais o modelo ou o objeto modelado não tem sentido lógico ou difere do resultado que se pretendia alcançar.

- Digitação: ocasiões nas quais o participante cometeu um erro de digitação, seja troca, ausência ou excesso de caracteres. 


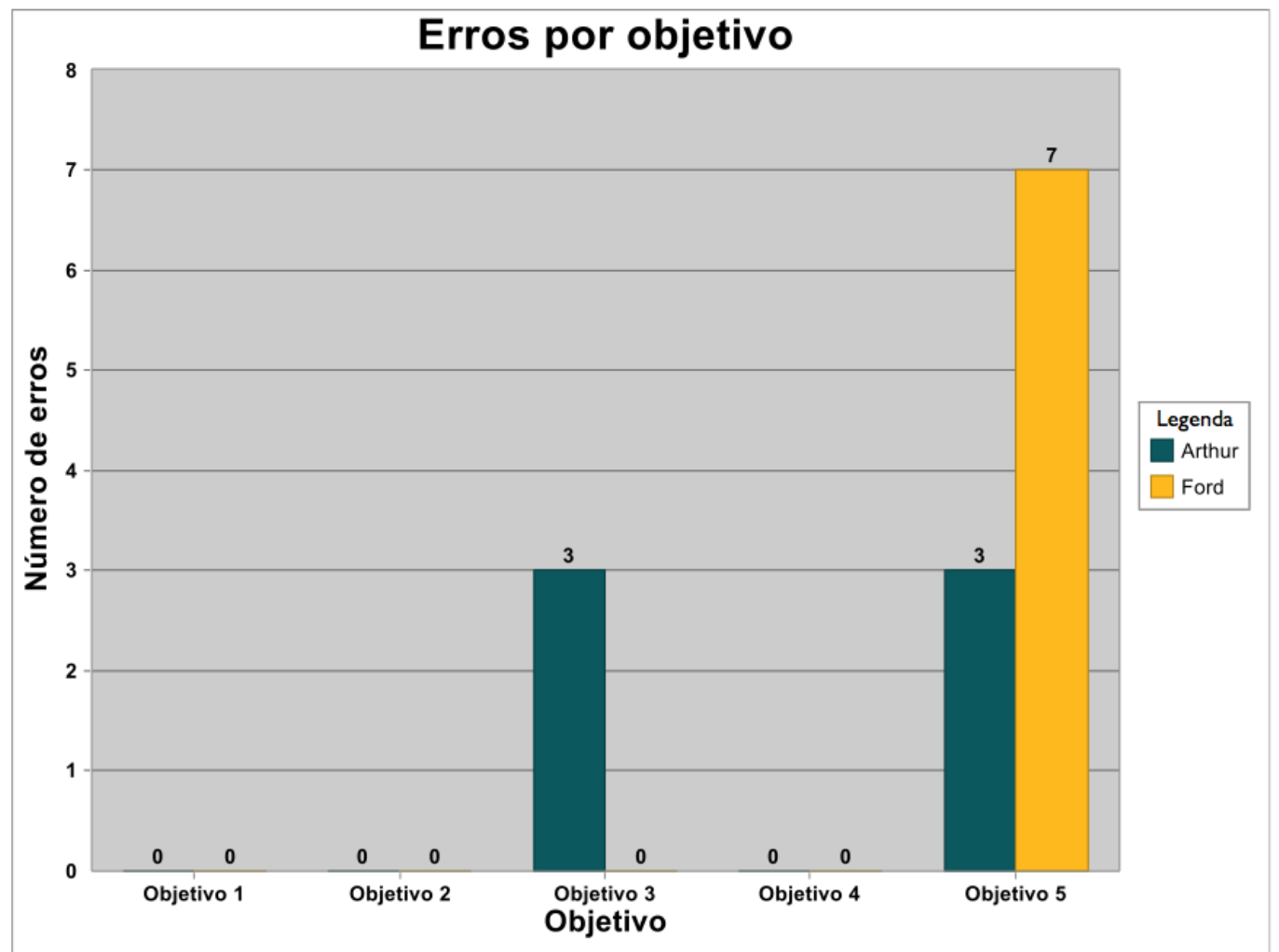

Figura 5.11: Gráfico mostrando o número de vezes em que mensagens de erro do interpretador de texto foram exibidas para os sujeitos em cada um dos objetivos.

Nota-se que nenhuma falha de lógica foi cometida, não houve nenhuma construção incorreta dos modelos e, como já citado, os participantes concluíram com sucesso os objetivos propostos. A Figura 5.12 mostra alguns gráficos para efeitos de comparação entre essas falhas. Podemos ver que no caso de Arthur, a maior parte das falhas foi de digitação, representando $62 \%$ de todas as falhas cometidas por ele. Esse dado reforça o fato observado por meio dos vídeos de que Arthur encontrou dificuldades em se adaptar ao teclado do notebook no qual foi conduzido o estudo de caso.

Já no caso de Ford, a quantidade de falhas de digitação foi bem menor, proporcionalmente à quantidade de falhas gramaticais, sendo que apenas $17 \%$ das falhas foram de digitação contra $83 \%$ de falhas gramaticais. Este número elevado de falhas, principalmente no objetivo 5 como mostra a Figura 5.12(b), mostra que o participante teve bastante dificuldade com as palavras chave e estruturas de linguagem textual. Grande parte dessas falhas foi esquecimento de modificador de acesso, que define se um método ou atributo é público ou privado e outro problema bastante recorrente foi a troca do tipo de dado "boolean" por "bool". Ambos são erros de baixa gravidade, e indicam apenas falta de familiaridade com a linguagem textual. Tanto pela observação quanto pelos dados coletados durante as entrevistas, não houve indícios de problemas graves ou dificuldades maiores relacionadas à linguagem textual. 
Tabela 5.3: Categorização das falhas inseridas por Arthur ao longo do estudo.

\begin{tabular}{cccl}
\hline Objetivo & Tempo & Tipo & Observação \\
\hline \multirow{3}{*}{3} & $00: 21: 48$ & Digitação & Buscando tecla de atalho \\
\cline { 2 - 4 } & $00: 21: 56$ & Digitação & Apagou a quebra de linha \\
\cline { 2 - 4 } & $00: 23: 25$ & Digitação & Buscando tecla, apagou espaço \\
\cline { 2 - 4 } & $00: 25: 54$ & Digitação & Faltou espaço entre palavras \\
\cline { 2 - 4 } & $00: 27: 19$ & Digitação & Pressionou seta para cima acidentalmente \\
\cline { 2 - 4 } & $00: 28: 38$ & Gramatical & Tipo básico com letra maiúscula \\
\hline \multirow{5}{*}{5} & $00: 41: 46$ & Gramatical & Faltou modificador de acesso do método \\
\cline { 2 - 4 } & $00: 42: 23$ & Gramatical & Faltou modificador de acesso do método \\
\cline { 2 - 4 } & $00: 42: 48$ & Digitação & Faltou espaço entre palavras \\
\cline { 2 - 4 } & $00: 44: 14$ & Digitação & Pressionou "Page Up" junto com "Enter" \\
\cline { 2 - 4 } & $00: 46: 02$ & Digitação & Pressionou seta para cima acidentalmente \\
\cline { 2 - 4 } & $00: 46: 04$ & Gramatical & Referência à classe com case diferente \\
\cline { 2 - 4 } & $00: 46: 15$ & Gramatical & Referência à classe com case diferente \\
\hline \multirow{2}{*}{} & & &
\end{tabular}

Para ambos os participantes, o objetivo 5 foi o que gerou mais falhas do tipo gramatical em função da tarefa de construção de um modelo novo, escrito inteiramente pelos participantes. 
Tabela 5.4: Categorização das falhas inseridas por Ford ao longo do estudo.

\begin{tabular}{cccl}
\hline Objetivo & Tempo & Tipo & Observação \\
\hline \multirow{3}{*}{3} & $00: 18: 04$ & Gramatical & Faltou modificador de acesso do atributo \\
\cline { 2 - 4 } & $00: 18: 29$ & Gramatical & Faltou modificador de acesso do atributo \\
\hline & $00: 28: 36$ & Gramatical & Faltou modificador de acesso do atributo \\
\hline $00: 28: 48$ & Gramatical & Faltou modificador de acesso do atributo \\
\hline $00: 29: 13$ & Gramatical & Trocou boolean por bool \\
\hline $00: 29: 20$ & Gramatical & Faltou modificador de acesso do método \\
\hline $00: 29: 26$ & Gramatical & Trocou boolean por bool \\
\hline $00: 29: 35$ & Gramatical & Faltou modificador de acesso do método \\
\hline $00: 29: 39$ & Gramatical & Trocou boolean por bool \\
\hline $00: 29: 44$ & Digitação & Escreveu "mrtodo" ao invés de "método" \\
\hline $00: 29: 50$ & Gramatical & Faltou modificador de acesso do atributo \\
\hline $00: 29: 52$ & Gramatical & Trocou boolean por bool \\
\hline $00: 30: 29$ & Digitação & Faltou espaço entre palavras \\
\hline $00: 30: 56$ & Gramatical & Faltou modificador de acesso do método \\
\hline $00: 31: 00$ & Gramatical & Trocou boolean por bool \\
\hline $00: 31: 08$ & Gramatical & Faltou modificador de acesso do método \\
\hline $00: 31: 11$ & Gramatical & Trocou boolean por bool \\
\hline $00: 31: 22$ & Gramatical & Faltou modificador de acesso do método \\
\hline $00: 31: 24$ & Gramatical & Trocou boolean por bool \\
\hline $00: 31: 27$ & Digitação & Faltou espaço entre palavras \\
\hline $00: 31: 29$ & Gramatical & Faltou modificador de acesso do método \\
\hline $00: 31: 31$ & Gramatical & Trocou boolean por bool \\
\hline $00: 32: 51$ & Gramatical & Faltou palavra-chave "relacao" \\
\hline $00: 35: 20$ & Digitação & Escreveu "booeanl" ao invés de "boolean" \\
\hline
\end{tabular}




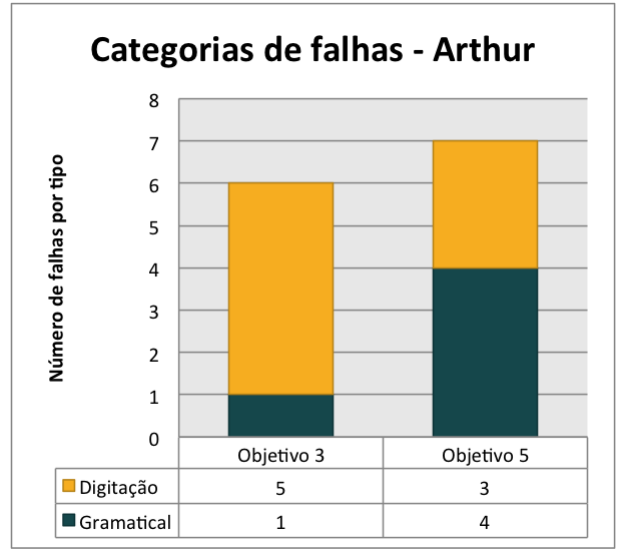

(a)

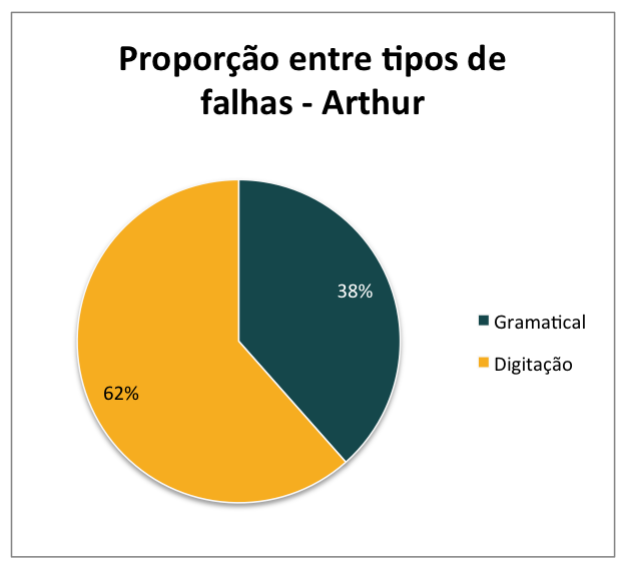

(c)

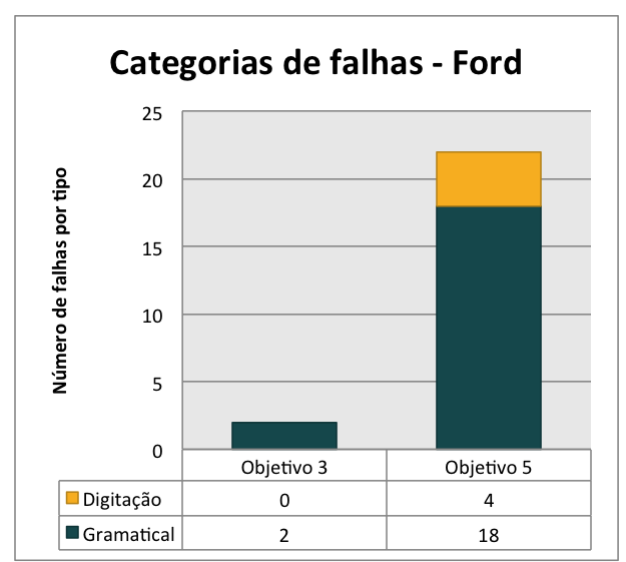

(b)

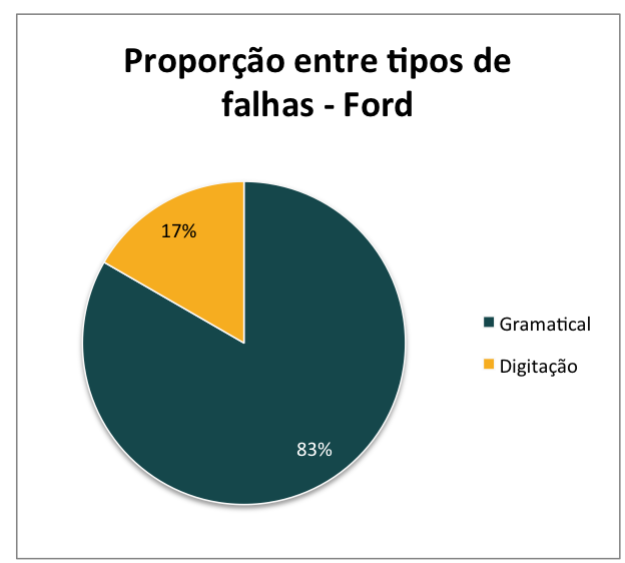

(d)

Figura 5.12: Gráficos ilustrando a categorização das falhas exibidas nas Tabelas 5.3 e 5.4 sendo: (a) - quantidade de falhas de Arthur em cada categoria e separadas por objetivo, (b) - quantidade de falhas de Ford em cada categoria e separadas por objetivo, (c) - proporção entre as categorias das falhas cometidas por Arthur e (d) - proporção entre as categorias das falhas cometidas por Ford. 


\subsection{Considerações finais}

Levando-se em consideração que os objetivos utilizados na fase de observação não foram demasiadamente complexos, mas similares a tarefas as quais um desenvolvedor de software pode encontrar ao trabalhar com diagramas de classe da UML em projetos reais, foi possível ver que no objetivo 3, por exemplo, Arthur levou 15,32 minutos e Ford levou 5,88 minutos para completá-la, sendo que foi necessária a modificação de uma classe e criação de duas outras com relação de herança com a primeira. Isso representa um tempo pequeno, principalmente se levarmos em consideração que ambos tiveram o primeiro contato com o diagrama durante a realização do objetivo 2, por cerca de 9 (Arthur) e 6 (Ford) minutos apenas.

O mesmo pode ser observado no objetivo 5, no qual os participantes precisaram criar um modelo completamente novo a partir de especificações simples fornecidas pelas instruções do objetivo. Considerando que ambos estavam tendo seu primeiro contato com a AWMo e lendo as instruções do objetivo pela primeira vez, Arthur levou menos de 13 minutos para criar o novo diagrama, abrí-lo na visão textual e modelá-lo de acordo com as especificações e Ford levou cerca de 26 minutos. Apesar da diferença entre os tempos dos dois participantes, acreditamos fortemente que a abordagem utilizada pela AWMo para modelagem de software traz pouca sobrecarga de trabalho ou aumento no tempo utilizado na atividade de modelagem, enquanto traz o benefício de que, uma vez que o modelo seja criado com uso da linguagem textual como feito pelos participantes, a representação gráfica está automaticamente pronta para ser utilizada por usuários com visão.

No caso específico de Ford, que levou um tempo maior, o próprio participante comentou sobre isso em alguns trechos extraídos da pós-entrevista:

"Cara, na verdade, a dificuldade foi lembrar a sintaxe, mas foi a primeira vez que eu usei, então com certeza usando isso no dia a dia se torna um pouco mais fácil. E as mensagens de erro, elas poderiam conter ali a mais, além da linha, que eu acho que facilita pra você chegar na linha e tudo mais. Seria alguma coisa como, por exemplo, a própria linha mesmo como algumas linguagens fazem na compilação, colocar ali um caractere do lado da onde ele acha que está o problema, né?"

“... a maior dificuldade que a pessoa vai sentir sinceramente, se é uma pessoa que usa a Web, é lembrar da sua sintaxe. Como eu disse, depois de dois ou três diagramas que a pessoa fizer, isso vai tá tão natural pra ela, que não vai sentir diferença, mas acho que num primeiro momento você ter ali os atalhos já ajudaria, já seria um facilitador pelo menos, ao invés dele ter que recorrer ao manual ele dá um "enterzinho" ali e já insere" 
Nota-se que, embora a quantidade de falhas gramaticais tenha sido alta, o próprio participante acredita que esse fato ocorreu devido à falta de prática com a linguagem, tanto que quando questionado se mudaria algo na estrutura da linguagem respondeu:

"Cara, na linguagem eu achei a estrutura bem bacana, eu achei que ficou bem legal. Porque ela segue uma linha de linguagem orientada a objetos mesmo, então por exemplo, para alguém que desenvolve com. NET hoje, com C\# ou Java, PHP ou com qualquer coisa que hoje em dia tem alguma orientação a objeto, tá bem legal mesmo, tá bem definido."

Portanto, o processo de modelagem por meio da linguagem textual da AWMo se mostrou eficaz para permitir o acesso e edição para modelos de classe da UML. Isso indica que a AWMo se mostra como uma opção viável para facilitar o acesso de desenvolvedores de software deficientes visuais a modelos de software e promover a colaboração e comunicação efetiva e de maneira independente entre usuários com e sem visão para atividades de modelagem de software, como mencionado pelos próprios participantes ao longo das entrevistas.

Além disso, tanto pelas informações coletadas nas entrevistas, quanto ao analisar a eficiência com que os participantes utilizaram a linguagem textual, é possível ver que a linguagem em si não se apresentou como uma barreira para a utilização da abordagem proposta pela AWMo. Embora exista espaço para melhorias, com pouco tempo de estudo independente, utilizando apenas uma apostila em PDF fornecida pelo pesquisador, os participantes foram capazes de aprender a linguagem textual e utilizá-la de maneira eficaz durante todos os objetivos propostos neste estudo. 



뭉

\section{Conclusões e trabalhos futuros}

\subsection{Considerações Iniciais}

Neste trabalho, o principal objetivo proposto foi o desenvolvimento de uma técnica textual para manipulação de diagramas por deficientes visuais.

Os estudos realizados sobre acessibilidade e MDD foram muito importantes para o andamento do projeto, fundamentando a teoria e fornecendo ferramentas para apoiar o bom desenvolvimento da pesquisa.

Os estudos sobre MDD permitiram conhecer em detalhes as principais abordagens de MDD existentes, o que possibilitou a escolha da abordagem Eclipse para auxiliar o desenvolvimento da AWMo, principalmente o projeto Xtext, que viabilizou a utilização da abordagem proposta por permitir a criação de uma linguagem textual, tornando possível a interação de deficientes visuais. Esses estudos também foram importantes para conhecer as principais ferramentas de apoio existentes para desenvolvimento orientado a modelos, o que auxiliou nas definições das funcionalidades para a AWMo, bem como as prioridades de desenvolvimento.

Os estudos sobre acessibilidade na $W e b$ permitiram conhecer os principais esforços do W3C, por meio da Web Accessibility Initiative para melhorar a acessibilidade de Web como um todo e mostraram que o tema é também uma preocupação crescente do governo em sua busca por possibilitar o acesso a uma vida independente para todos os cidadãos. Além disso, estes estudos permitiram ao aluno construir um protótipo acessível e ainda, colaborar com melhorias de acessibilidade para a interface da arquitetura de referência utilizada pela AWMo. 
As disciplinas cursadas durante o mestrado, tais como Metodologia de pesquisa e Tópicos em Hipermídia também colaboraram para o embasamento teórico e desenvolvimento técnico deste trabalho.

\subsection{Contribuições}

Um protótipo da ferramenta AWMo foi desenvolvido utilizando uma abordagem textual para interação com um subconjunto dos diagramas de classe da UML e com a capacidade de converter automaticamente o conteúdo textual em diagrama gráfico e vice-versa.

Com o protótipo em mãos, um estudo de caso foi conduzido com dois participantes para avaliar se a técnica proposta seria capaz de permitir o acesso de edição e visualização a modelos de software para deficientes visuais. Os resultados do estudo mostraram que o protótipo proposto não apenas permitiu o acesso desses usuários aos modelos, como os participantes acreditam que a interação com o texto seja, de fato, a melhor forma de fazê-lo. A linguagem textual desenvolvida não se apresentou como uma barreira para a utilização da abordagem e, além disso, os próprios participantes acreditam que as poucas dificuldades encontradas devem-se principalmente à falta de prática com o uso da linguagem, que foi aprendida por eles de maneira independente, utilizando um manual em PDF fornecido pelo autor.

Durante o desenvolvimento do mestrado, os resultados foram publicados nos seguintes artigos científicos:

- Artigo publicado no Workshop on Graphical Modeling Language Development (GMLD) na $8^{\text {th }}$ European Conference on Modelling Foundations and Applications (ECMFA) 2012: Towards Collaboration between sighted and visually impaired developers in the context of Model-Driven Engineering [25].

- Artigo publicado no workshop Rethinking Universal Accessibility: A broader approach considering the digital gap - INTERACT 2013: Creating a project towards universal access: is it possible? [17].

- Artigo publicado no XII Workshop on Tools and Applications - WebMedia 2013: AWMo: Accessible Web Modeler [22].

- Artigo publicado no evento Software Development and Technologies for Enhancing Accessibility and Fighting Info-exclusion - DSAI 2013: Accessible modeling on the Web: a case study [26]. 
- Artigo aceito para publicação no $16^{\text {th }}$ International Conference on Human-Computer Interaction - HCII 2014: Tests with blind programmers using AWMo: an accessible web modeling tool.

Além disso, os dados completos do estudo de caso, incluindo seu protocolo, resultados e transcrições das entrevistas foram publicados como Notas do ICMC-USP, Série Computação:

- Notas do ICMC-USP. Série Computação. Número 96: Estudo de caso Modelagem de software acessivel na Web [24].

Um manual técnico e operacional da AWMo também foi publicado no ICMC-USP na forma de um relatório técnico com informações sobre instalação, uso e um guia sobre como contribuir com o projeto:

- Relatórios Técnicos do ICMC-USP. Número 397: AWMo: Accessible Web Modeler - Manual técnico e operacional [23].

Por fim, o código da ferramenta AWMo foi disponibilizado como software livre sob a licença $\mathrm{BSD}^{1}$ e se encontra disponível no GitHub: https://github.com/awmo/awmo.

\subsection{Premiação da ferramenta AWMo}

Um resultado bastante relevante obtido pela AWMo foi a obtenção do segundo lugar na segunda edição do Todos@Web - Prêmio Nacional de Acessibilidade na Web, em 2013, organizado pela W3C Brasil, NIC.br e CGI.br.

Em sua segunda edição, a organização concedeu prêmios para as seguintes categorias: Pessoas / Instituições, Projetos Web (Governamentais, Serviços / E-commerce e Instituições / Entretenimento / Cultura / Educação / Blogs) e Aplicações e Tecnologias Assistivas. A AWMo foi inscrita na categoria Aplicações e Tecnologias Assistivas.

Ao todo, esta edição do Todos@Web recebeu 66 inscrições, um aumento de 40\% em relação à edição anterior, ocorreu no dia 3 de Dezembro, Dia Internacional da Pessoa com Deficiência e foi realizado no Memorial da Inclusão² em São Paulo.

Como premiação o projeto recebeu o valor de $\mathrm{R} \$ 3.000,00$, um troféu e a exposição permanente do trabalho em publicação do W3C [42].

Além disso, a premiação teve boa repercussão na mídia, o que contribui para aumentar a consciência da população em relação à necessidade de investimentos em pesquisas e importância da área.

\footnotetext{
${ }^{1}$ http://opensource.org/licenses/BSD-3-Clause

${ }^{2}$ http://www.memorialdainclusao.sp.gov.br
} 


\subsection{Limitações}

Durante o desenvolvimento deste trabalho buscou-se seguir o rigor científico a todo momento, no entanto, existem algumas limitações que derivam do escopo da proposta, tempo para realização, metodologia utilizada e por outras variáveis.

No desenvolvimento do protótipo, em função de problemas técnicos que levaram muito tempo para ser resolvidos, não foi possível finalizar o desenvolvimento da interface gráfica da AWMo a tempo para a execução dos estudos de caso. Por esse motivo, optou-se por finalizar apenas a interface textual que é a principal inovação da abordagem proposta.

Por fim, na condução do estudo de caso, um das principais limitações foi a quantidade de participantes com os quais o estudo foi conduzido e as métricas extraídas. Por se tratar de um grupo bastante restrito de usuários, foi bastante difícil encontrar participantes e o número reduzido destes faz com que seja mais difícil extrapolar os resultados para um público maior.

\subsection{Trabalhos futuros}

A realização deste trabalho criou diversas possibilidades para a realização de trabalhos futuros que continuem esta pesquisa. Entre elas, podemos destacar:

- Finalização da interface gráfica: finalizar o desenvolvimento da visão gráfica da AWMo, isso permitirá que novos estudos sejam realizados com a participação de usuários com e sem deficiências visuais.

- Expandir o estudo de caso: o estudo de caso pode ser executado com mais sujeitos a fim de aumentar sua confiabilidade e abrangência. Além disso, uma vez que a interface gráfica seja finalizada, novos experimentos podem ser planejados para avaliar a interface gráfica e o uso da AWMo por usuários com visão.

- Integração abordagem com IDEs tradicionais: um ponto que foi levantado tanto pelos participantes do estudo de caso quanto pelos membros do júri avaliador do prêmio Todos@Web é a integração da ferramenta com IDEs de desenvolvimento tais como o Eclipse e o NetBeans. Isso tornaria o uso da abordagem mais simples por fazer parte das ferramentas de trabalho que seus potenciais usuários já estão habituados. Uma possibilidade seria a integração de modo que a aplicação Web atue como um hub central em que todas as informações ficam armazenadas, porém as IDEs possam acessá-las por meio de uma API. 
- Explorar novas interfaces: do ponto de vista técnico, a AWMo possui uma arquitetura bastante flexível que permite que futuros colaboradores desenvolvam novas formas de visualização e edição de modelos sem afetar os que já existem. Uma dessas possíveis formas de visualização, é uma representação em HTML, utilizando links para melhorar a navegação do usuário no conteúdo do modelo durante sua leitura e permitindo que a leitura possa ser realizada de maneira não linear.

À luz das possibilidades descritas acima, a AWMo foi disponibilizada como uma ferramenta open source e um manual técnico foi publicado para atrair futuros desenvolvedores que possam vir a contribuir com a ferramenta. 



\section{Referências}

[1] Lei 10.098, de 19 Dezembro de 2000. Estabelece normas gerais e critérios básicos para a promoção da acessibilidade das pessoas portadoras de deficiência ou com mobilidade reduzida, e dá outras providências. Diário Oficial [da] República Federativa do Brasil, p. 2 - 3, n. 244, Seção 1, ISSN 1415-1537, 2000.

[2] Decreto $\mathrm{N}^{o}$ 5.296, de 2 de Dezembro de 2004. Regulamenta as Leis n. 10.048, de 8 de Novembro de 2000, que dá prioridade de atendimento às pessoas que especifica, e 10.098, de 19 de Dezembro de 2000, que estabelece normas gerais e critérios básicos para a promoção da acessibilidade das pessoas portadoras de deficiência ou com mobilidade reduzida, e dá outras providências. Diário Oficial [da] República Federativa do Brasil, p. 5 - 10, n. 232, Seção 1, ISSN 1677-7042, 2004.

[3] Decreto $\mathrm{N}^{o}$ 6.949, de 15 de Agosto de 2009. Promulga a Convenção Internacional sobre os Direitos das Pessoas com Deficiência e seu Protocolo Facultativo, assinados em Nova York, em 30 de Março de 2007. Diário Oficial [da] República Federativa do Brasil, p. 3, n. 163, Seção 1, ISSN 1677-7042, 2004.

[4] Portaria $\mathrm{N}^{o}$ 3, de 7 de maio de 2007. Institucionaliza o Modelo de Acessibilidade em Governo Eletrônico - e-MAG no âmbito do Sistema de Administração dos Recursos de Informação e Informática - SISP. Diário Oficial [da] República Federativa do Brasil, p. 103, n. 87, Seção 1, ISSN 1677-7042, 2007.

[5] Decreto Legislativo $N^{o} 186$, de 2008. Aprova o texto da Convenção sobre os Direitos das Pessoas com Deficiência e de seu Protocolo Facultativo, assinados em Nova Iorque, em 30 de Março de 2007. Diário Oficial [da] República Federativa do Brasil, p. 1, n. 131, Seção 1, ISSN 1677-7042, 2008. 
[6] Allaire, J. Macromedia Flash MX - A next-generation rich client. Disponível em http://download.macromedia.com/pub/flash/whitepapers/richclient.pdf. Acesso em 16/01/2012, 2002.

[7] Ambler, S. Agile model driven development is good enough. Software, IEEE, v. 20, n. 5 , p. $71-73,2003$.

[8] Babcock, C. Five questions for Peter Lundblad, Google programmer. Information Week, disponível em http://www.informationweek.com/news/193100330. Acesso em 08/02/2014, 2006 .

[9] Bergsten, H. Javaserver faces. O'Reilly Media, Inc., 2004.

[10] Chen, Z.; Marx, D. Experiences with Eclipse IDE in programming courses. $J$. Comput. Small Coll., v. 21, p. 104-112, 2005.

[11] Cohen, R. F.; Meacham, A.; Skaff, J. Teaching graphs to visually impaired students using an active auditory interface. SIGCSE Bull., v. 38, p. 279-282, 2006.

[12] Cook, A. M.; Polgar, J. M. Cook and hussey's assistive technologies: principles and practice. Elsevier Health Sciences, 2013.

[13] Crane, D.; Pascarello, E.; James, D. Ajax in action. Manning Publications, 1st edition, ISBN 1-932394-61-3, 2006.

[14] Davis, J. GME: the Generic Modeling Environment. In: Companion of the 18th annual ACM SIGPLAN Conference on Object-oriented Programming, Systems, Languages, and Applications (OOPSLA '03), New York, NY, USA: ACM, 2003, p. 82-83.

[15] Eysholdt, M.; Behrens, H. Xtext: implement your language faster than the quick and dirty way. In: Proceedings of the ACM International Conference Companion on Object-oriented Programming Systems Languages and Applications companion (SPLASH '10), New York, NY, USA: ACM, 2010, p. 307-309.

[16] Farwick, M.; Agreiter, B.; White, J.; Forster, S.; Lanzanasto, N.; Breu, R. A Web-based collaborative metamodeling environment with secure remote model access. In: Proceedings of the 10th International Conference on Web Engineering (ICWE'10), Berlin, Heidelberg: Springer-Verlag, 2010, p. 278-291.

[17] Fortes, R. P. M.; Dias, A. L.; Grillo, F. D. N.; Masiero, P. C. Creating a project towards universal access: is it possible? In: Proceedings of INTERACT 2013 Workshop on Rethinking Universal Accessibility: A broader approach considering the 
digital gap, Cape Town (South Africa): INTERACT 2013 Workshop on Rethinking Universal Accessibility: A broader approach considering the digital gap, 2013.

[18] Fowler, M. Patterns of enterprise application architecture. Addison-Wesley Longman Publishing Co., Inc., 2002.

[19] Freire, A. P.; Linhalis, F.; Bianchini, S. L.; Fortes, R. P.; da Graça C. Pimentel, M. Revealing the whiteboard to blind students: An inclusive approach to provide mediation in synchronous e-learning activities. Computers $\&$ Education, v. 54, n. 4, p. $866-876,2010$.

[20] Garcia, V. Censo IBGE na contramão da inclusão. Disponível em http://www . deficienteciente.com.br/2011/08/censo-ibge-na-contramao-da-inclusao. html Último acesso: 22/01/2012, 2011.

[21] Greenfield, J.; Short, K. Software factories: assembling applications with patterns, models, frameworks and tools. In: Companion of the 18th annual ACM SIGPLAN Conference on Object-oriented Programming, Systems, Languages, and Applications (OOPSLA '03), New York, NY, USA: ACM, 2003, p. 16-27.

[22] Grillo, F. D. N.; Fortes, R. P. M. AWMo: Accessible Web Modeler. In: WebMedia '13: XII Workshop on Tools and Applications (WFA), 19th Brazilian Symposium on Multimedia and the Web, 2013.

[23] Grillo, F. D. N.; Fortes, R. P. M. Awmo: Accessible web modeler. manual técnico e operacional. Relatórios Técnicos do ICMC-USP. 397, Instituto de Ciências Matemáticas e de Computação, Universidade de São Paulo, 2014.

[24] Grillo, F. D. N.; Fortes, R. P. M. Estudo de caso - modelagem de software acessivel na web. Notas do ICMC-USP. Série Computação. 96, Instituto de Ciências Matemáticas e de Computação, Universidade de São Paulo, 2014.

[25] Grillo, F. D. N.; Fortes, R. P. M.; Lucrédio, D. Towards collaboration between sighted and visually impaired developers in the context of model-driven engineering. In: Workshop GMLD (on Graphical Modeling Language Development). Joint Proceedings, 8th European Conference on Modelling Foundations and Applications (ECMFA 2012), Copenhagen: Technical University of Denmark - DTU Informatics, 2012, p. 241-251.

[26] Grillo, F. D. N.; de Mattos Fortes, R. P. Accessible modeling on the web: A case study. Procedia Computer Science, v. 27, n. 0, p. 460 - 470, 5th International Conference on Software Development and Technologies for Enhancing Accessibility 
and Fighting Info-exclusion, \{DSAI\} 2013, 2014.

Disponível em http://www.sciencedirect.com/science/article/pii/ S1877050914000520

[27] Hillen, H.; Evers, V. Website navigation for blind users. ISBN-13: 978-0-470-01866-8. John Wiley \& Sons, Ltd., 2007.

[28] IBGE Censo Demográfico 2000. Rio de Janeiro: Instituto Brasileiro de Geografia e Estatística, 2001.

[29] IBGE Censo Demográfico 2010 - Características gerais da população, religião e pessoas com dificiência. ISSN: 0104-3145. Av. Franklin Roosevelt, 166 - Centro 20021-120 - Rio de Janeiro, RJ - Brasil: Instituto Brasileiro de Geografia e Estatística, 2012 .

[30] Jeschke, S.; Pfeiffer, O.; Vieritz, H. Using Web accessibility patterns for web application development. In: Proceedings of the 2009 ACM Symposium on Applied Computing (SAC '09), New York, NY, USA: ACM, 2009, p. 129-135.

[31] Jouault, F.; Kurtev, I. On the architectural alignment of ATL and QVT. In: Proceedings of the 2006 ACM Smposium on Applied Computing (SAC '06), New York, NY, USA: ACM, 2006, p. 1188-1195.

[32] Kaczmirek, L.; Wolff, K. Survey design for visually impaired and blind people. In: Stephanidis, C., ed. Universal Access in Human Computer Interaction. Coping with Diversity, v. 4554 de Lecture Notes in Computer Science, Springer Berlin Heidelberg, p. $374-381,2007$.

[33] King, A.; Blenkhorn, P.; Crombie, D.; Dijkstra, S.; Evans, G.; Wood, J. Presenting UML Software Engineering Diagrams to Blind People. In: Miesenberger, K.; Klaus, J.; Zagler, W.; Burger, D., eds. Computers Helping People with Special Needs, v. 3118 de Lecture Notes in Computer Science, Springer Berlin / Heidelberg, p. 626-626, 2004.

[34] Lazar, J.; Feng, J.; Hochheiser, H. Research methods in human-computer interaction. Indianapolis, IN: Wiley, 2010.

[35] Leiner, B. M.; Cerf, V. G.; Clark, D. D.; Kahn, R. E.; Kleinrock, L.; Lynch, D. C.; Postel, J.; Roberts, L. G.; Wolff, S. A brief history of the Internet. SIGCOMM Comput. Commun. Rev., v. 39, p. 22-31, 2009. 
[36] Lethbridge, T. C.; Sim, S. E.; Singer, J. Studying software engineers: Data collection techniques for software field studies. Empirical Softw. Engg., v. 10, n. 3, p. 311-341, 2005.

Disponível em http://dx.doi.org/10.1007/s10664-005-1290-x

[37] Lettner, M.; Tschernuth, M.; Mayrhofer, R. A Critical Review of Applied MDA for Embedded Devices: Identification of Problem Classes and Discussing Porting Efforts in Practice. In: Whittle, Jon and Clark, Tony and Kühne, Thomas, ed. Model Driven Engineering Languages and Systems, v. 6981 de Lecture Notes in Computer Science, Springer Berlin / Heidelberg, p. 228-242, 2011.

[38] Lucrédio, D. Uma Abordagem Orientada a Modelos para Reutilização de Software. Tese de doutorado, Universidade de São Paulo, Instituto de Ciências Matemáticas e de Computação - ICMC/USP. São Carlos SP., 2009.

[39] Metatla, O.; Bryan-Kinns, N.; Stockman, T. Using hierarchies to support non-visual access to relational diagrams. In: Proceedings of the 21st British HCI Group Annual Conference on People and Computers: HCI...but not as we know it (BCS-HCI 'O7), Swinton, UK, UK: British Computer Society, 2007, p. 215-225.

[40] Metatla, O.; Bryan-Kinns, N.; Stockman, T. Comparing interaction strategies for constructing diagrams in an audio-only interface. In: Proceedings of the 22nd British HCI Group Annual Conference on People and Computers: Culture, Creativity, Interaction (BCS-HCI '08), Swinton, UK, UK: British Computer Society, 2008, p. $65-69$.

[41] Mikovec, Z.; Vystrcil, J.; Slavik, P. Web toolkits accessibility study. SIGACCESS Access. Comput., p. 3-8, 2009.

[42] N., G. F. D.; Fortes, R. P. M. Awmo: Accessible web modeler. Diponível em: http://premio.w3c.br/finalistas/AWMo-acessible_web_modeler.html Último acesso: 12/02/2014, 2013.

[43] OMG MDA Guide Version 1.0.1. Misponível em http://www.omg.org/cgi-bin/doc?omg/03-06-01. Acesso em 15/01/2012, 2003.

[44] OMG Meta Object Facility (MOF) 2.0 Query/View/ Transformation Specification. Disponível em http://www.omg.org/spec/QVT/1.1/PDF/. Acesso em 15/01/2012, 2011.

[45] OMG Meta Object Facility (MOF) Core Specification. Disponível em http://www.omg.org/spec/MOF/2.4.1/PDF/. Acesso em 15/01/2012, 2011. 
[46] OMG MOF 2 XMI Mapping Specification. Disponível em http://www.omg.org/spec/XMI/2.4.1/. Acesso em 15/01/2012, 2011.

[47] OMG Unified Modeling LanguageTM (OMG UML), Infrastructure. Disponível em http://www.omg.org/spec/UML/2.4.1/. Acesso em 15/01/2012, 2011.

[48] Petrie, H.; Kheir, O. The relationship between accessibility and usability of websites. In: Proceedings of the SIGCHI Conference on Human Factors in Computing Systems (CHI '07), New York, NY, USA: ACM, 2007, p. 397-406.

[49] Pietrzak, K. UML-Generalization-20060325.svg. Disponível em http://en.wikipedia.org/wiki/File:KP-UML-Generalization-20060325.svg. Acesso em 20/02/2012, 2006.

[50] Pressman, R. Software engineering: a practitioner's approach. Mcgraw Hill: higher Education, 6th ed. McGraw-Hill, 2005.

[51] Rittgen, P. Coma: A tool for collaborative modeling. In: CAiSE Forum, 2008, p. $61-64$.

[52] Runeson, P.; Höst, M. Guidelines for conducting and reporting case study research in software engineering. Empirical Software Engineering, v. 14, n. 2, p. 131-164, 2008.

Disponível em http://www.springerlink.com/index/10.1007/ s10664-008-9102-8

[53] Schwaber, K. Scrum development process. In: Business Object Design and Implementation, Springer, p. 117-134, 1997.

[54] Shinohara, K.; Tenenberg, J. Observing sara: a case study of a blind person's interactions with technology. In: Proceedings of the 9th international ACM SIGACCESS conference on Computers and accessibility, Assets '07, New York, NY, USA: ACM, 2007, p. 171-178 (Assets '07, ).

Disponível em http://doi.acm.org/10.1145/1296843.1296873

[55] Siegfried, R. M. Visual programming and the blind: the challenge and the opportunity. SIGCSE Bull., v. 38, p. 275-278, 2006.

[56] SLIM SLIM - Synchronous Lightweight Environment Modeling Blog. Disponível em http://slim.uni-mannheim.de/?page_id=18 Acesso em 12/02/2012, 2009.

[57] Stake, R. The art of case study research. Sage Publications Inc, 1995.

Disponível em http://books.google.com/books?hl=no\&lr=\&id= 
ApGdBx76b9kC\&oi=fnd\&pg=PR11\&dq=case+study\&ots=KrNKk2Fnbo\&sig= tBVSrcFVI4tzDG3AzErMhF__xe4

[58] Thomas, D. MDA: revenge of the modelers or UML utopia? Software, IEEE, v. 21, n. 3, p. $15-17,2004$.

[59] Thum, C.; Schwind, M.; Schader, M. SLIM - A Lightweight Environment for Synchronous Collaborative Modeling. In: Proceedings of the 12th International Conference on Model Driven Engineering Languages and Systems (MODELS '09), Berlin, Heidelberg: Springer-Verlag, 2009, p. 137-151.

[60] UN enable Convention on the Rights of Persons with Disabilities. Disponível em http://www.un.org/disabilities/default.asp?id=150 . Acesso em 19/01/2012, 2007.

[61] Velasco, C. A.; Denev, D.; Stegemann, D.; Mohamad, Y. A Web compliance engineering framework to support the development of accessible rich Internet applications. In: Proceedings of the 2008 International Cross-disciplinary Conference on Web Accessibility (W4A '08), New York, NY, USA: ACM, 2008, p. 45-49.

[62] W3C Authoring Tool Accessibility Guidelines 1.0 - W3C Recommendation. Disponível em http://www.w3.org/TR/ATAG10/. Acesso em 23/01/2012, 2000.

[63] W3C User Agent Accessibility Guidelines 1.0 - W3C Recommendation. Disponível em http://www.w3.org/TR/UAAG10/. Acesso em 23/01/2012, 2002.

[64] W3C Essential Components of Web Accessibility. Disponível em http://www.w3.org/WAI/intro/components.php. Acesso em 23/02/2012, 2005.

[65] W3C Introduction to Web Accessibility. Disponível em http://www.w3.org/WAI/intro/accessibility.php. Acesso em 11/01/2012, 2005.

[66] W3C Web Content Accessibility Guidelines (WCAG) 2.0 - W3C Recommendation. Disponível em http://www.w3.org/TR/WCAG20/. Acesso em 23/01/2012, 2008.

[67] W3C Accessible Rich Internet Applications (WAI-ARIA) 1.0 - W3C Candidate Recommendation. Disponível em http://www.w3.org/TR/wai-aria/. Acesso em 23/01/2012, 2011.

[68] W3C Authoring Tool Accessibility Guidelines (ATAG) 2.0 - W3C Working Draft. Disponível em http://www.w3.org/TR/ATAG20/. Acesso em 25/01/2012, 2011.

[69] W3C W3C Accessibility. Disponível em http://www.w3.org/standards/webdesign/accessibility. Acesso em 11/02/2012, 2011. 
[70] White, J.; Schmidt, D. C.; Mulligan, S. The Generic Eclipse Modeling System. In: Model-Driven Development Tool Implementer's Forum at 45th International Conference on Objects, Models, Components and Patterns, 2007.

[71] Yin, R. K. Case Study Research: Design and Methods. 2nd ed. SAGE Publications Inc., 1994. 
Apêndice

$A$

Diagrama Sistema Bancário

Listagem A.1: Modelo de um sistema bancário fictício na linguagem textual da AWMo e que foi utilizado durante a fase de observação do estudo de caso.

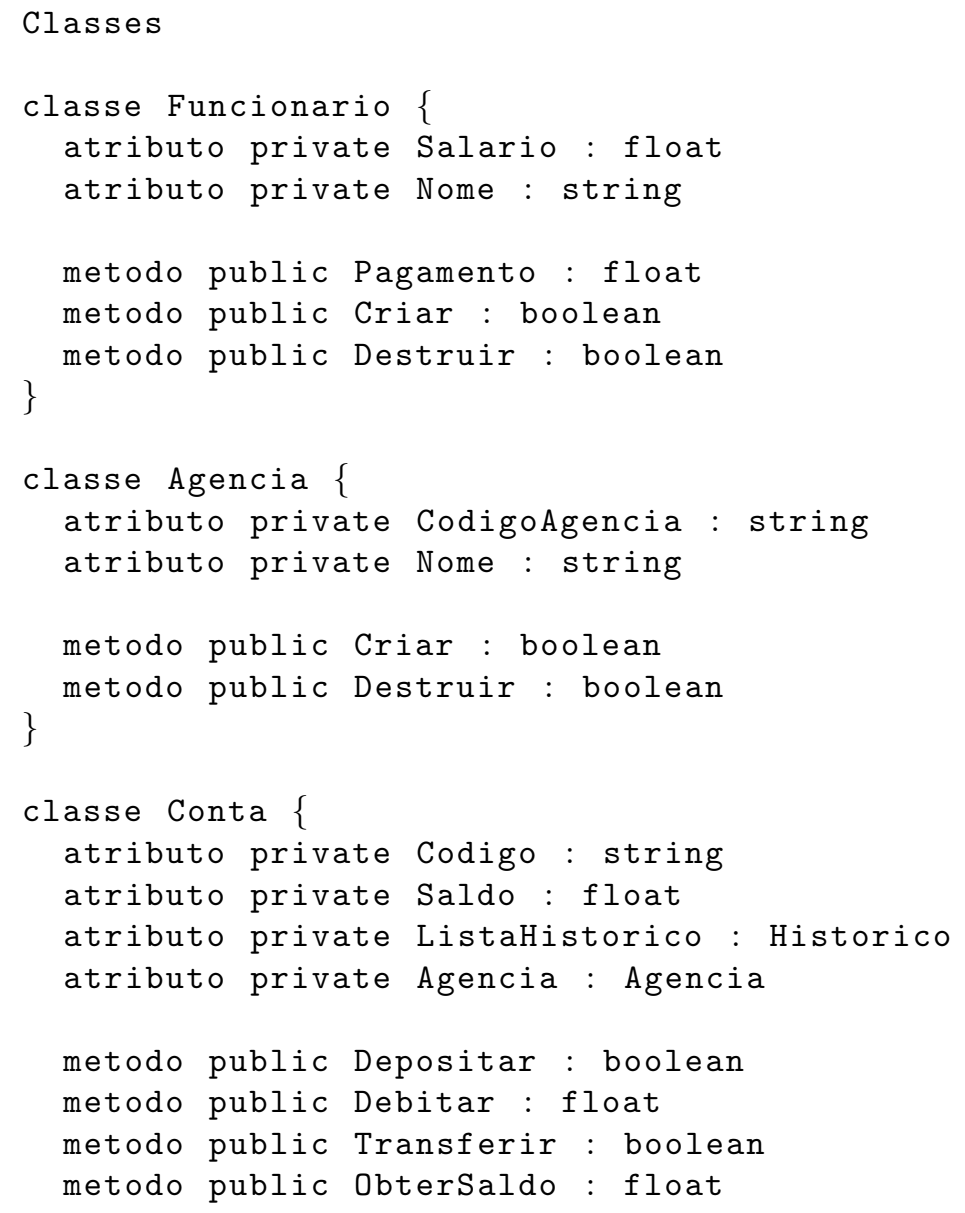




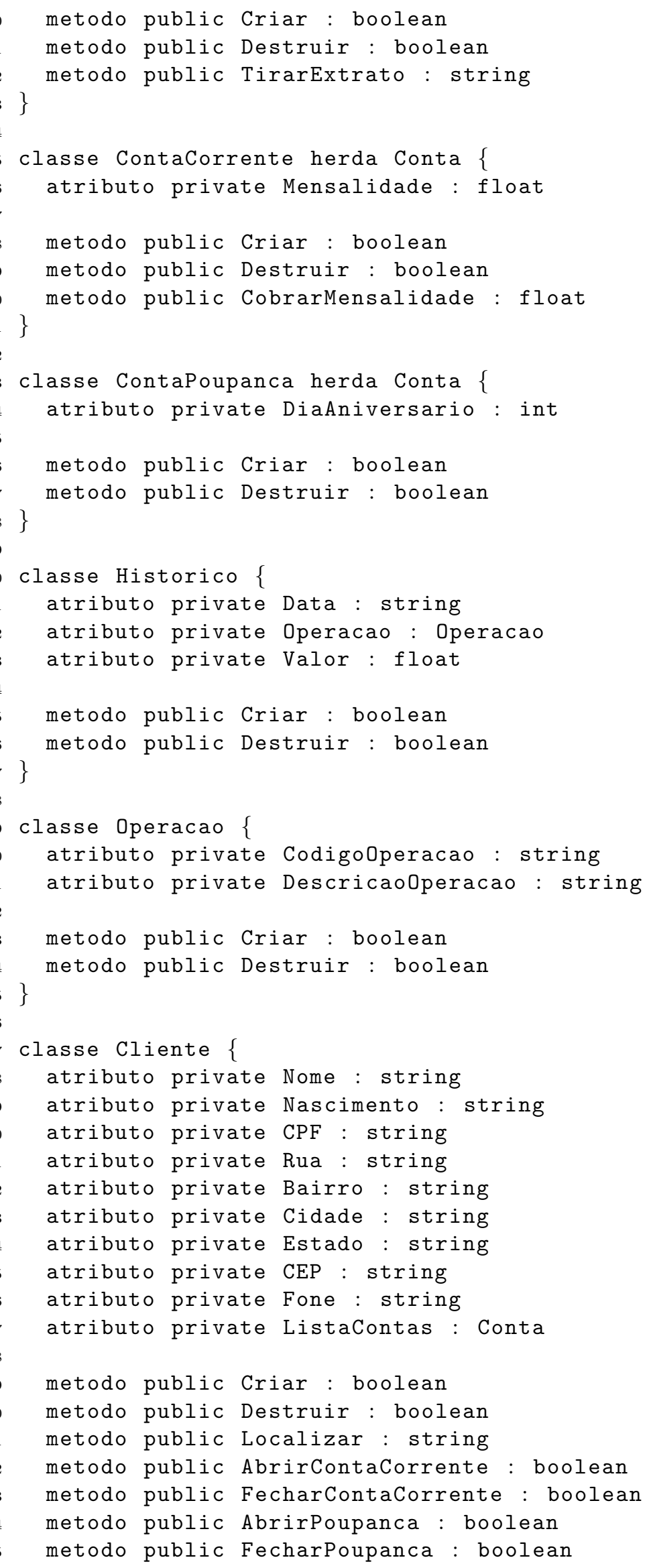


APÊNDICE A. DIAGRAMA SISTEMA BANCÁRIO

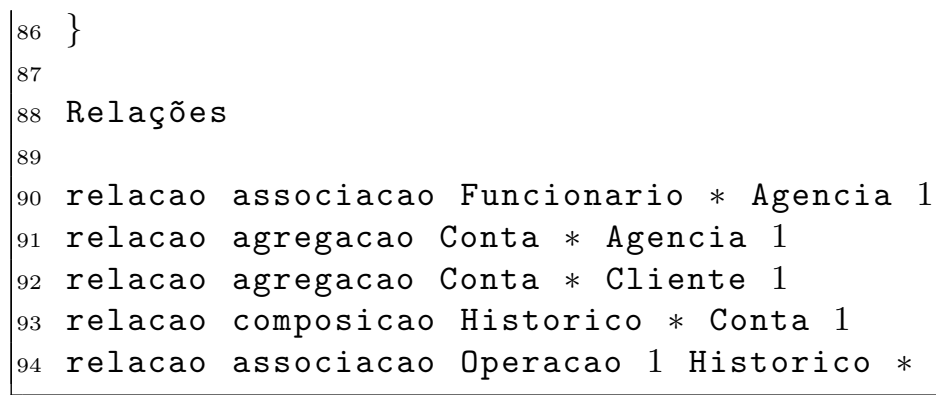

